\title{
A DETAILED MULTI-ZONE THERMODYNAMIC SIMULATION FOR DIRECT-INJECTION DIESEL ENGINE COMBUSTION
}

\author{
A Dissertation \\ by \\ XINGYU XUE

\begin{abstract}
Submitted to the Office of Graduate Studies of
Texas A\&M University

in partial fulfillment of the requirements for the degree of

DOCTOR OF PHILOSOPHY
\end{abstract}

$\begin{array}{ll}\text { Approved by: } & \\ \begin{array}{ll}\text { Chair of Committee, } \\ \text { Committee Members, }\end{array} & \begin{array}{l}\text { Jerald A. Caton } \\ \text { Rodney D.W. Bowersox } \\ \text { Timothy J. Jacobs } \\ \text { Eric L. Petersen }\end{array} \\ \text { Head of Department, } & \text { Jerald A. Caton }\end{array}$

December 2012

Major Subject: Mechanical Engineering

Copyright 2012 Xingyu Xue 


\begin{abstract}
A detailed multi-zone thermodynamic simulation has been developed for the direct-injection (DI) diesel engine combustion process. For the purpose of predicting heterogeneous type combustion systems, the model explores the formation of preignition radicals, start of combustion, and eventual heat release. These mechanisms are described based on the current understanding and knowledge of the diesel engine combustion acquired through advanced laser-based diagnostics. Six zones are developed to take into account the surrounding bulk gas, liquid- and vapor-phase fuel, pre-ignition mixing, fuel-rich combustion products as well as the diffusion flame combustion products. A three-step phenomenological soot model and a nitric oxide emission model are applied based on where and when each of these reactions mainly occurs within the diesel fuel jet evolution process.
\end{abstract}

The simulation is completed for a 4.5 liter, inline four-cylinder diesel engine for a range of operating conditions. Specifically, the engine possesses a compression ratio of 16.6, and has a bore and stroke of 106 and $127 \mathrm{~mm}$. The results suggest that the simulation is able to accurately reproduce the fuel jet evolution and heat release process for conventional diesel engine combustion conditions. The soot and nitric oxide models are able to qualitatively predict the effects of various engine parameters on the engineout emissions. In particular, the detailed thermodynamics and characteristics with respect to the combustion and emission formation processes are investigated for different engine speed/loads, injection pressures and timings, and EGR levels. The local 
thermodynamic properties and energy, mass distributions obtained from the simulation offer some fundamental insights into heterogeneous type combustion systems. The current work provides opportunities to better study and understand the diesel engine combustion and emission formation mechanisms for conventional diesel engine combustion modes. The flexible, low computational cost features of this simulation result in a convenient tool for conducting parametric studies, and benefits for engine control and diagnostics. 


\section{ACKNOWLEDGEMENTS}

I would like to express my deepest gratitude to my committee chair, Dr. Jerald Caton, for his excellent guidance, patience and support throughout the course of this research. I would never have been able to finish my dissertation without his guidance. I would like to thank Dr. Jacobs, who is always willing to help and give his best suggestions. My sincerest appreciation goes to Dr. Petersen and Dr. Bowersox for their support of my research.

Many thanks to Josh Bittle, Hoseok Song, Jiafeng Song in the Advanced Engine Research Lab for the experimental data used in the model comparisons and suggestions on my research. I would also like to thank Junnian Zheng who helped me learn CHEMKIN. My research would not have been possible without their help. I also want to extend my gratitude to my friends and colleagues and the department faculty and staff for making my time at Texas A\&M University a great experience.

Finally, my profoundest love goes to my mother and father for their amazing love and encouragement with their best wishes. Your unwavering love and support have made me who I am today. 


\section{TABLE OF CONTENTS}

Page

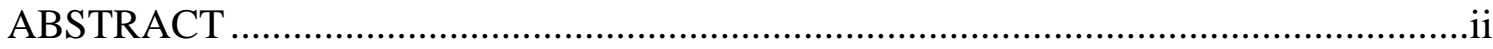

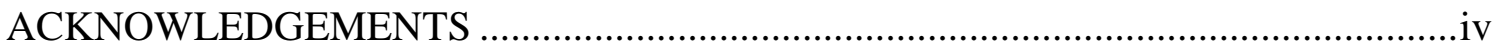

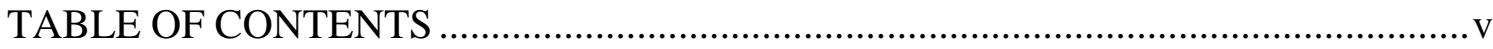

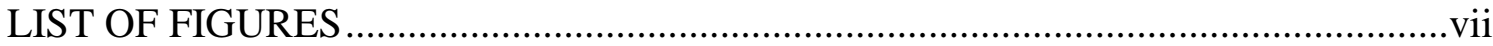

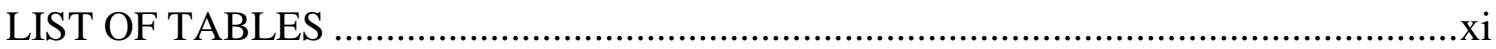

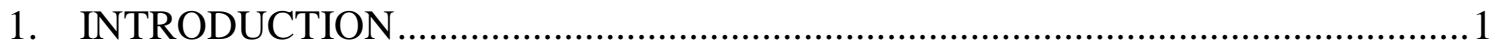

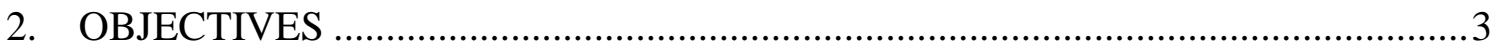

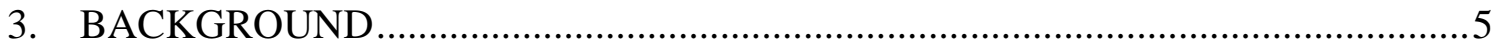

3.1. Conceptual model development ...........................................................6

3.2. Engine combustion and emission simulation......................................... 11

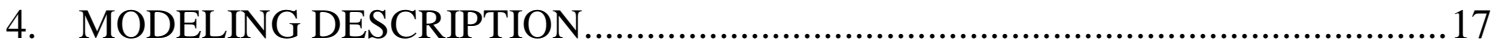

4.1. Modeling structure and fuel jet evolution description ............................... 17

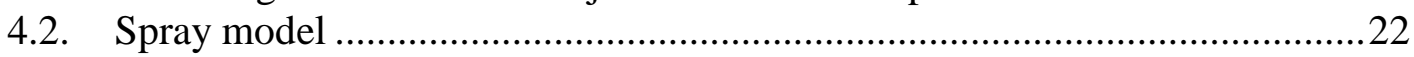

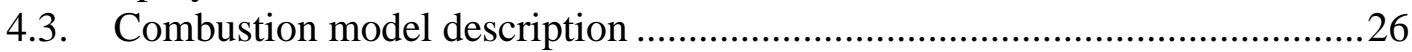

4.3.1. Equilibrium products of combustion ..........................................26

4.3.2. Ignition delay model and heat transfer............................................22

4.3.3. Combustion rate calculation .......................................................29

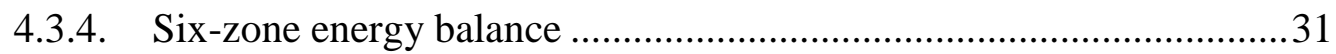

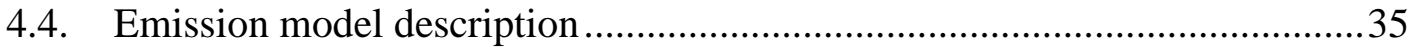

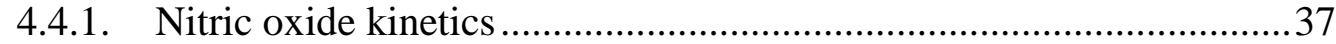

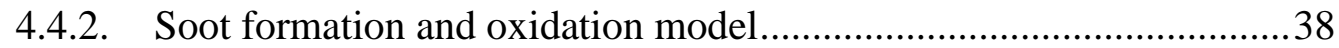

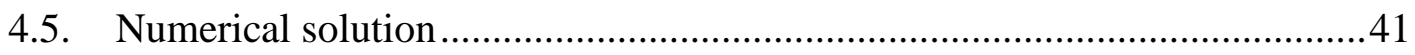

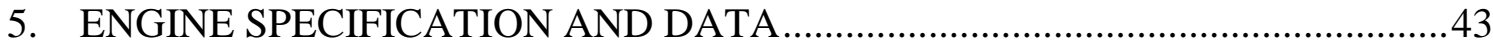

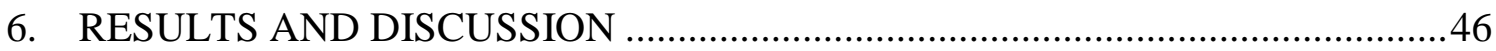

6.1. Calibration of model parameters ........................................................ 46 
6.1.1. Combustion model calibration ...................................................4

6.1.2. NO versus gas entrainment rate ..............................................52

6.1.3. Soot versus model constants ......................................................54

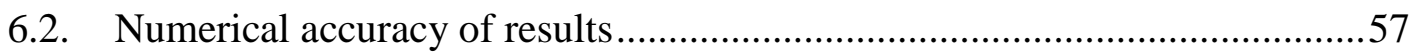

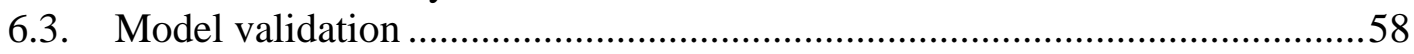

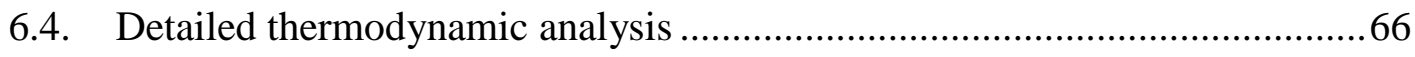

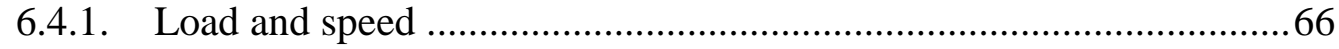

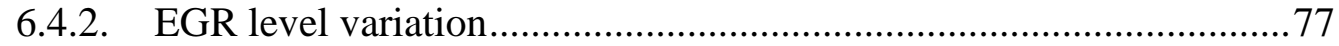

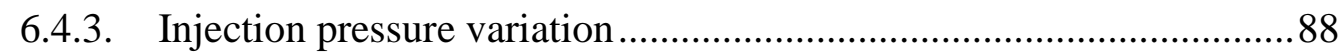

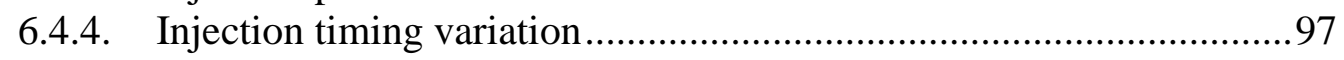

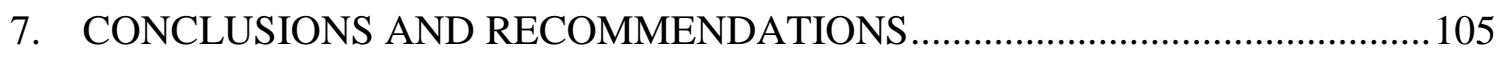

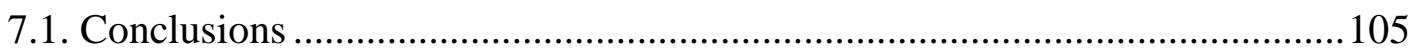

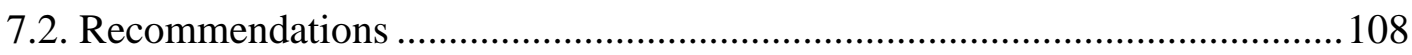

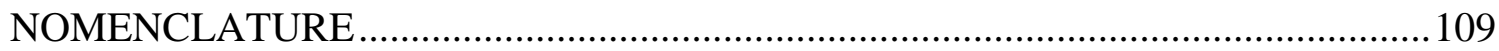

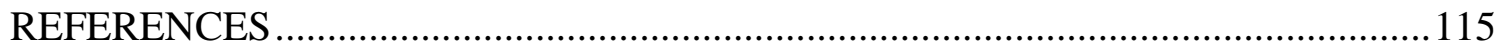




\section{LIST OF FIGURES}

Page

Figure 1. An example of the "old" conceptual model for the diesel fuel spray combustion process. Reproduced from Kuo [3].

Figure 2. Dec's conceptual model [9] of DI diesel combustion during the mixing controlled combustion period.

Figure 3. Schematic of the diesel fuel jet combustion proposed by Pickett et al. [10]. 10

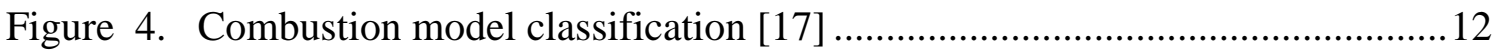

Figure 5. Schematic diagram of the zone description. ........................................ 18

Figure 6. Temporal sequence of schematics showing the fuel spray jet evolution.......19

Figure 7. EGR composition as a function of fuel/air equivalence ratio (n-heptane).....27

Figure 8. Schematic diagram of emission formation regimes for the conventional diesel engine combustion. The "phi-T" map with soot and NOx formation islands is adapted from [49].

Figure 9. The effect of lift-off length on the calculated in-cylinder pressure and accumulative diffusion burned fuel mass for the base case.

Figure 10. The effect of gas entrainment rate into zone 4 on the calculated incylinder pressure and fuel-rich combustion product temperature for the base case.

Figure 11. The effect of gas entrainment rate into zone 5 on nitric oxide formation and diffusion flame combustion product temperature for the base case. ......53

Figure 12. The sensitivity of soot model parameters to engine-out soot emissions........56

Figure 13. In-cylinder maximum pressure as a function of time step for the base case. 57

Figure 14. Absolute error as a function of crank angle for the base case. 58

Figure 15. Pressure and AHRR comparisons for three different speed/load cases .60 
Figure 16. Pressure and AHRR comparisons as injection pressure is varied for the base case (1400 rpm, $50 \mathrm{ft}-\mathrm{lbs}, 1.1 \%$ EGR, 860 bar injection pressure)

Figure 17. Pressure and AHRR comparisons as EGR is varied for the base case (1400 rpm, $50 \mathrm{ft}-\mathrm{lbs}, 1.1 \%$ EGR, 860 bar injection pressure)

Figure 18. The nitric oxide and soot comparisons for three different speed/load cases. 63

Figure 19. Soot emissions as functions of the nitric oxide emissions as either injection pressure (a) or EGR level (b) is varied for the base case.

Figure 20. The calculated zonal temperatures, cylinder averaged temperature, and corresponding mixture stoichiometries for the low speed/load case.

Figure 21. The calculated zonal temperatures, cylinder averaged temperature, and corresponding mixture stoichiometries for the moderate speed/load case....69

Figure 22. The calculated zonal temperatures, cylinder averaged temperature, and corresponding mixture stoichiometries for the high speed/load case.

Figure 23. The fuel distributions for three different speed/load cases (note the scale change for (a), (b), (c) ).

Figure 24. The instantaneous NO concentrations for three different speed/load cases ..74

Figure 25. The instantaneous behaviors of soot mass and soot precursor mass for three different speed/load cases (note the scale change for (a), (b), (c) )......76

Figure 26. The calculated in-cylinder pressure and AHRR as EGR level is varied for the base case.

Figure 27. The calculated temperatures for (a) zone 4, (b) zone 5, and (c) cylinder average temperatures as EGR level is varied for the base case.

Figure 28. The heat transfer rate as a function of crank angle as EGR level is varied for the base case.

Figure 29. The (a) instantaneous fuel mass in zone 3 and (b) the premixed fuel burn rate as a function of crank angle as EGR level is varied for the base case. ..82

Figure 30 . The flame lift-off length, ambient oxygen mole fraction and $\phi(\mathrm{LOL})$ as EGR level is varied for the base case. 
Figure 31. The instantaneous nitric oxide formation as EGR level is varied for the base case.

Figure 32. The instantaneous behaviors of soot mass and soot precursor mass as EGR level is varied for the base case.

Figure 33. The calculated soot formation and oxidation, oxidation percentage at the end of each combustion cycle as EGR level is varied for the base case.

Figure 34. The calculated in-cylinder pressure and AHRR as injection pressure is varied for the base case

Figure 35. The calculated temperatures for (a) zone 4, (b) zone 5, and (c) cylinder average temperature as injection pressure is varied for the base case

Figure 36. The instantaneous fuel mass in zone 3 (a) and the premixed fuel burn rate (b) as a function of crank angle as injection pressure is varied for the base case.

Figure 37 . The flame lift-off length and $\phi(\mathrm{LOL})$ as injection pressure is varied for the base case.

Figure 38. The instantaneous nitric oxide formation as injection pressure is varied for the base case.

Figure 39. The instantaneous behaviors of soot mass and soot precursor mass as injection pressure is varied for the base case.

Figure 40. The calculated soot formation and oxidation, oxidation percentage at the end of each combustion cycle as injection pressure is varied for the base case.

Figure 41. The calculated in-cylinder pressure and AHRR as injection timing is varied for the base case

Figure 42. The calculated temperatures for (a) zone 4, (b) zone 5, and (c) cylinder average temperatures as injection timing is varied for the base case.

Figure 43. The heat transfer rate as a function of crank angle as injection timing is varied for the base case.

Figure 44. The flame lift-off length and $\phi(\mathrm{LOL})$ as injection timing is varied for the base case. 
Figure 45. The instantaneous nitric oxide formation as injection timing is varied for the base case.

Figure 46. The instantaneous behaviors of soot mass and soot precursor mass as injection timing is varied for the base case.

Figure 47. The calculated soot formation and oxidation, oxidation percentage at the end of each combustion cycle as injection timing is varied for the base case. 


\section{LIST OF TABLES}

Page

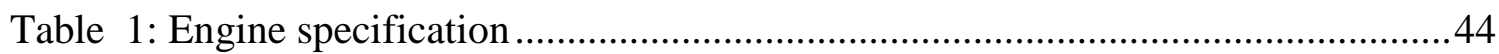

Table 2: Operating conditions for three different speed/load cases ............................45

Table 3: Operating conditions for different EGRs and injection pressures ..................45

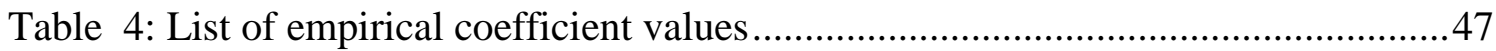




\section{INTRODUCTION}

Internal combustion engines are deemed major contributors to the hazardous emissions and consumers of fossil-fuel resources. In contrast with the homogenous type combustion mode (spark-ignition engine), the heterogeneous type combustion mode (compression-ignition engine) exhibits a more complex, turbulent and multiphase combustion process which involves fuel injection and mixing, the formation of preignition radicals, and eventual heat release process. These features result in complex diesel fuel jet evolution and emission formation processes. A thorough understanding of the DI diesel engine combustion process is of particular interest to meet the stringent emission standards with high engine efficiency.

The numerical simulation is an important tool to enhance our understanding of real physical phenomenon, offer guidance and framework for interpreting experimental observations. Various mathematical models have been developed and applied over a half century. These models range from simple one-zone, zero-dimensional models for engine control to sophisticated, complex three-dimensional models. While the one-zone, zerodimensional non-linear engine models are easy to handle and are characterized by low computational effect, the solutions are generally non-predictive and also lack "local" information in the combustion chamber. On the other hand, three-dimensional engine models utilizing CFD (computational fluid dynamics) simulation involve complex temporal and spatial resolutions. The expensive computational effort of CFD model makes it impractical for extensively examining the effects of various engine parameters 
on combustion and emission formations or conducting engine constant calibration routines. The intermediate, phenomenological multi-zone models bridge the gap between the fast, non-predictive one zone model and the sophisticated time-consuming threedimensional CFD model. Phenomenological models are able to provide a relatively complete assessment of the fuel jet evolution and combustion process with substantial reduced computational time, and offer some important "local" information so that qualitative prediction of engine-out emissions become achievable. Phenomenological models, therefore, are often considered as the most practical method to describe the diesel engine combustion process.

The progress of phenomenological models relies heavily on accurate information and knowledge of the diesel fuel jet evolution process. With the assistance of advanced laser-based diagnostics, current understanding of DI diesel engine combustion processes is substantially improved. The in-cylinder and combustion bomb studies provide an abundance of new information and important knowledge on the reacting diesel fuel jet development. The laser-sheet images of the flame structure, nitric oxide and soot distribution exhibit a different picture of the diesel fuel jet evolution process as expected from previous descriptions. This reliable information and knowledge can provide a basic framework and guidance for the development of numerical simulations. A new phenomenological model which incorporates all of the information is of particular importance for researchers to study and better understand the features of diesel engine combustion systems. 


\section{OBJECTIVES}

The overall purpose of this research is intended to develop a six-zone predictive phenomenological model with detailed thermodynamics by applying the current understanding of DI diesel engine combustion process. This model should be able to accurately predict the evolution of the diesel fuel jet, offer detailed local thermodynamic information, and provide some fundamental insights of the combustion and emission formation processes. The flexible, low computational cost features can bring some benefits for engine control and diagnostics. This new model is limited to the fuel injection and combustion phase, and the intake, compression and exhaust processes are not covered. The specific tasks will be achieved as follows:

1. Construct the model structure and describe the occurrence of the DI diesel engine combustion based on the updated information and knowledge of the reacting diesel fuel jet. This model should be able to capture the basic features of the diesel fuel jet penetration, fuel/gas mixing and evaporation, ignition and heat release processes.

2. Build the soot and nitric oxide emission models by applying the current understanding of the emission formation processes in the reacting diesel fuel jet. A three-step phenomenological soot model and a nitric oxide emission model would be developed based on where and when each of these reactions mainly occurs within the diesel fuel jet evolution process. The qualitative prediction for the effects of major engine parameters on engine-out emissions should be achieved. 
3. Calibrate and validate the combustion and emission models with experimental data for a range of operating conditions. Explore the major effects of engine model constants on the engine performance and emissions. Examine the numerical accuracy of the simulation results.

4. Investigate the detailed thermodynamics and characteristics of the diesel engine combustion and emission formation processes for different operating conditions including load and speed, EGR level, injection pressure and timing. Uncover several fundamental insights of the DI diesel engine combustion system. Provide opportunities to better understand the diesel engine combustion and emission formation mechanisms for conventional diesel engine combustion processes. 


\section{BACKGROUND}

The complex task of improving on diesel engines becomes more challenging in recent years in order to comply with the stringent emission standards with high thermal efficiency. As a result of the high complexity of the diesel fuel jet reacting process, fundamental understanding of the diesel engine combustion process can be only achieved by the combination of experimental and modeling approaches. The advanced experimental studies can provide some accurate information and knowledge within the combustion chamber to interpret measurement observations, to validate and calibrate new mathematical models. On the other hand, the numerical simulations are advantageous to carry out extensive parametric studies, help understand the complex physical sub-processes, obtain more detailed information about fuel spray and combustion processes. Nowadays, the phenomenological description or "conceptual model" of diesel engine combustion has been greatly improved thanks to advanced laserbased diagnostics which is able to offer detailed spatial and temporal knowledge of the reacting diesel fuel jet. These features are of importance for the development of more accurate mathematical models. The following subsections include a summary of background information regarding the diesel engine conceptual model development and a review of engine combustion and emission simulation in the literature. 


\subsection{Conceptual model development}

Prior to the advanced laser diagnostics applied in optically accessible engines, the understanding of diesel engine combustion processes was very limited. The direct measurements via high-speed cinematographic data and sampling probes only provided some limited spatial resolution and quantitative data which cannot fully describe the actual diesel fuel jet combustion process. As a result, the initial attempt to describe diesel combustion was based on a series of assumption and yielded a lot of uncertainties.

The basic concept was assuming a distribution of fuel/air mixture from the rich center to lean edge of the spray [1]. The initial premixed combustion was thought to occur in regions that were nearly stoichiometric around the jet periphery [2]. Figure 1 shows an example of the "old" conceptual model for the diesel fuel spray combustion process as reproduced from Kuo [3]. The fuel droplets penetrated well out of injector and the diesel diffusion combustion was connected by both the sheath flame and a collection of individual droplet flames. The soot was assumed to form on the fuel-rich side of the diffusion flame because of the sufficiently high temperature [4]. Although these descriptions seemed logical and fitted some of the limited cinematographic and sampling probes data at that time, researchers should recognize that these descriptions are not based on direct measurements and subject to further verification. 


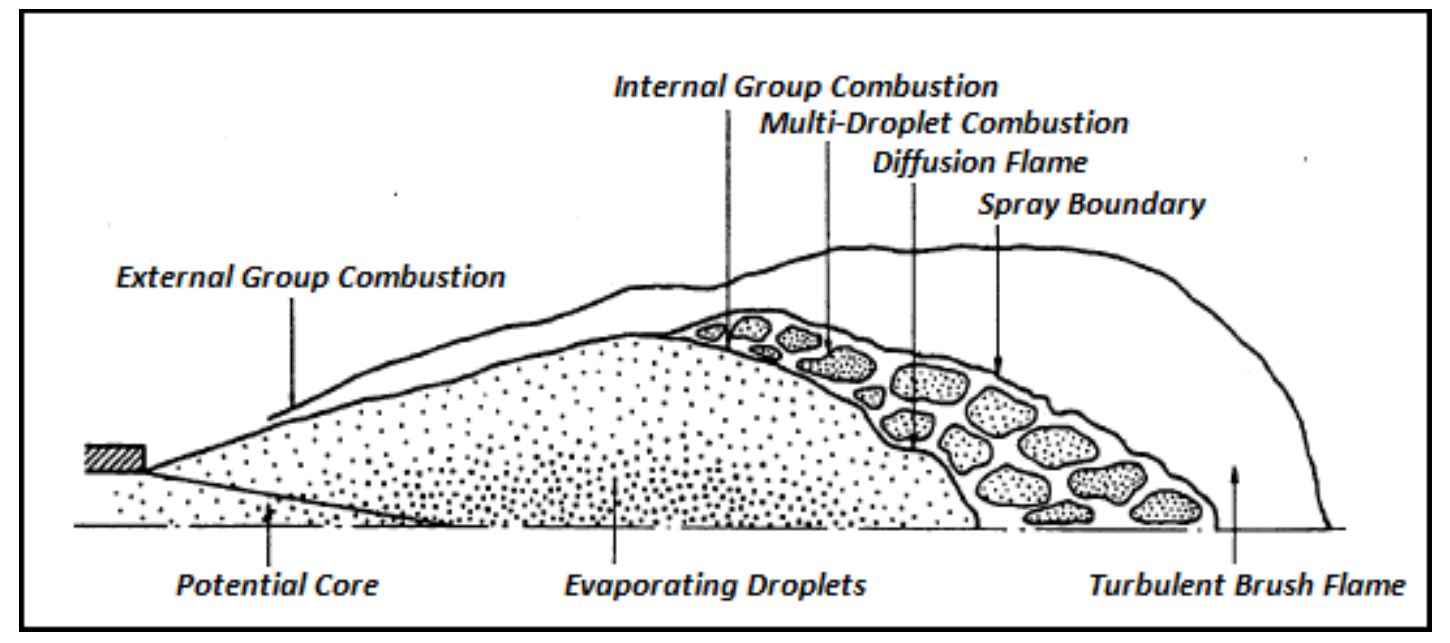

Figure 1. An example of the "old" conceptual model for the diesel fuel spray combustion process. Reproduced from Kuo [3].

With the development of advanced laser-based diagnostics applied in optically accessible engines, an abundance of new information and important knowledge on the reacting diesel fuel jet have been discovered. The elastic-scatter imaging obtained by Espey and Dec [5] showed that liquid fuel penetration is very limited and beyond the liquid length, all of the fuel is vaporized by the entrainment of hot ambient gas. Espey et al. [6] found the evolution of vapor fuel distribution finally leads to a relatively homogenous fuel/gas mixture with equivalence ratios ranging generally from 2 to 4 . The obtained chemiluminescence imaging by Dec and Espey [7] illustrated that the volumetric premixed combustion occurs in these fuel rich conditions, and not in a stoichiometric environment. All the fuel in the main combustion zone is vapor-phase. The phenomenon with fuel droplets presenting near the diffusion flame zone, as implied in "old" conceptual models, is disproved. After the initial volumetric premixed combustion, the OH-radical signals [8] showed the diffusion flame is developed along 
the jet edge. The majority of thermal nitric oxide formation mainly occurs here due to the high diffusion flame temperature and available source of oxygen. The flame remains lifted so that fuel and ambient gas premix upstream of the reaction zone. The flame liftoff length, defined as the distance from the nozzle to the edge of flame, is critical since it determines the amount of ambient gas entrained into fuel rich reaction zone. The natural soot luminosity images [9] provided important information about the soot formation. Rather than near the diffusion flame, current study indicated that soot occurs throughout the jet cross-section and mainly in the central region of the fuel jet.

The updated information and knowledge on the diesel combustion exhibit a completely different picture from the "old" descriptions. Dec [9] proposed a conceptual model by combining these results and provided a detailed understanding of the temporal and spatial evolution of a reacting diesel fuel jet. Figure 2 shows Dec's conceptual model of the DI diesel combustion during the mixing-controlled combustion period. This proposed conceptual model is very promising since it virtually incorporates all the information provided by the sophisticated optical measurement techniques. The complete description of this conceptual model has been well documented elsewhere [9]. 


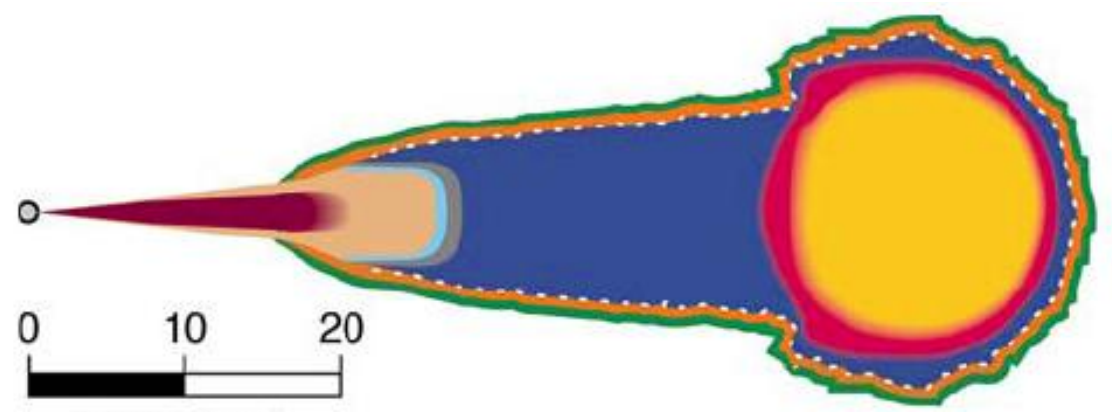

Scale $(\mathrm{mm})$

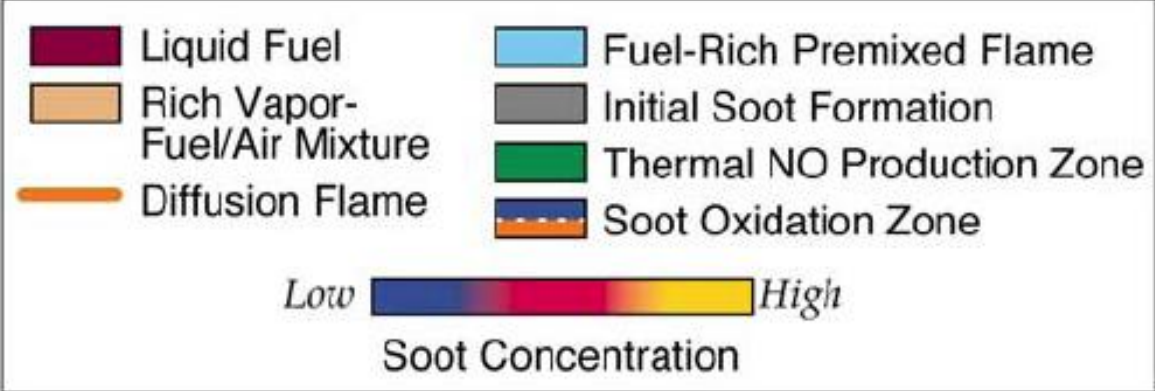

Figure 2. Dec's conceptual model [9] of DI diesel combustion during the mixing controlled combustion period.

Another attractive and concise conceptual picture for describing diesel fuel jet combustion is presented in Figure 3 by Pickett et al. [10]. In their description, zone 1 represents the non-reacted fuel/ambient mixture upstream of the flame lift-off length. The reaction propagation, as depicted in zone 2, feeds the fuel-rich product zone 4 by the volumetric premixed combustion and replenishes high-temperature product reservoir (zone 3) through the mixing-controlled diffusion combustion. The high-temperature products in zone 3 tend to stabilize the flame lift-off length. Although their study did not identify if this reaction propagation is related with a fuel/gas mixing process or a flame, this proposed model is considered as an important reference for the modeling structure description in the current work. 


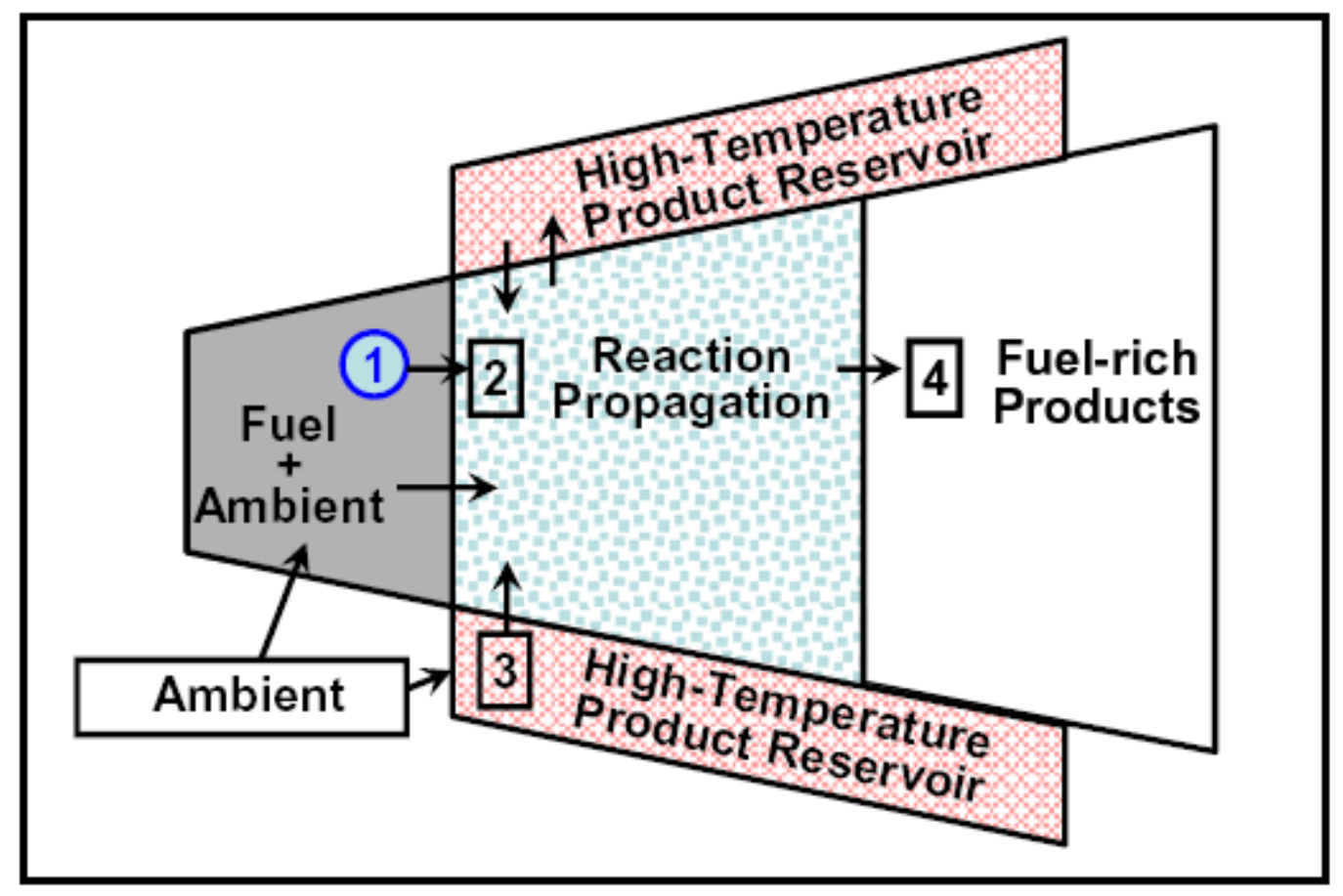

Figure 3. Schematic of the diesel fuel jet combustion proposed by Pickett et al. [10].

Dec indicated that a standing fuel-rich partially premixed flame is assumed to form downstream of the lift-off length which leads to the initial soot formation (as shown in Figure 2). Pickett and Siebers [11] investigated the soot formation region near the lift-off length in depth. They confirmed the existence of this fuel-rich partially premixed flame, but suggested the first soot formation occurs after a finite distance of this flame. The soot precursor formation is expected to fill the gap. The relationship between flame lift-off length and soot formation has been studied and emphasized [1214]. Pickett and co-workers conducted a series of investigations on soot formation processes of diesel fuel jets under different orifice diameters [12], ambient temperatures, 
gas densities, injection pressures [13], and oxygen concentrations [14]. The soot level and formation rate have been found to closely correlate with the equivalence ratio at the lift-off length and the fuel-rich combustion temperature. Generally, enhanced fuel-air mixing upstream of the lift-off length reduces the soot level. Lower combustion temperature prohibits the soot formation rate and soot formation region will be effectively stretched out associated with longer residence time.

\subsection{Engine combustion and emission simulation}

The development and application of engine simulations have been extensively emphasized for researchers to study various features and issues in combustion engines. Three different categories are distinguished based on the model complexity. As shown in Figure 4, the one-zone, zero-dimensional non-linear engine models [15] are capable of engine control and diagnostics due to their "real time" ability. The solutions used to model the engine combustion process are generally non-predictive. They are unable to make predictions of effects of important engine parameters on combustion. The engineout emissions cannot be calculated due to the lack of "local" information in the combustion chamber. On the other hand, three-dimensional engine models utilizing CFD simulation [16] involve complex temporal and spatial resolutions and a series of partial differential equations to be solved. The overall computation process is extremely expensive. The predictive quality such as in-cylinder pressure, heat release rate, and emissions, however, is not necessarily better than that with simpler models. It is because the small errors generated within particular sub-models due to the mutual interactions may eventually add up to considerable error within the overall computation result [17]. 
And the inevitable employment of empirical correlations further reduces the reliability of CFD calculation.

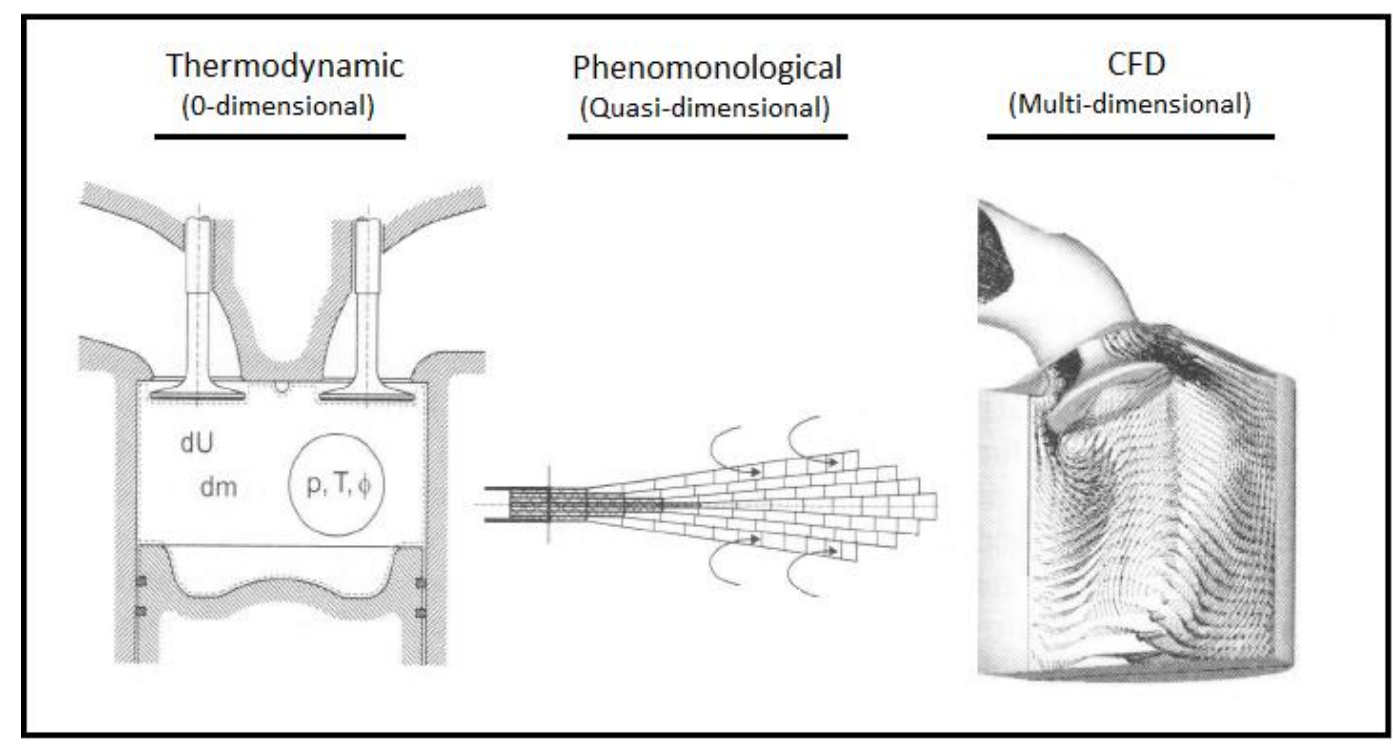

Figure 4. Combustion model classification [17]

Phenomenological multi-zone models are often considered as the most practical method to predict the diesel engine combustion. The phenomenological models divide the combustion chamber into multiple zones, ranging between as few as two and as many as several hundreds, with different temperatures and chemical compositions. The spatial resolution, albeit much coarser than in CFD codes, is enough to describe the physical sub-processes during the fuel jet evolution process. The accurate prediction of the influence of important engine parameters on the diesel combustion and emissions can be achieved. Since the phenomenological models only involve ordinary differential 
equations, the computing time is significantly reduced. For the above reasons, the phenomenological multi-zone model is chosen in this study.

Since previous phenomenological models $[18,19]$ have been developed based on the "old" conceptual model, some researchers are trying to incorporate new information and knowledge into current models. Maiboom et al. [20] developed a phenomenological combustion model based on Dec's conceptual model. They were able to predict relatively accurate heat release rate and provide some important local information. This work did not include chemistry and thus was not able to model EGR-incurred low temperature combustion (LTC) conditions. The accurate prediction of pollutant emissions was also unreachable. Asay [21] and Ebrahimi et al. [22] created a five zone diesel cycle simulation model with the knowledge of the internal structure of DI diesel fuel jets as well as empirical correlations predicting fuel jet development. This model included all the basic features of diesel combustion. In particular, they extended the chemical equilibrium model with 21 species which allows the program to solve for problems with local equivalence ratios up to at least 8 . The downside of this model was the lack of important sub-models such as lift-off length, gas entrainment into combustion products, and allocation of heat transfer. The lack of these sub-models result in some inaccuracy of local thermodynamic properties as well as the heat release rate.

Nitric oxide and soot emissions represent the toughest challenges for internal combustion engine researchers to meet the future emission legislations. Modeling efforts for these emissions from internal combustion engines have been developed since the 1960s. The nitric oxide emissions produced in internal combustion engines are mainly 
from thermal, prompt, fuel nitrogen and $\mathrm{N}_{2} \mathrm{O}$ intermediate mechanisms [23-25]. The Zeldovich (thermal) mechanism accounts for the majority of nitric oxide emissions under conventional engine operating conditions. The Fenimore (prompt) mechanism prevails for rich mixtures at relatively low temperature where residence time is short. The nitrogen-containing fuel can contribute to the total nitric oxide formation with similar route as that occurs in prompt mechanism. The $\mathrm{N}_{2} \mathrm{O}$-intermediate pathway is of particular importance for diluted, low temperature combustion conditions [25].

Unlike nitric oxide formation kinetics, the soot formation and oxidation mechanisms are not fully understood and remain one of the biggest challenges for diesel engine simulations. Probably the simplest soot emission model is based on a two-step empirical formula proposed by Hiroyasu et al. [26]. Tesner et al. [27] suggested a chaintype soot formation process from the formation of radical nuclei to the soot particle growth later. Schubiger et al. [28] introduced a characteristic turbulent mixing timing into the soot oxidation rate calculation so as to account for the turbulence effects on the soot oxidation. More sophisticated but still quasi-global models have been developed by Surovikin [29] and Fusco et al. [30]. Both models [29, 30] are intended to provide detailed soot precursor kinetics and soot particle dynamics as well as the oxidation process. These models have been used in diesel engine simulations and generally implemented under the standard KIVA codes $[30,31]$. The predictive quality of soot emission models, however, still yields considerable uncertainties. Sencic et al. [32] found the ambient pressure influence on soot emissions by applying the Fusco soot model cannot be well reproduced. Liu et al. [33] discovered that the Fusco soot model is 
not consistent with the experimental measurements with various injection timings, and Tao et al. [34] proposed an improved multi-step soot model based on Fusco’s description and suggested that the pathway of soot precursor radical formation via acetylene $\left(\mathrm{C}_{2} \mathrm{H}_{2}\right)$ is more important. Their results, however, still seem to contradict experimental evidence for different injection pressures.

More detailed multi-step models are only achievable when researchers have a deeper understanding of the physical and chemical processes. The complex precursor formation mechanisms such as whether formation of precursors (PAH) is directly related to growth species $\mathrm{C}_{2} \mathrm{H}_{2}$ or the parent fuel itself are still the subject of uncertainty $[34,35]$. The sub-mechanisms including agglomeration, surface growth, direct deposit processes are very demanding, and the employment of only semi-empirical kinetic models requires further validation. On the other hand, the proper adjustment of multi-step mechanisms is much more difficult and only possible with a very large number of experimental data points. Consequently, the simpler soot model, despite the possible unrealistically low peak value during combustion, is still prevalent in engine simulations to offer a relatively reasonable engine-out soot emission prediction.

Instead of the semi-global mechanisms discussed before, several comprehensive reaction mechanisms that describe the gas-phase kinetics have been proposed to capture the physical and chemical processes leading from the fuel molecules to soot particles on a molecular scale $[36,37]$. The core of the reaction model includes the formation of benzene and phenyl from linear hydrocarbon molecules up to $\mathrm{C}_{6}$ species, the creation of larger polycyclic aromatic hydrocarbons $(\mathrm{PAH})$ by the so-called HACA sequence and 
finally soot particle formation with different structures and sizes resulting from a number of polymerization steps. These detailed chemistry soot models have been successfully applied for the laminar and turbulent diffusion flames with enormous computational expenditure. But they are not yet a standard in diesel engine modeling [38] because of the practical uncertainties of diesel fuel pyrolysis and oxidation, dominance of turbulent mixing and the unsteady nature of the process under engine conditions. These detailed chemistry soot models are outside the scope of the current work.

The overall purpose of the current research is intended to develop a new, detailed six-zone phenomenological diesel engine model. A reduced phenomenological threestep soot model and a nitric oxide formation model are imbedded. Once the simulation is formulated, the model is calibrated and validated by comparison to the existing experimental data. A number of engine parameters, numerical accuracy, detailed thermodynamics and characteristics of diesel engine combustion and emission formation processes under different engine operating conditions will be evaluated. 


\section{MODELING DESCRIPTION}

The detailed model description is presented in this section. The evolution of the diesel jet is introduced based on current understanding of diesel engine combustion process. The model includes six zones. All zones have the same instantaneous pressure, but each zone has individual temperature and chemical composition. The spray geometry is obtained from Siebers et al. [39-42] studies. The empirical ignition delay model, heat transfer and combustion rates are determined. The combustion products are calculated by applying the well-developed chemical equilibrium model with twelve species. The first law of thermodynamics, mass balances and the ideal gas equation are utilized to derive the instantaneous thermodynamic properties such as the zonal temperatures, volumes and pressures. The three-step soot model is developed by incorporating the physical processes of fuel pyrolysis, soot inception and oxidation. The nitric oxide model is governed by the Zeldovich (thermal) mechanism and $\mathrm{N}_{2} \mathrm{O}$ intermediate mechanism.

\subsection{Modeling structure and fuel jet evolution description}

The model structure is constructed to describe the occurrence of DI diesel combustion in the absence of wall interactions and swirl. As shown in Figure 5, the combustion chamber is divided into six zones: liquid fuel zone, vapor fuel zone, preignition mixing zone, fuel-rich combustion product zone, diffusion flame combustion product zone and surrounding bulk gas zone, respectively. The fuel jet evolution from the start of injection up through the end of combustion is described in Figure 6. 


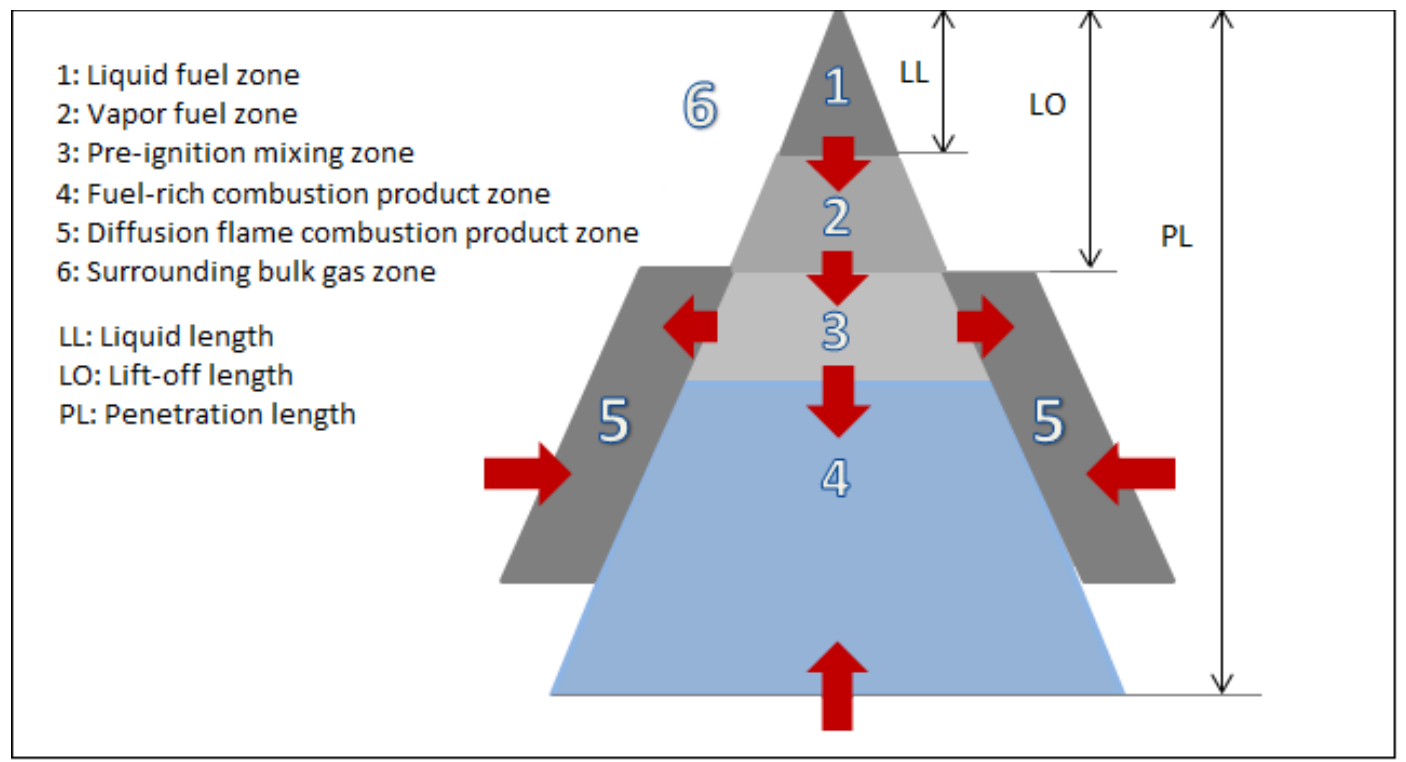

Figure 5. Schematic diagram of the zone description.

A liquid fuel zone is first formed as the fuel jet is injected into the cylinder. The liquid fuel including droplets and ligaments covers this zone and a small vapor-fuel region begins to develop along the sides of this zone. The fuel evaporation process occurs in a supercritical environment. As the spray reaches the maximum liquid penetration, which is called liquid length, the liquid fuel zone becomes constant and beyond the liquid length, the entrainment of hot gas into the jet is sufficient to vaporize the fuel. Since the amount of vapor fuel in this zone is small, it is neglected in this work. The composition of zone 1 is assumed to be only liquid fuel, and entrained gas.

Vapor fuel zone begins to form as the injected fuel continues to penetrate across the chamber beyond the liquid length and until the flame lift-off length. Zone 2 contains all the vapor fuel with well-mixed gas entrained from zone 6 . The flame lift-off allows the fuel and gas to mix upstream prior to any combustion and thus significantly 
influences the diesel fuel jet combustion and emission formation processes. The investigation of flame lift-off by Siebers et al. [39] illustrates that the lift-off length is strongly affected by the cylinder pressure, temperature, oxygen concentration and injector conditions.

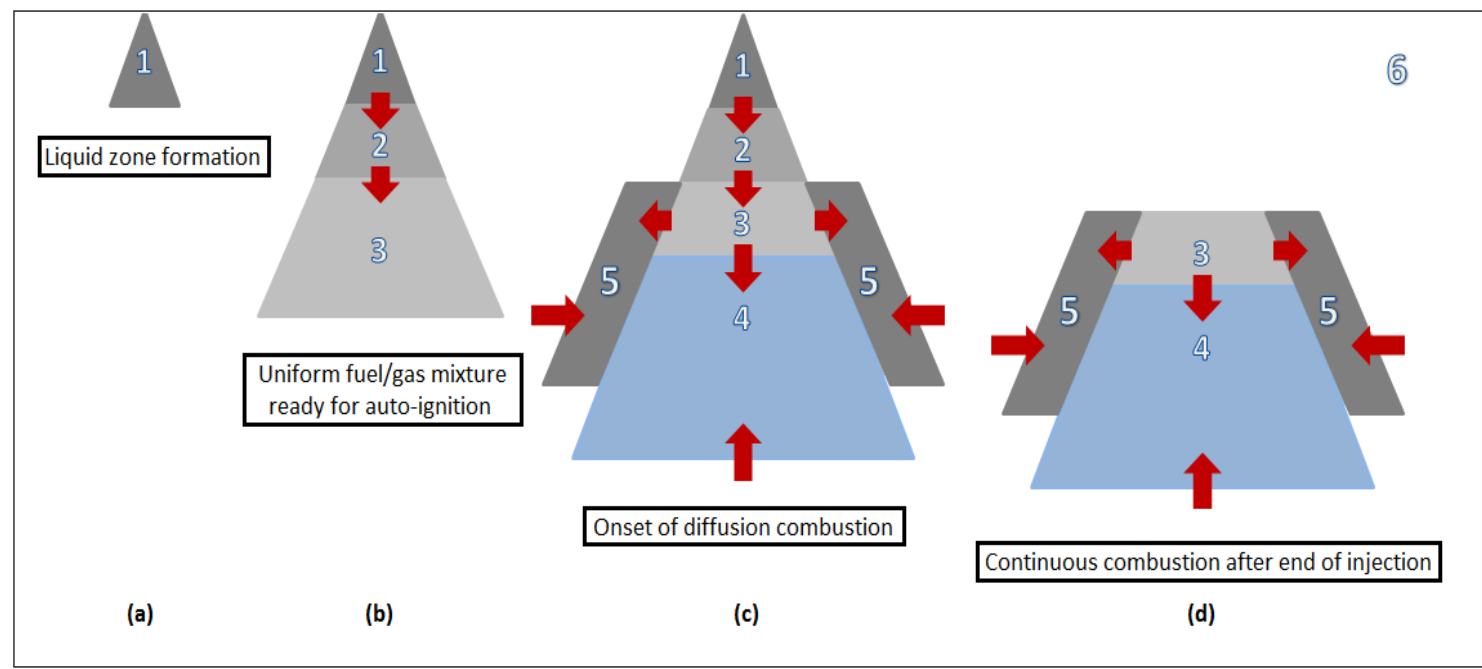

Figure 6. Temporal sequence of schematics showing the fuel spray jet evolution.

As the penetration of the fuel jet continues, the leading portion is made up of a relatively uniform fuel/gas mixture with equivalence ratios ranging from approximately 2 to 4 (Figure 6(b)). With the high cylinder temperature and pressure, the auto-ignition begins to occur volumetrically throughout zone 3 . The fuel-rich combustion product zone 4 begins to grow toward both the injector and spray tip corresponding to the rapid shrinking of pre-ignition mixing zone 3 and continuous fuel jet penetration, respectively. The initial part of the premixed burn consumes the previous well-mixed gas in zone 3 and a large amount of incomplete combustion products are generated at intermediate 
temperature. The temperature does not reach the stoichiometric flame temperature because a large portion of the chemical energy remains in carbon monoxide and unoxidized products due to the lack of oxygen. These incomplete combustion products will be oxidized with the subsequent gas entrainment into zone 4 . The oxidation process is determined by the fresh gas entrainment rate, which is related to the turbulent kinetic energy, as well as the concentration of oxygen. Meanwhile, the volumetric soot formation is marked by the start of initial premixed combustion. Zone 3 consists of the unconsumed fuel/gas mixture and zone 4 is composed of fuel-rich combustion products.

After the initial premixed combustion, a diffusion flame forms at the jet edge. The onset of the diffusion flame corresponds to the midpoint of the premixed burn spike in the apparent heat release rate [9]. The unconsumed fuel left from the volumetric fuelrich premixed burn as well as the subsequent fuel-rich mixture entrained into zone 3 will burn as a mixing-controlled diffusion flame associated with high temperature resulting from stoichiometric combustion. The high temperature diffusion combustion product zone 5 develops. The combustion gradually transitions to being a purely mixingcontrolled, lifted, turbulent diffusion flame combustion mode. There is no fresh gas entrained into zone 3 since it is consumed in the diffusion flame. The bulk of thermal nitric oxide production and soot oxidation process mainly occur in zone 5 due to the high diffusion flame temperature and available source of oxygen.

A lot of researchers $[9,11]$ have confirmed that a fuel-rich partially premixed flame (normally with an equivalence ratio of 3 to 5) forms at the zone 3 periphery after the start of combustion which creates an almost ideal environment for the soot precursor 
formation just downstream of the lift-off length. It is thought that all these extreme fuelrich combustion products will meet the surrounding fresh gas in zone 6 , combust as diffusion flame and convert to complete combustion products promptly after this fuelrich premixed combustion. The effect on fuel heat release is actually modest. In this work, the fuel-rich partially premixed flame is only intended to predict the soot precursor formation process (in more detail later), and is neglected in the combustion model.

The fuel jet evolution after the end of injection has not been well understood. Few investigations have been conducted to uncover the spray evolution after the end of injection. For this work, the last portion of injected fuel is assumed to penetrate into the cylinder associated with the gas entrainment similar to the previous fuel parcels, going through the liquid fuel zone, vapor fuel zone, pre-ignition mixing zone and eventually burning as diffusion flame. The end of the fuel jet corresponds to the penetration of the last injected fuel. As the end of the fuel jet moves forward, the mass and volume of the liquid fuel zone (zone 1) begin to shrink and vanish when the last fuel penetration is beyond the liquid length, a similar phenomenon will occur in vapor fuel zone (zone 2) and pre-ignition mixing zone (zone 3). As shown in Figure 6(d), after the end of injection, the fuel-rich products keep penetrating throughout the cylinder, associated with the growth of zone 5 . The zone 3 shrinks gradually and eventually vanishes when the last fuel parcels burn out as a diffusion flame, and the combustion process is terminated. 


\subsection{Spray model}

The spray model is based on Siebers et al. [39-42] for a typical diesel spray penetration using a constant-volume combustion vessel, and common-rail fuel injectors. By examining the effects of ambient gas density, fuel vaporization, oxygen concentration, injection tips parameters and gas temperature on the vaporizing/nonvaporizing spray penetration, liquid length and flame lift-off length, a series of scaling laws have been developed and a relatively completed, idealized diesel spray penetration model has been proposed regarding the geometry of the fuel spray. This includes the penetration length, spread angle, liquid length, lift-off length and gas entrainment rate. Since the combustion process is not covered in this spray model, the information is used to only describe the fuel jet evolution for zone 1, zone 2 and zone 3.

The penetration correlation is derived based on the fuel mass balance and momentum balance for the non-vaporizing fuel spray. The idealized spray [39] assumes (a) no velocity slip between the injected fuel and the entrained surrounding gas, (b) quasi-steady flow with a uniform growth rate, and (c) uniform velocity, fuel concentration. The comparison between vaporizing penetration data and this correlation shows that the vaporization reduces or slows penetration as much as $20 \%$ at extremely low gas density conditions. However, the reduction becomes smaller for typical diesel gas density and long penetration distance. A more accurate vaporizing fuel spray penetration may be needed for the improvement of this part. The dimensionless penetration time $\tilde{\mathrm{t}}$ is expressed as a function of the dimensionless penetration distance $\tilde{\mathrm{s}}$ : 
$\tilde{\mathrm{t}}=\tilde{\mathrm{s}} / 2+\tilde{\mathrm{s}} \sqrt{1+16 \widetilde{\mathrm{s}}^{2}} / 4+\ln (4 \widetilde{\mathrm{s}}+\sqrt{1+16 \tilde{\mathrm{s}}}) / 16$

with $\tilde{\mathrm{s}}=\mathrm{s} / \mathrm{s}^{+}, \tilde{\mathrm{t}}=\mathrm{t}^{+} / \mathrm{t}$,

The normalization factor $\mathrm{t}^{+}$and $\mathrm{s}^{+}$are defined as:

$\mathrm{t}^{+}=\mathrm{d}_{\mathrm{f}} \tilde{\rho}^{0.5} /\left(\mathrm{U}_{\mathrm{f}} \tan (\alpha / 2)\right)$

$\mathrm{s}^{+}=\mathrm{d}_{\mathrm{f}} \tilde{\rho}^{0.5} / \tan (\alpha / 2)$

with effective nozzle diameter $d_{f}$, fuel injection velocity $U_{f}$, and the ratio of fuel density to surrounding gas density $\tilde{\rho}$ given by

$\mathrm{d}_{\mathrm{f}}=\mathrm{c}_{\mathrm{a}}^{0.5} \mathrm{~d}_{0}$

$\mathrm{U}_{\mathrm{f}}=\mathrm{c}_{\mathrm{v}} \sqrt{2\left(\mathrm{P}_{\mathrm{f}}-\mathrm{P}_{\mathrm{avg}}\right) / \rho_{\mathrm{f}}}$

$\tilde{\rho}=\rho_{\mathrm{f}} / \rho_{\mathrm{g}}$

where $c_{a}, c_{v}$ are area contraction coefficient and velocity contraction coefficient. $d_{0}$ is the nozzle orifice diameter. $\mathrm{P}_{\mathrm{f}}$ and $\mathrm{P}_{\mathrm{avg}}$ represent the injection fuel pressure and cylinder average pressure, respectively.

An accurate inverse penetration correlation to evaluate the non-dimensional penetration as a function of the non-dimensional time is given by:

$\tilde{\mathrm{s}}=\tilde{\mathrm{t}} /\left(1+\tilde{\mathrm{t}}^{2.2 / 2}\right)^{1 / 2.2}$

The spray angle was developed by Siebers [40] by using schlieren technology. The measured spray excludes the unsteady head vortex of spray (zone 3).

$\tan (\theta / 2)=0.26\left[(1 / \tilde{\rho})^{0.19}-0.0043 \tilde{\rho}^{0.5}\right]$

The modeled spray angle " $\alpha$ " is related to the "real" measured angle as shown in Equation (9) by equating the density, mass flow and momentum flow to those of a 
"realistic" spray [39]. The value of 0.66 is used based on a best fit of the correlation to the non-vaporizing data:

$\tan (\alpha)=0.66 \tan (\theta)$

Using the principle of overall momentum balance, the ratio of gas mass flux to the fuel mass flux at any location is expressed as:

$\dot{\mathrm{m}}_{\mathrm{g}}(\widetilde{\mathrm{s}}) / \dot{\mathrm{m}}_{\mathrm{f}}(\widetilde{\mathrm{s}})=\left(\sqrt{1+16 \widetilde{\mathrm{s}}^{2}}-1\right) / 2$

Furthermore, the scaling law for the liquid length was developed based on the energy balance between the energy entrained from hot surrounding gas and the injected fuel vaporization process, and the maximum penetration length of liquid fuel was presented as [42]:

$\mathrm{LL}=10.5 \tilde{\rho}^{0.58} \mathrm{~B}^{0.59} \mathrm{~d}_{0}$

with the specific energy ratio, B, proposed by Siebers [40] as:

$B=\frac{Z_{f}\left(T_{s}, P_{s}\right) \cdot\left(P_{g}-P_{s}\right) \cdot M_{g}}{Z_{g}\left(T_{s}, P_{g}-P_{s}\right) \cdot P_{s} \cdot M_{f}}=\frac{h_{f}\left(T_{s}\right)-h_{f}\left(T_{f}, P_{g}\right)}{h_{g}\left(T_{g}, P_{g}\right)-h_{g}\left(T_{s}, P_{g}-P_{s}\right)}$

where $\mathrm{Z}_{\mathrm{f}}$ and $\mathrm{Z}_{\mathrm{g}}$ are the vaporized fuel and ambient gas compressibility, $\mathrm{M}_{\mathrm{f}}$ and $\mathrm{M}_{\mathrm{g}}$ are fuel and ambient gas molecular weights. The last term of equation (12) is the quotient of enthalpy difference required to heat and vaporize liquid fuel and enthalpy difference for the entrained ambient gas to heat and vaporize the fuel. The saturation temperature " $\mathrm{T}_{\mathrm{s}}$ " at the location of liquid length, can be iteratively solved with the knowledge of fuel and gas properties and the initial conditions. $\mathrm{P}_{\mathrm{S}}$ is the corresponding partial pressure of the vapor fuel. 
As mentioned above, the flame lift-off length plays a crucial role in the combustion and soot emissions in DI diesel engines. Siebers et al. [41] conducted a series of investigation under quiescent conditions and derived the following scaling law for the calculation of lift-off length:

$\mathrm{LO}=\left(\mathrm{c}_{\mathrm{LO}} \mathrm{U}_{\mathrm{f}} \mathrm{d}_{0}^{0.34}\right) /\left(\mathrm{T}_{\mathrm{g}}^{3.74} \rho_{\mathrm{g}}^{0.85} \mathrm{Z}_{\mathrm{st}}\right)$

where $T_{g}$ and $\rho_{g}$ are surrounding gas temperature and density, $Z_{s t}$ is the stoichiometric fuel mass fraction, $\mathrm{c}_{\mathrm{LO}}$ is the empirical coefficient.

The above fuel spray correlations are based on a constant volume combustion vessel with nearly constant thermodynamic conditions (temperature, density). Some deviations may be caused in the highly transient diesel engine environment. Based on the comparison between developed fuel penetration correlations and experimental measurements of local equivalence ratio and fuel penetration by Espey et al. [6], Naber and Siebers [39], however, illustrated that the agreement with engine results is fairly good which indicates the slight variation of thermodynamic conditions has modest effect on the fuel spray evolution. In this work, the thermodynamic conditions at the start of injection (SOI) are applied in the spray model and maintained constant during the fuel jet evolution. In addition, the fluctuation of lift-off length due to the start and end of injection transients has been experimentally shown [12]. The evolution of flame lift-off is expected to influence the fuel jet combustion and soot emission formation. Since there is no data to predict the evolution of flame lift-off, the empirical coefficient $\mathrm{c}_{\mathrm{LO}}$ would be calibrated to determine a time-average flame lift-off length. The model can be improved in this area as additional information is available. 
Finally, the injection rate model which strongly affects the diesel combustion process needs to be specified. The start and end of injection correspond to the measured opening and closing of the needle lift. The rate of injection is based on the experimental instantaneous injector voltage signals. A varying nozzle area [20] is applied to achieve the best fit. The instantaneous injection mass rate is expressed as:

$\dot{\mathrm{m}}_{\mathrm{f}, \mathrm{inj}}(\mathrm{t})=\mathrm{c}_{\mathrm{d}} \rho_{\mathrm{f}} \mathrm{S}_{\mathrm{noz}} \sqrt{2\left(\mathrm{P}_{\mathrm{f}}-\mathrm{P}_{\mathrm{avg}}\right) / \rho_{\mathrm{f}}}$

where $c_{d}$ is the discharge coefficient, $c_{d}=c_{a} c_{v}$. $S_{\text {noz }}$ is the nozzle area.

\subsection{Combustion model description}

\subsubsection{Equilibrium products of combustion}

The calculation of the equilibrium products of combustion is based on the work by Olikara and Borman [43]. Twelve species are included in the combustion products. To introduce the EGR gas into the combustion reaction equation, the overall reaction equation is modified as:

$\mathrm{C}_{\mathrm{n}} \mathrm{H}_{\mathrm{m}} \mathrm{O}_{\mathrm{l}} \mathrm{N}_{\mathrm{k}}+(\mathrm{n}+\mathrm{m} / 4-\mathrm{l} / 2) / \Phi /\left(1+4.771 \mathrm{r}_{\mathrm{EGR}} /\left(1-\mathrm{r}_{\mathrm{EGR}}\right) \cdot \mathrm{X}_{\mathrm{O} 2, \mathrm{EGR}}\right) \cdot$

$\left(\mathrm{O}_{2}+3.727 \mathrm{~N}_{2}+0.044 \mathrm{Ar}+4.771 \mathrm{r}_{\mathrm{EGR}} /\left(1-\mathrm{r}_{\mathrm{EGR}}\right) \mathrm{EGR}\right) \rightarrow \mathrm{x}_{1} \mathrm{H}+\mathrm{x}_{2} \mathrm{O}+\mathrm{x}_{3} \mathrm{~N}+$

$\mathrm{x}_{4} \mathrm{H}_{2}+\mathrm{x}_{5} \mathrm{OH}+\mathrm{x}_{6} \mathrm{CO}+\mathrm{x}_{7} \mathrm{NO}+\mathrm{x}_{8} \mathrm{O}_{2}+\mathrm{x}_{9} \mathrm{H}_{2} \mathrm{O}+\mathrm{x}_{10} \mathrm{CO}_{2}+\mathrm{x}_{11} \mathrm{~N}_{2}+\mathrm{x}_{12} \mathrm{Ar}$

where $x_{i}$ is the mole of product species $i$ for one mole fuel. $r_{E G R}$ is the mole EGR ratio which is defined as the mole fraction of exhaust gas in the intake manifold. The EGR composition is determined by the equilibrium products of combustion at a specific equivalence ratio value [2]. $\mathrm{X}_{\mathrm{O} 2 \mathrm{EGR}}$ is the oxygen mole fraction of EGR. Figure 7 presents the calculated EGR composition as a function of the fuel/air equivalence ratio. 
In this work, only six major species including $\mathrm{CO}_{2}, \mathrm{H}_{2} \mathrm{O}, \mathrm{N}_{2}, \mathrm{O}_{2}, \mathrm{CO}$, and $\mathrm{H}_{2}$ are considered in the computation of the EGR composition.

To solve this problem, there must be 12 equations. The first 5 equations are the carbon, hydrogen, oxygen, nitrogen and argon balances, and the rest come from equilibrium reactions. By using the Newton-Raphson method and Gaussian elimination method, the products can be solved with a proper initial guess close to the correct solution [43]. Note that the equilibrium calculation is limited between $1350^{\circ} \mathrm{C}$ to $9000^{\circ} \mathrm{C}$. In addition, this calculation cannot handle the formation of free carbon. It is limited to equivalence ratio less than $(n+0.25 m-0.5 \mathrm{l}) /\left(1+4.7718 /\left(1-\mathrm{r}_{\mathrm{EGR}}\right) \cdot \mathrm{X}_{\mathrm{O} 2 \text {,EGR }}\right) /$ $(0.5 n-0.51)$

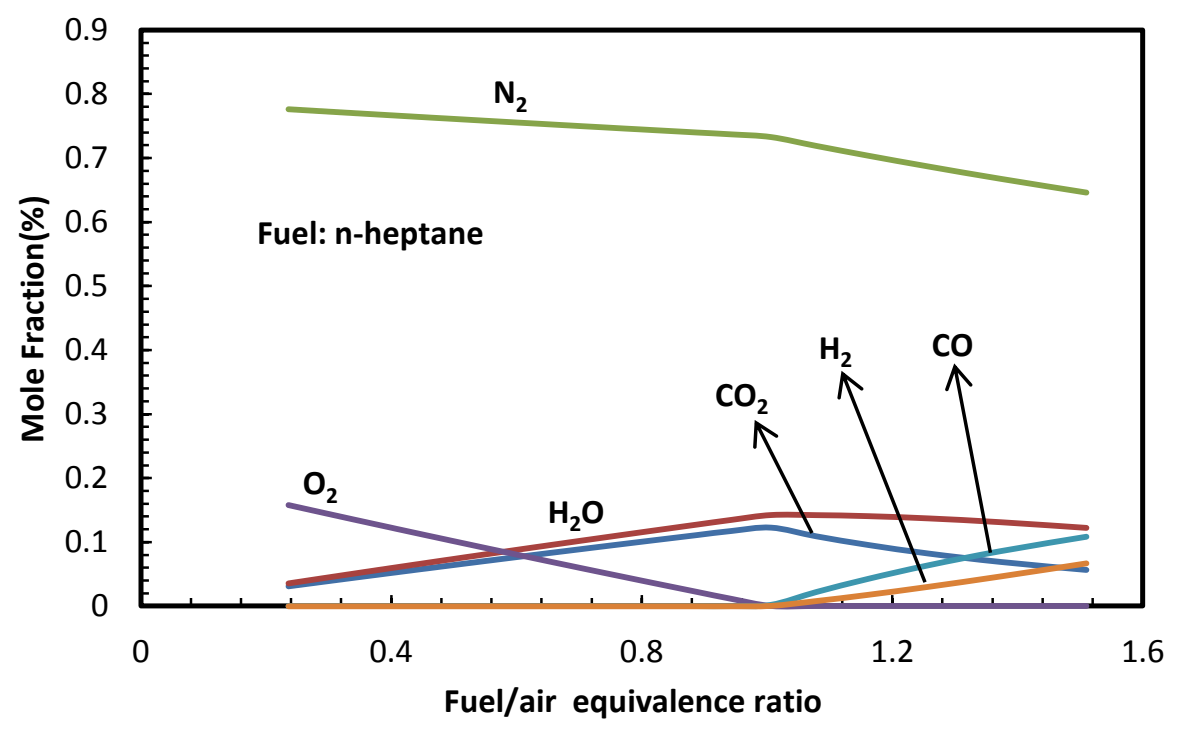

Figure 7. EGR composition as a function of fuel/air equivalence ratio (n-heptane). 


\subsubsection{Ignition delay model and heat transfer}

The ignition delay is defined as the time between start of injection $t_{\text {inj }}$ and start of ignition $\mathrm{t}_{\text {ign }}$. The overall ignition delay consists of physical ignition delay which accounts for the time elapsing for the evaporation of injected fuel and chemical ignition delay which represents the chemical kinetics of the ignition process. The physical ignition delay $\mathrm{ID}_{\text {evap }}$ can be modeled with the time needed for the fuel spray to reach the liquid length. The chemical ignition delay $\mathrm{ID}_{\text {chem }}$ is modeled with the Arrhenius type correlation. $\Phi_{2 / 3}$ and $\mathrm{T}_{2 / 3}$ are the average equivalence ratio and temperature of fuel/gas mixture in zone 2 and zone 3. Ignition is considered to occur when the integral of 1/ID from $t_{\text {inj }}$ to $t_{\text {ign }}$ is equal to 1.0.

$\mathrm{ID}=\mathrm{ID}_{\text {evap }}+\mathrm{ID}_{\text {chem }}$

where $I_{\text {chem }}=c_{1} \Phi_{2 / 3}{ }^{c_{2}}\left(P_{a v g} / P_{\text {ref }}\right)^{c_{3}} \exp \left(c_{4} / T_{2 / 3}\right)$

$\int_{t_{\text {inj }}}^{t_{\text {ign }}} d t / I D=1$

The overall cylinder heat transfer model is based on forced convection. A number of correlations for the instantaneous heat transfer coefficients have been developed. The Hohenberg model [44] is used to calculate the heat transfer coefficient:

$\mathrm{h}_{\mathrm{ht}}=130 \cdot \mathrm{V}_{\mathrm{cyl}}^{-0.06} \cdot \mathrm{P}_{\mathrm{avg}}^{0.8} \cdot \mathrm{T}_{\mathrm{avg}}^{-0.4} \cdot\left(\overline{\mathrm{v}}_{\mathrm{p}}+1.4\right)^{0.8}$

where $\mathrm{V}_{\text {cyl }}$ is the cylinder volume and $\overline{\mathrm{v}}_{\mathrm{p}}$ is the mean piston speed. The overall heat transfer rate to the cylinder gases is expressed as:

$\dot{\mathrm{Q}}=\mathrm{h}_{\mathrm{ht}} \cdot \mathrm{A} \cdot\left(\mathrm{T}_{\mathrm{wall}}-\mathrm{T}_{\mathrm{avg}}\right)$ 
The overall heat transfer is derived based on the cylinder averaged temperature and the total surface area (A). To accurately reflect the local information, it is critical to allocate the total heat transfer to each zone. For this work, the heat transfer in each zone is assumed to be proportional to individual volume and the temperature difference based on Caton's description [45]. The allocated heat transfer is expressed as following equations.

$$
\begin{aligned}
& \dot{\mathrm{Q}}_{\mathrm{j}}=\left(\mathrm{V}_{\mathrm{j}} / \mathrm{V}_{\text {cyl }}\right)^{2 / 3}\left(\mathrm{~T}_{\mathrm{wall}}-\mathrm{T}_{\mathrm{j}}\right) /\left(\mathrm{T}_{\text {wall }}-\mathrm{T}_{\text {avg }}\right) \dot{\mathrm{Q}} \quad \text { with } \mathrm{j}=1,2,3,4,5 \\
& \dot{\mathrm{Q}}_{6}=\dot{\mathrm{Q}}_{\text {total }}-\sum_{\mathrm{j}=1}^{5} \dot{\mathrm{Q}}_{\mathrm{j}}
\end{aligned}
$$

\subsubsection{Combustion rate calculation}

Different empirical combustion rates have been developed and discussed elsewhere [45-47]. In this work, the premixed burn rate is calculated by using the widely adopted empirical model developed by Watson [46]. The available gas mass prepared for premixed combustion is the limiting factor.

$\dot{\mathrm{m}}_{\mathrm{f} \text { pre }}(\mathrm{t})=\mathrm{m}_{\mathrm{a}, 3, \mathrm{soc}} \cdot \Phi_{3, \mathrm{soc}} / \mathrm{f}_{\mathrm{s}} \cdot \mathrm{k}_{\mathrm{p} 1} \mathrm{k}_{\mathrm{p} 2} \cdot \mathrm{t}_{\mathrm{norm}}^{\mathrm{kp} 1-1}\left(1-\mathrm{t}_{\mathrm{norm}}^{\mathrm{kp} 1}\right)^{\mathrm{k}_{\mathrm{p} 2}-1}$

where $\mathrm{m}_{\mathrm{a}, 3, \mathrm{soc}}, \Phi_{3, \mathrm{soc}}$ represent the well-mixed gas mass and equivalence ratio in zone 3 at start of combustion. $\mathrm{f}_{\mathrm{s}}$ is the ambient gas mass necessary for the combustion of $1 \mathrm{~kg}$ of fuel. $\mathrm{t}_{\mathrm{norm}}$ is the normalized time ranging from 0 to $1 . \mathrm{k}_{\mathrm{p} 1}, \mathrm{k}_{\mathrm{p} 2}$ variables can be correlated for different diesel engines. The values used here are based on Watson's correlation.

$\mathrm{k}_{\mathrm{p} 1}=2.0+1.25 \mathrm{e}-8(\mathrm{ID} \cdot \mathrm{rpm})^{2.4} \quad \mathrm{k}_{\mathrm{p} 2}=5000$ 
The upper constraint of $\Phi_{3, \text { soc }}$ is set as 2.5. This can have two major explanations: (1) it would fail to get solutions when equivalence ratio is beyond approximately 3 during the calculation of premixed combustion products due to the limitation of the equilibrium model [43]. (2) The gas-fuel mixture prepared for premixed combustion is not homogeneous. Several hot spots would likely develop in this premixed rich combustion and some fuel, especially upstream of zone 3, may not meet oxygen and combust. Therefore, it is assumed that the normalized equivalence ratio $\Phi_{3, \text { soc }}$ is 2.5 if the actual value is beyond 2.5 . Modest change of this parameter would not significantly change the results of the current study.

The remaining fuel left in zone 3 , together with the subsequent entrained fuel/gas mixture from zone 2 will mix with the ambient fresh gas in zone 6 such that a diffusion flame forms and the high temperature diffusion combustion product zone 5 begins to develop. As the last of the premixed gas is consumed, the combustion transitions to be purely mixing-controlled. The overall process is governed by the mixing-frequency approach described by Barba et al. [47]. The concept of a frequency model is proposed to predict the mixing-controlled burn rate as:

$\dot{\mathrm{m}}_{\mathrm{f}, \mathrm{diff}}(\mathrm{t})=\mathrm{f}_{\mathrm{M}} \cdot \mathrm{m}_{\mathrm{f}, 3}(\mathrm{t})$

The characteristic mixing frequency $f_{M}$ should be interpreted as a control of the diffusion process. Mixing frequency is considered as the quotient of the characteristic mixing velocity $\gamma_{\text {mix }}$ and the characteristic mixing length $l_{\text {mix }}$. The cubic root of the cylinder volume $V_{c y l}$, overall equivalence ratio $\Phi$ and the number of nozzle holes $n_{N}$ are constructed to represent the characteristic mixing length. The characteristic mixing 
velocity is given by the turbulence in the cylinder. It is composed by the turbulence caused by the motion of the charge air $\mathrm{c}_{\mathrm{G}} \overline{\mathrm{V}}_{\mathrm{p}}^{2}$ and the turbulence caused by the injection turbulent kinetic energy $c_{k} k$. The two parameters $c_{G}$ and $c_{k}$ are evaluated as 2.5 and 0.2 respectively [47].

$\mathrm{f}_{\mathrm{M}}=\gamma_{\text {mix }} / \mathrm{l}_{\text {mix }}=\frac{\sqrt{\mathrm{c}_{\mathrm{G}} \overline{\mathrm{v}}_{\mathrm{p}}^{2}+\mathrm{c}_{\mathrm{k}} \mathrm{k}}}{\sqrt[3]{\mathrm{\Phi} \cdot \mathrm{v}_{\mathrm{cyl}} / \mathrm{n}_{\mathrm{N}}}}$

The density of turbulent kinetic energy $k$ is expressed based on the conservation of energy:

$\dot{\mathrm{k}}(\mathrm{t})=\mathrm{c}_{\text {spray }} \dot{\mathrm{k}}_{\mathrm{I}}(\mathrm{t})-\mathrm{c}_{\text {diss }} / \mathrm{d}_{0} \cdot \mathrm{k}^{1.5}$

The first part of equation (26) is the kinetic energy of the injected fuel, which can be expressed as [20]:

$\dot{\mathrm{k}}_{\mathrm{I}}(\mathrm{t})=\left(\mathrm{n}_{\mathrm{N}} \rho_{\mathrm{f}} \mathrm{S}_{\text {noz }}\right)^{-2} \dot{\mathrm{m}}_{\mathrm{f}, \mathrm{inj}}(\mathrm{t})^{3} /\left(2 \cdot \mathrm{m}_{\text {cyl }}\right)$

The second part is the dissipation of energy. The pre-factors $c_{\text {diss }}$ and $c_{\text {spray }}$ are given as 0.04 and 0.3 [47], respectively.

\subsubsection{Six-zone energy balance}

The first law of thermodynamics is applied to solve the thermodynamic properties in each zone. The volumes of liquid fuel zone (zone 1) and vapor fuel zone (zone 2) are derived with the knowledge of penetration length and spray spreading angle. For the unsteady head vortex including zone 3 , zone 4 , and zone 5 , the ideal gas equation is applied. The instantaneous internal energy (absolute quantities including the enthalpy of formation) is derived based on the conservations of energy and mass, and the specific gas constant, molecular mass, temperature are calculated. 
In the liquid zone (zone 1), the fuel droplets are sprayed and vaporized in a supercritical environment. The high-pressure droplet vaporization involves complex gas absorption, liquid solubility and liquid-vapor equilibrium process. Although the incylinder gas temperature and pressure are typically beyond the fuel critical condition, Siebers [40] indicated that diesel fuel still experiences subcritical vaporization process. The calculated saturated fuel vapor temperature, $\mathrm{T}_{\mathrm{s}}$, never reaches supercritical conditions. This temperature is considered as the approximate average temperature in zone 1 . The instantaneous internal energy in zone 1 is calculated based on the energy balance.

$$
\begin{aligned}
\dot{\mathrm{U}}_{1}(\mathrm{t})= & \dot{\mathrm{m}}_{\mathrm{f}, \text { inj }}(\mathrm{t}) \mathrm{h}_{\mathrm{f}, \mathrm{T}_{\mathrm{inj}}}+\dot{\mathrm{m}}_{\mathrm{g}, 1, \mathrm{in}}(\mathrm{t}) \mathrm{h}_{\mathrm{g}, \mathrm{T}_{6}}-\dot{\mathrm{m}}_{\mathrm{f}, 1-2}(\mathrm{t}) \mathrm{h}_{\mathrm{f}, \mathrm{T}_{1}} \\
& -\dot{\mathrm{m}}_{\mathrm{g}, 1-2}(\mathrm{t}) \mathrm{h}_{\mathrm{g}, \mathrm{T}_{1}}-\mathrm{P}_{\mathrm{avg}} \dot{\mathrm{V}}_{1}(\mathrm{t})+\dot{\mathrm{Q}}_{1}
\end{aligned}
$$

The composition of zone 2 is vapor fuel and gas. The average temperature of zone 2 is derived as:

$$
\begin{aligned}
\dot{\mathrm{U}}_{2}(\mathrm{t})= & \dot{\mathrm{m}}_{\mathrm{f}, 1-2}(\mathrm{t}) \mathrm{h}_{\mathrm{f}, \mathrm{T}_{1}}+\dot{\mathrm{m}}_{\mathrm{g}, 1-2}(\mathrm{t}) \mathrm{h}_{\mathrm{g}, \mathrm{T}_{1}}+\dot{\mathrm{m}}_{\mathrm{g}, 2, \text { in }}(\mathrm{t}) \mathrm{h}_{\mathrm{g}, \mathrm{T}_{6}} \\
& -\dot{\mathrm{m}}_{\mathrm{f}, 2-3}(\mathrm{t}) \mathrm{h}_{\mathrm{f}, \mathrm{T}_{2}}-\dot{\mathrm{m}}_{\mathrm{g}, 2-3}(\mathrm{t}) \mathrm{h}_{\mathrm{g}, \mathrm{T}_{2}}-\mathrm{P}_{\mathrm{avg}} \dot{\mathrm{V}}_{2}(\mathrm{t})+\dot{\mathrm{Q}}_{2}
\end{aligned}
$$

Zone 3 is the pre-ignition mixing zone. Beyond the lift-off length, well-premixed fuel-gas mixture begins to burn volumetrically as the premixed combustion mode after ignition delay period. And the remaining fuel, together with the subsequent entrained fuel/gas mixture, will meet the ambient fresh gas and burn as diffusion flame. The overall internal energy in zone 3 is expressed as: 


$$
\begin{aligned}
\dot{\mathrm{U}}_{3}(\mathrm{t})= & \dot{\mathrm{m}}_{\mathrm{f}, 2-3}(\mathrm{t}) \mathrm{h}_{\mathrm{f}, \mathrm{T}_{2}}+\dot{\mathrm{m}}_{\mathrm{g}, 2-3}(\mathrm{t}) \mathrm{h}_{\mathrm{g}, \mathrm{T}_{2}}+\dot{\mathrm{m}}_{\mathrm{g}, 3, \mathrm{in}}(\mathrm{t}) \mathrm{h}_{\mathrm{g}, \mathrm{T}_{6}}-\dot{\mathrm{m}}_{\mathrm{f}, \text { pre }}(\mathrm{t}) \mathrm{h}_{\mathrm{f}, \mathrm{T}_{3}}- \\
& \dot{\mathrm{m}}_{\mathrm{g}, \text { pre }}(\mathrm{t}) \mathrm{h}_{\mathrm{g}, \mathrm{T}_{3}}-\dot{\mathrm{m}}_{\mathrm{f}, \text { diff }}(\mathrm{t}) \mathrm{h}_{\mathrm{f}, \mathrm{T}_{3}}-\dot{\mathrm{m}}_{\mathrm{g}, \text { diff, } 3}(\mathrm{t}) \mathrm{h}_{\mathrm{g}, \mathrm{T}_{3}}-\mathrm{P}_{\mathrm{avg}} \dot{\mathrm{V}}_{3}(\mathrm{t})+\dot{\mathrm{Q}}_{3}
\end{aligned}
$$

where $\dot{\mathrm{m}}_{\mathrm{g}, \text { pre }}(\mathrm{t})=\dot{\mathrm{m}}_{\mathrm{f} \text {,pre }}(\mathrm{t}) \cdot \mathrm{f}_{\mathrm{s}} / \Phi_{3, \mathrm{soc}}$

$$
\dot{\mathrm{m}}_{\mathrm{g}, \mathrm{diff}, 3}(\mathrm{t})=\dot{\mathrm{m}}_{\mathrm{f}, \text { diff }}(\mathrm{t}) \cdot \mathrm{f}_{\mathrm{s}} / \Phi_{3}
$$

$\dot{\mathrm{m}}_{\mathrm{g}, \mathrm{diff}, 3}(\mathrm{t})$ represents the previously well-mixed gas in zone 3 . Note that the gas entrainment $\dot{\mathrm{m}}_{\mathrm{g}, 3, \mathrm{in}}(\mathrm{t})$ is determined from the spray model prior to the start of diffusion combustion. The onset of the diffusion flame prohibits further gas entrainment into zone $3, \dot{\mathrm{m}}_{\mathrm{g}, 3, \mathrm{in}}(\mathrm{t})=0$ if $\mathrm{t}>\mathrm{t}_{\mathrm{soc}}$. The high temperature, low density gas developed in zone 5 depresses the turbulence level and local strain, stabilizes the diffusion flame. The turbulent mixing with the ambient fresh gas from zone 6, which ignites the rich fuel/gas mixture in zone 3, will be governed by the mixing-frequency as shown in the following equation.

$\dot{\mathrm{m}}_{\mathrm{g}, \text { diff, } 6}(\mathrm{t})=\dot{\mathrm{m}}_{\mathrm{f}, \text { diff }}(\mathrm{t}) \cdot \mathrm{f}_{\mathrm{s}} / \Phi_{\text {diff }}-\dot{\mathrm{m}}_{\mathrm{g}, \text { diff }, 3}(\mathrm{t}) \quad$ with $\Phi_{\text {diff }}=1$

In the combustion product zones (zone 4 and zone 5), some fresh gas is entrained into combustion products and reaches a new equilibrium condition. The phenomenon involves the dilution, oxidization, energy release of incomplete combustion products. The rate of gas entrainment into combustion products is derived based on the concept of contact area between two zones with a characteristic mixing time [48].

$\dot{\mathrm{m}}_{\mathrm{after}, \mathrm{i}}(\mathrm{t})=\mathrm{c}_{\mathrm{after}, \mathrm{i}} \cdot 1 / \tau_{\mathrm{m}} \cdot \mathrm{m}_{\mathrm{g}} \cdot \mathrm{m}_{\mathrm{prod}, \mathrm{i}} /\left(\mathrm{m}_{\mathrm{g}}+\mathrm{m}_{\mathrm{prod}, \mathrm{i}}\right) \quad \mathrm{i}=4,5$

where $\mathrm{m}_{\mathrm{g}}$ is the unburned gas mass of zone 6 , and $\mathrm{m}_{\text {prod,i }}$ is the combustion product mass of zone 4 or zone 5 . The mixing time scale $\tau_{m}$ is evaluated with the same 
correlation utilized as a mixing frequency for the diffusion combustion model with $1 / \tau_{m}=f_{M}$. The constant $c_{a f t e r, i}$ scales the magnitude of the resulting gas entrainment rate.

The internal energy of zone 4 and zone 5 is expressed as:

$$
\begin{aligned}
\dot{\mathrm{U}}_{4}(\mathrm{t})= & \dot{\mathrm{m}}_{\mathrm{f}, \mathrm{pre}}(\mathrm{t}) \mathrm{h}_{\mathrm{f}, \mathrm{T}_{3}}+\dot{\mathrm{m}}_{\mathrm{g}, \mathrm{pre}}(\mathrm{t}) \mathrm{h}_{\mathrm{g}, \mathrm{T}_{3}}+\dot{\mathrm{m}}_{\mathrm{after}, 4}(\mathrm{t}) \mathrm{h}_{\mathrm{g}, \mathrm{T}_{6}}-\mathrm{P}_{\mathrm{avg}} \dot{\mathrm{V}}_{4}(\mathrm{t})+\dot{\mathrm{Q}}_{4} \\
\dot{\mathrm{U}}_{5}(\mathrm{t})= & \dot{\mathrm{m}}_{\mathrm{f}, \mathrm{diff}}(\mathrm{t}) \mathrm{h}_{\mathrm{f}, \mathrm{T}_{3}}+\dot{\mathrm{m}}_{\mathrm{g}, \mathrm{diff}, 3}(\mathrm{t}) \mathrm{h}_{\mathrm{g}, \mathrm{T}_{3}}+\dot{\mathrm{m}}_{\mathrm{g}, \text { diff, },}(\mathrm{t}) \mathrm{h}_{\mathrm{g}, \mathrm{T}_{6}}+\dot{\mathrm{m}}_{\mathrm{after}, 5}(\mathrm{t}) \mathrm{h}_{\mathrm{g}, \mathrm{T}_{6}}- \\
& \mathrm{P}_{\mathrm{avg}} \dot{\mathrm{V}}_{5}(\mathrm{t})+\dot{\mathrm{Q}}_{5}
\end{aligned}
$$

Zone 6 is the surrounding bulk gas, of which the composition is always air and EGR. The internal energy in zone 6 can be determined.

$$
\begin{aligned}
\dot{\mathrm{U}}_{6}(\mathrm{t})= & -\sum_{\mathrm{i}=1}^{3} \dot{\mathrm{m}}_{\mathrm{g}, \mathrm{i}, \mathrm{in}}(\mathrm{t}) \mathrm{h}_{\mathrm{g}, \mathrm{T}_{6}}-\sum_{\mathrm{i}=4}^{5} \dot{\mathrm{m}}_{\mathrm{after}, \mathrm{i}}(\mathrm{t}) \mathrm{h}_{\mathrm{g}, \mathrm{T}_{6}}-\dot{\mathrm{m}}_{\mathrm{g}, \text { diff, }, 6}(\mathrm{t}) \mathrm{h}_{\mathrm{g}, \mathrm{T}_{6}} \\
& -\mathrm{P}_{\mathrm{avg}} \dot{\mathrm{V}}_{6}(\mathrm{t})+\dot{\mathrm{Q}}_{6}
\end{aligned}
$$

Once all the zone temperatures are determined based on the energy equations, the overall cylinder averaged temperature is obtained.

$\mathrm{T}_{\mathrm{avg}}=\sum_{\mathrm{i}=1}^{6} \mathrm{~m}_{\mathrm{i}} \mathrm{C}_{\mathrm{v}, \mathrm{i}} \mathrm{T}_{\mathrm{i}} / \mathrm{m}_{\mathrm{cyl}} \mathrm{C}_{\mathrm{v}, \mathrm{cyl}}$

The overall pressure can be determined by using ideal gas equation. The sum of all zonal volumes is equal to the instantaneous cylinder volume. The apparent heat release rate is calculated using the First Law of Thermodynamics, as shown:

$$
\begin{aligned}
& \mathrm{P}_{\mathrm{avg}}=\mathrm{m}_{\text {cyl }} \mathrm{RT}_{\mathrm{avg}} / \mathrm{V}_{\text {cyl }} \\
& \mathrm{V}_{\text {cyl }}=\sum_{\mathrm{i}=1}^{6} \mathrm{~V}_{\mathrm{i}} \\
& \dot{\mathrm{Q}}_{\mathrm{hr}}=\left(1+\frac{1}{\gamma-1}\right) \mathrm{P}_{\mathrm{avg}} \dot{\mathrm{V}}_{\text {cyl }}+\frac{\mathrm{V}_{\text {cyl }}}{\gamma-1} \dot{\mathrm{P}}_{\text {avg }}-\frac{\mathrm{m}_{\text {cyl }} \mathrm{T}_{\mathrm{avg}}}{\gamma-1} \dot{\mathrm{R}}+\dot{\mathrm{Q}}
\end{aligned}
$$

with $\gamma$ is the ratio of specific heat. 


\subsection{Emission model description}

The successful development of phenomenological soot and nitric oxide models requires determining where and when each of these reactions occurs during the combustion process. These determinations need to be consistent with the current understanding of emission formation process within the reacting diesel fuel jet [11]. Figure 8 illustrates emission formation regimes in the multi-zone thermodynamic model and how the emissions are related to the so-called "phi-T" map. The green path line shown on the "phi-T" map corresponds to the adiabatic flame temperature. The arrows correspond to the typical diesel fuel evolution process.

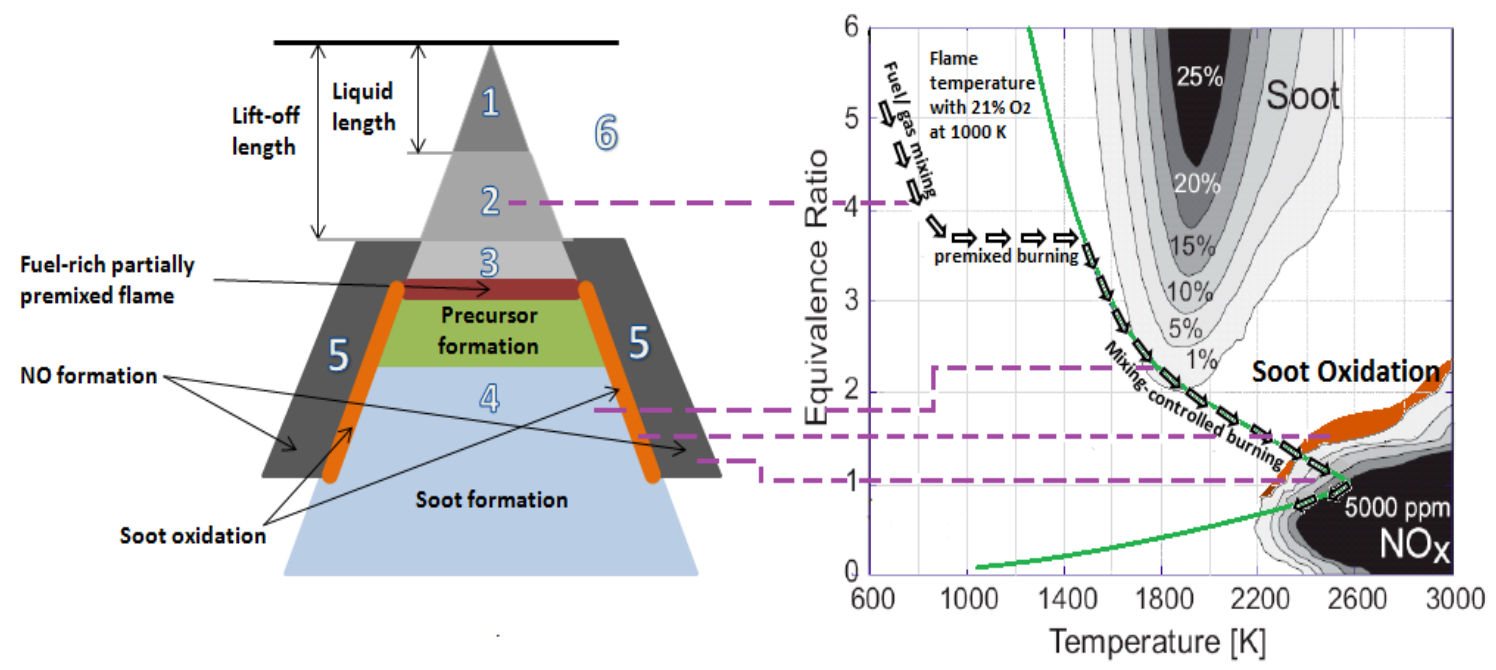

Figure 8. Schematic diagram of emission formation regimes for the conventional diesel engine combustion. The "phi-T" map with soot and NOx formation islands is adapted from [49]. 
The fuel parcels experience the vaporization and mixing process with the entrained hot gas in zones 1-3. A fuel-rich partially premixed flame, supported by the fuel-rich mixture in zone 3 , forms at the zone 3 periphery (this flame is neglected in the combustion model because of the modest effect on the overall heat release rate). The first condensed phase material, such as propargyl and acetylene radicals, its higher analogues $\left(\mathrm{C}_{2 \mathrm{n}} \mathrm{H}_{2}\right)$ and polycyclic aromatic hydrocarbons $(\mathrm{PAH})$ are identified to occur in a mixture of combustion products originating from this standing premixed flame associated with relatively low combustion temperature and high equivalence ratio. The soot precursors experience complex chemical pathways such as surface growth, direct deposit, coagulation, and aggregation as they move down the turbulent fuel jet toward the head vortex of zone 4 , leading to soot formation. At the jet edge where a stoichiometric diffusion flame forms, the high temperature diffusion combustion product zone 5 develops and that is where the oxidation of soot particles occurs when they reach or pass through the high temperature reservoir. The soot particles are burned in the presence of oxidizers to form gaseous products such as $\mathrm{CO}$ and $\mathrm{CO}_{2}$. The final engineout soot emissions will result from the balance between soot formation and burnout.

The presented typical conventional diesel combustion process indicates that all of the premixed combustion is generally under the equivalence ratios of 2-4 with low combustion temperature which is not conducive to nitric oxide production either by thermal (require high temperature, typically above $2200 \mathrm{~K}$ ) or prompt mechanism (require the equivalence ratio to be below 1.8 [50]). The majority of nitric oxide emissions are produced in the diffusion flame combustion products because of the high 
temperature and available source of oxygen. This diffusion flame combustion product zone (zone 5), therefore, is deemed as the major control volume for nitric oxide formation.

\subsubsection{Nitric oxide kinetics}

As mentioned above, the kinetics of nitric oxides has been extensively studied. Four major pathways have been proposed. In this work, only the thermal and $\mathrm{N}_{2} \mathrm{O}$ intermediate mechanisms are considered to be the primary pathways. The process is governed by the following reactions:

$\mathrm{R}_{1}: \mathrm{O}+\mathrm{N}_{2} \leftrightarrow \mathrm{NO}+\mathrm{N}$

$\mathrm{k}_{\mathrm{f}, 1}=1.95 \mathrm{e}^{8} \exp (-38660 / \mathrm{T}) \quad \mathrm{k}_{\mathrm{r}, 1}=4.11 \mathrm{e}^{7} \exp (-715 / \mathrm{T})$

$\mathrm{R}_{2}: \mathrm{N}+\mathrm{O}_{2} \leftrightarrow \mathrm{NO}+\mathrm{O}$

$\mathrm{k}_{\mathrm{f}, 2}=9 \mathrm{e}^{3} \mathrm{Texp}(-3270 / \mathrm{T}) \quad \mathrm{k}_{\mathrm{r}, 2}=1.9 \mathrm{e}^{3} \mathrm{Texp}(-19410 / \mathrm{T})$

$\mathrm{R}_{3}: \mathrm{N}+\mathrm{OH} \leftrightarrow \mathrm{NO}+\mathrm{H}$

$\mathrm{k}_{\mathrm{f}, 3}=1.1 \mathrm{e}^{8} \exp (-565 / \mathrm{T}) \quad \mathrm{k}_{\mathrm{r}, 3}=2.92 \mathrm{e}^{8} \exp (-24675 / \mathrm{T})$

$\mathrm{R}_{4}: \mathrm{O}+\mathrm{N}_{2}+\mathrm{M} \leftrightarrow \mathrm{N}_{2} \mathrm{O}+\mathrm{M}$

$\mathrm{k}_{\mathrm{f}, 4}=4.44 \mathrm{e}^{32} \mathrm{~T}^{-8.358} \exp (-28234 / \mathrm{T}) \quad \mathrm{k}_{\mathrm{r}, 4}=5.7 \mathrm{e}^{8} \exp (-28230 / \mathrm{T})$

$\mathrm{R}_{5}: 2 \mathrm{NO} \leftrightarrow \mathrm{N}_{2} \mathrm{O}+\mathrm{O}$

$\mathrm{k}_{\mathrm{f}, 5}=1.45 \mathrm{e}^{-29} \mathrm{~T}^{9.259} \exp (-11651 / \mathrm{T}) \quad \mathrm{k}_{\mathrm{r}, 5}=2.9 \mathrm{e}^{7} \exp (-11651 / \mathrm{T})$

In the above expressions, $\mathrm{k}_{\mathrm{f}, \mathrm{i}}$ is the forward rate constant and $\mathrm{k}_{\mathrm{r}, \mathrm{i}}$ is the corresponding reverse rate constant. The rate constants are obtained by [50-52]. The rate constant $\mathrm{k}_{\mathrm{f}, 4}$ has the unit of $\mathrm{m}^{6} / \mathrm{mol}^{2}$-s, and the units for other constants are $\mathrm{m}^{3} / \mathrm{mol}$-s. 
Nitric oxides form in the diffusion flame front and post flame gases where combustion reaction rates are sufficiently fast and the burned gases are close to thermodynamic equilibrium. It is, therefore, appropriate to decouple the combustion and nitric oxide formation process, and approximate the equilibrium concentrations of $\mathrm{O}, \mathrm{O}_{2}$, $\mathrm{H}, \mathrm{OH}$ and $\mathrm{N}_{2}$. By assuming steady-state concentrations for $\mathrm{N}$ and $\mathrm{N}_{2} \mathrm{O}$, an explicit nitric oxide formation can be derived based on Lavoie et al. [53]:

$\mathrm{d}[\mathrm{NO}] / \mathrm{dt}=2\left(1-\alpha^{2}\right)\left(\mathrm{R}_{1} /\left(1+\alpha \mathrm{K}_{1}\right)+\mathrm{R}_{5} /\left(1+\alpha \mathrm{K}_{2}\right)\right)$

with $\alpha=[\mathrm{NO}] /[\mathrm{NO}]_{\mathrm{e}}, \mathrm{K}_{1}=\mathrm{R}_{1} /\left(\mathrm{R}_{2}+\mathrm{R}_{3}\right), \mathrm{K}_{2}=\mathrm{R}_{5} / \mathrm{R}_{4}$

where $R_{i}$ represents the equilibrium rate of the $i$-th reaction. Subscript "e" denotes equilibrium concentration (e.g. $\mathrm{R}_{1}=\mathrm{k}_{\mathrm{f}}[\mathrm{O}]_{\mathrm{e}}\left[\mathrm{N}_{2}\right]_{\mathrm{e}}=\mathrm{k}_{\mathrm{r}}[\mathrm{NO}]_{\mathrm{e}}[\mathrm{N}]_{\mathrm{e}}$ ). The first term of equation (45) corresponds to the Zeldovich (thermal) mechanism and the second term corresponds to $\mathrm{N}_{2} \mathrm{O}$-intermediate mechanism. Examination of this equation by Lavoie $e t$ al. [53] implies that most of the nitric oxide formation occurs via Zeldovich (thermal) mechanism except for lean mixtures with low temperature, where then the $\mathrm{N}_{2} \mathrm{O}$ intermediate mechanism will become dominant.

\subsubsection{Soot formation and oxidation model}

The actual soot precursor formation involves complex fuel pyrolysis mechanisms, such as production of paraffinic hydrocarbons up to $\mathrm{C}_{7}$ for growth species and the formation of benzene and pyrene as seed species. For simplicity, the soot precursor formation rate is expressed based on an Arrhenius type equation:

$\dot{\mathrm{m}}_{\mathrm{pf}}=\mathrm{A}_{\mathrm{p}} \cdot \mathrm{m}_{\mathrm{f}, \mathrm{v}, 3} \cdot \mathrm{P}_{\mathrm{avg}}^{0.5} \cdot \Phi_{3} \cdot \exp \left(-12500 / \mathrm{RT}_{\text {rich,prod }}\right)$ 
The pre-exponential factors include the precursor formation constant $A_{p}$, available vapor fuel mass $\mathrm{m}_{\mathrm{f}, \mathrm{v}, 3}$, average cylinder pressure $\mathrm{P}_{\mathrm{avg}}$ and fuel-rich premixed reaction equivalence ratio $\Phi_{3}$. The original formation rate calculation (equation 46), proposed by Bayer and Foster [54], used vapor fuel as the inception species for soot formation. The soot particle precursors actually are closely linked to concentration of parent fuel. This work considers the fuel vapor forms soot precursors first via the fuelrich partially premixed flame. $\mathrm{m}_{\mathrm{f}, \mathrm{v}, 3}$ is the total fuel vapor mass available for soot precursor production in zone 3 . The term, equivalence ratio $\Phi_{3}$, indicates that not all the fuel is "available" for conversion to soot precursors, the soot precursor formation kinetics occurs at the same time as the fuel oxidation kinetics. The equivalence ratio $\Phi_{3}$ of this premixed flame and fuel vapor mass $m_{\mathrm{f}, \mathrm{v}, 3}$ for the above reaction is determined by the fuel and gas in zone 3 . The CHEMKIN chemistry solver is used to calculate this temperature ( $\mathrm{T}_{\text {rich,prod }}$ ) of the rich reaction equilibrium products with detailed chemical kinetic mechanisms of n-heptane developed by Curran et al. [55].

The actual fuel pyrolysis reaction depends on the breakdown path of fuel, and a detailed fuel gas chemistry reaction could be proposed to provide a high level of accuracy. The combustion reaction rates, however, are considered to be sufficiently fast with equilibrium products in a time scale much shorter than the time scale modeled here.

The equivalence ratio of the fuel-rich partially premixed flame depends on the flame lift-off length. The onset of diffusion flame prevents further gas entrainment into zone 3. Longer flame lift-off length allows more oxygen available within the fuel spray and a lower equivalence ratio for the fuel-rich premixed reaction. 
The soot formation rate originating from soot precursors is expressed based on the work of Fusco et al. [30]. The pre-exponential factors include the soot formation constant $A_{f}$, the net mass of soot precursors $m_{p}$. The temperature of soot formation is determined from zone 4.

$\dot{\mathrm{m}}_{\mathrm{sf}}=\mathrm{A}_{\mathrm{f}} \cdot \mathrm{m}_{\mathrm{p}} \cdot \exp \left(-50000 / \mathrm{RT}_{4}\right)$

The soot oxidation rate is described based on the work of Schubiger et al. [28]. To account for the turbulence effects on the soot oxidation, the overall soot oxidation rate is expressed as:

$\mathrm{m}_{\mathrm{so}}=\mathrm{A}_{\mathrm{o}} \cdot 1 / \tau_{\mathrm{m}} \cdot \mathrm{m}_{\text {soot }} \cdot\left(\mathrm{P}_{\mathrm{O} 2} / \mathrm{P}_{\mathrm{O} 2, \mathrm{ref}}\right)^{n} \cdot \exp \left(-15000 / \mathrm{T}_{5}\right)$

The pre-exponential factors include the soot oxidation constant $A_{o}$, The turbulence time scale $\tau_{m}$, the net mass of soot mass $m_{\text {soot }}$, and the pressure term. The turbulence time scale $\tau_{\mathrm{m}}$, once again, can be established by applying equation (25). The temperature $\mathrm{T}_{5}$ and partial pressure of oxygen $\mathrm{P}_{\mathrm{O} 2}$ for the oxidation process, therefore, are determined from zone $5 . \mathrm{P}_{\mathrm{O} 2 \text {,ref }}$ represents the oxygen partial pressure of air under the standard state. The rate of net soot precursor and soot particle mass $\dot{\mathrm{m}}_{\mathrm{p}}, \dot{\mathrm{m}}_{\text {soot }}$ are expressed as follows:

$$
\begin{aligned}
& \dot{\mathrm{m}}_{\mathrm{p}}=\dot{\mathrm{m}}_{\mathrm{pf}}-\dot{\mathrm{m}}_{\mathrm{sf}} \\
& \dot{\mathrm{m}}_{\mathrm{soot}}=\dot{\mathrm{m}}_{\mathrm{sf}}-\dot{\mathrm{m}}_{\mathrm{so}}
\end{aligned}
$$

The pre-exponential factors $A_{p}, A_{f}, A_{o}$ and exponent term $n$ in equation (48) need to be calibrated with experimental soot emissions for a specific engine and fuel type. Again, it should be emphasized that the proposed three-step soot model is empirical and highly simplified due to a lack of chemical reaction details. In practice, the soot 
oxidation occurs throughout the soot formation process including precursor, nuclei, and particles stages [2]. Many species such as $\mathrm{O}_{2}, \mathrm{O}, \mathrm{OH}, \mathrm{CO}_{2}$ and $\mathrm{H}_{2} \mathrm{O}$ in or near the diffusion flame could oxidize soot. For practical engine simulations, however, the sensitive and demanding submodels to describe these complex physical processes in turbulent environment within the combustion chamber still yield considerable uncertainties. In addition, because of the principal mathematical problem that the final engine-out soot mass is only a small difference between two large quantities of soot formation and oxidation, quantitative prediction of absolute engine-out soot concentrations is impossible. For the above two reasons, even a more comprehensive soot model is still likely to result in considerable relative errors in the predicted engineout emissions. Consequently, a simply soot oxidation model only through $\mathrm{O}_{2}$ attack is adopted in this work. The qualitative effects of various engine parameters on the soot emission can be estimated.

\subsection{Numerical solution}

The current formulation of this simulation is developed using MATLAB. The MATLAB toolbox can provide a lot of sophisticated numerical algorithms, such as Euler or fourth-order Runge-Kutta method, with sufficient accuracy for the approximation of solutions of these ordinary differential equations.

For the implementation of the thermodynamic combustion simulation, the initial conditions including temperature, pressure, and mixture composition at the start of injection need to be acquired. This information can be obtained by using some commercial engine cycle simulation program. In this work, the simulation program, GT- 
Power, is used to acquire the information. The measured experimental data such as inlet pressure, temperature, and fuel flow rate are considered as inputs for GT-Power. The initial conditions at the start of injection are determined and utilized as inputs for the model.

A number of internal consistency checks may be used to determine the simulation accuracy. The level of accuracy in this calculation is examined by the introduction of "computational error". The error is determined by summing the various energy terms including the overall internal energy, heat loss, indicated work, fuel enthalpy. The instantaneous cylinder internal energy change should be equal to the sum of the changes of indicated work, heat loss and injected fuel enthalpy. As shown in the overall energy balance equation below. Any unbalance would be deemed as computational error. $\dot{\mathrm{U}}(\mathrm{t})=\dot{\mathrm{m}}_{\mathrm{f}, \mathrm{inj}}(\mathrm{t}) \mathrm{h}_{\mathrm{T}_{\text {inj }}}-\mathrm{P}_{\mathrm{avg}} \dot{\mathrm{V}}_{\mathrm{cyl}}+\dot{\mathrm{Q}}$ 


\section{ENGINE SPECIFICATION AND DATA}

The selected engine for this study is a 4.5 liter, inline four-cylinder John Deere engine. Engine specifications are given in Table 1. An electronically controlled fuel system and exhaust gas recirculation system were equipped in this engine. The exhaust emissions measurements including $\mathrm{CO}, \mathrm{CO}_{2}, \mathrm{O}_{2}, \mathrm{NO}, \mathrm{HC}$ were conducted using a standard emission bench. Exhaust nitric oxide concentration was measured with chemiluminescence technology. The soot concentration was estimated by the filter smoke number (FSN). The device for measuring the FSN was an AVL smoke-meter.

The correlations between FSN unit and absolute mass of carbonaceous particles (dry soot) were investigated and studied elsewhere [58-60]. The correlation developed by Christian et al. [59] has been illustrated to best correlate with the experimental data [61] and therefore this correlation [59] is adopted in this work. Detailed information concerning the selected engine experiments and exhaust emissions measurement technology can be found in $[56,57]$.

The experimental data was provided by the Advanced Engine Research laboratory of Texas A\&M University for model comparisons. Table 2 and Table 3 list the selected experimental operating conditions. The experiments were first completed under three different speed and load cases including $1400 \mathrm{rev} / \mathrm{min}$ with $50 \mathrm{ft}-\mathrm{lbs}$ torque, 1900 $\mathrm{rev} / \mathrm{min}$ with $150 \mathrm{ft}-\mathrm{lbs}$ torque and $2400 \mathrm{rev} / \mathrm{min}$ with $300 \mathrm{ft}-\mathrm{lbs}$ torque as shown in Table 2. These cases were referred as low speed/load, moderate speed/load and high speed/load, respectively. Each case had corresponding injection configuration and EGR 
level. The operating point with $1400 \mathrm{rev} / \mathrm{min}, 50 \mathrm{ft}-\mathrm{lbs}$ torque (EGR level: $1.1 \%, \mathrm{P}_{\mathrm{inj}}$ : 816 bar) was denoted as the base case. Table 3 shows experimental data for two sets of parametric studies for the base case. The first test mode was the EGR level sweep. The EGR level increased from $1.1 \%$ up to $49.6 \%$ under constant injection pressure ( 816 bar). The other test mode was the injection pressure sweep. The injection pressure increased from 750 bar to 1250 bar with constant EGR level (1.1\%). Fuel flow rate and injection timing were held constant throughout the experiments. Inlet temperature and pressure were not constrained and varied with different operating conditions.

Table 1: Engine specification

\begin{tabular}{c|c}
\hline Item & Value \\
\hline Manufacturer & John Deere, lnc. \\
Displacement & 4.5 liter \\
Compression Ratio & 16.57 \\
Bore & $106 \mathrm{~mm}$ \\
Stroke & $127 \mathrm{~mm}$ \\
Connecting rod length & $200 \mathrm{~mm}$ \\
Injection system & Common-rail system, direct injection \\
Number of injection holes & 6 \\
Injection nozzle diameter & $0.18 \mathrm{~mm}$ \\
Air system & Variable geometry, turbocharger with EGR \\
\hline
\end{tabular}


Table 2: Operating conditions for three different speed/load cases

\begin{tabular}{c|ccc}
\hline Item & \multicolumn{3}{c}{ Value } \\
\hline Speed (rpm) & 1400 & 1900 & 2400 \\
Fuel flow rate (g/s) & 1.1 & 3.0 & 6.6 \\
Torque (ft-lb) & 50 & 150 & 300 \\
EGR level(\%) & 1.1 & 0.8 & 13.2 \\
SOI*( ${ }^{\circ}$ bTDC) & 8.0 & 8.4 & 13.4 \\
Injection pressure (bar) & 816 & 1165 & 1255 \\
Inlet pressure (bar) & 1.2 & 1.6 & 2.4 \\
Inlet temperature (K) & 302 & 312 & 349 \\
\hline
\end{tabular}

* current signal, the actual needle lift open is retarded with a nearly constant time $\operatorname{period}(\sim 1.7 \mathrm{~ms})$

Table 3: Operating conditions for different EGRs and injection pressures

\begin{tabular}{c|c}
\hline Item & Value \\
\hline Speed (rpm) & 1400 \\
Fuel flow rate $(\mathrm{g} / \mathrm{s})$ & $\sim 1.1$ \\
Torque (ft-lb) & $50 \sim 60$ \\
EGR level(\%) & $1.1 \sim 49.6$ \\
SOI* $\left({ }^{\circ}\right.$ bTDC) & 8.0 \\
Injection pressure (bar) & $750 \sim 1250$ \\
Inlet pressure (bar) & $1 \sim 1.2$ \\
Inlet temperature (K) & $302 \sim 342$ \\
\hline
\end{tabular}

* current signal, the actual needle lift open is retarded with a nearly constant time $\operatorname{period}(\sim 1.7 \mathrm{~ms})$ 


\section{RESULTS AND DISCUSSION}

In this section, the results from the simulation are presented and discussed. First, the empirical coefficients are determined and calibrated through the comparisons between the calculated and experimental data. In particular, the effects of model constants on engine performance and emissions are evaluated. Then the numerical accuracy results are examined. The outputs of the thermodynamic simulation are validated within a range of operating conditions. Finally, the detailed thermodynamic results of combustion and emissions are discussed.

\subsection{Calibration of model parameters}

The principle for choice of the empirical coefficients is the agreement between calculated and experimental data. The combustion model constants including ignition delay parameters, lift-off length coefficient, and gas entrainment multiplier into combustion product zone $4\left(\mathrm{c}_{\mathrm{after}, 4}\right)$ are first determined by comparisons to experimental in-cylinder pressures. The gas entrainment multiplier into combustion product zone 5 $\left(c_{a f t e r, 5}\right)$, which significantly affects nitric oxide formation, is calibrated to achieve best agreement on engine-out nitric oxide emissions for the base case. Finally, the determination of soot model constants is completed by checking the predicted soot masses against a series of experimental data points. The calibrated parameters are summarized in Table 4. The specific model calibration routines, as well as the major effects of engine model constants on the engine performance and emissions are analyzed and discussed in the following subsections. 
Table 4: List of empirical coefficient values

\begin{tabular}{|c|c|c|}
\hline \multicolumn{2}{|l|}{ Item } & \multirow{2}{*}{$\begin{array}{l}\text { Value } \\
0.24\end{array}$} \\
\hline Ignition delay parameters & $\mathrm{c}_{1}$ & \\
\hline & $\mathrm{c}_{2}$ & -0.2 \\
\hline & $\mathrm{c}_{3}$ & -1.02 \\
\hline & $\mathrm{c}_{4}$ & 4000 \\
\hline Lift-off length coefficient & $\mathrm{c}_{\mathrm{LO}}$ & $1.2 \mathrm{e}^{8}$ \\
\hline \multirow[t]{2}{*}{ Gas entrainment multiplier } & $\mathrm{c}_{\mathrm{after}, 4}$ & 0.25 \\
\hline & $\mathrm{c}_{\mathrm{after}, 5}$ & 0.05 \\
\hline \multirow[t]{4}{*}{ Soot model constants } & $A_{p}$ & 15 \\
\hline & $A_{f}$ & $1.0 \mathrm{e}^{10}$ \\
\hline & $\mathrm{A}_{0}$ & 1050 \\
\hline & $n$ & 0.75 \\
\hline
\end{tabular}

\subsubsection{Combustion model calibration}

To achieve a high level of accuracy for the predicted in-cylinder pressure, the empirical coefficients including ignition delay parameters, lift-off length coefficient, and gas entrainment multiplier into combustion product zone $4\left(\mathrm{c}_{\mathrm{after}, 4}\right)$ need to be determined. The ignition delay parameters $c_{1}$ to $c_{4}$ are first determined by checking experimental onsets of combustion crank angle as indicated by apparent heat release rates (AHRRs) with calculated values for different operating conditions shown in Table 2 and Table 3. A good match to the experimental pressure curve is obtained with the values listed in Table 4. 
Use of scaling law for the calculation of lift-off length requires the choice of empirical coefficient $\mathrm{c}_{\mathrm{LO}}$. Lift-off length determines the quantity of fuel and gas prepared for the initial volumetric premixed combustion, and thus influences the diesel fuel jet combustion process. Figure 9 shows the effect of lift-off length on the calculated in-cylinder pressure and accumulative diffusion burned fuel mass for the base case. The experimental in-cylinder pressure is shown as a comparison. Longer lift-off length slightly effects in-cylinder pressure during the initial combustion, while apparently increases in-cylinder pressure for the rest of combustion. The empirical coefficient $c_{\mathrm{LO}}=1.2 \mathrm{e}^{8}$ shows the best match. The phenomenon can be explained by checking the effect of lift-off length on fuel distribution. As shown in Figure 9(b), the longer lift-off length enhances the fuel mass involved in the diffusion combustion, and the quantity of fuel involved for the volumetric premixed combustion is reduced correspondingly. This feature results in the slight pressure reduction during premixed combustion dominated initial phase and pressure rise during diffusion combustion dominated later phase. The location of the peak pressure varies correspondingly. 

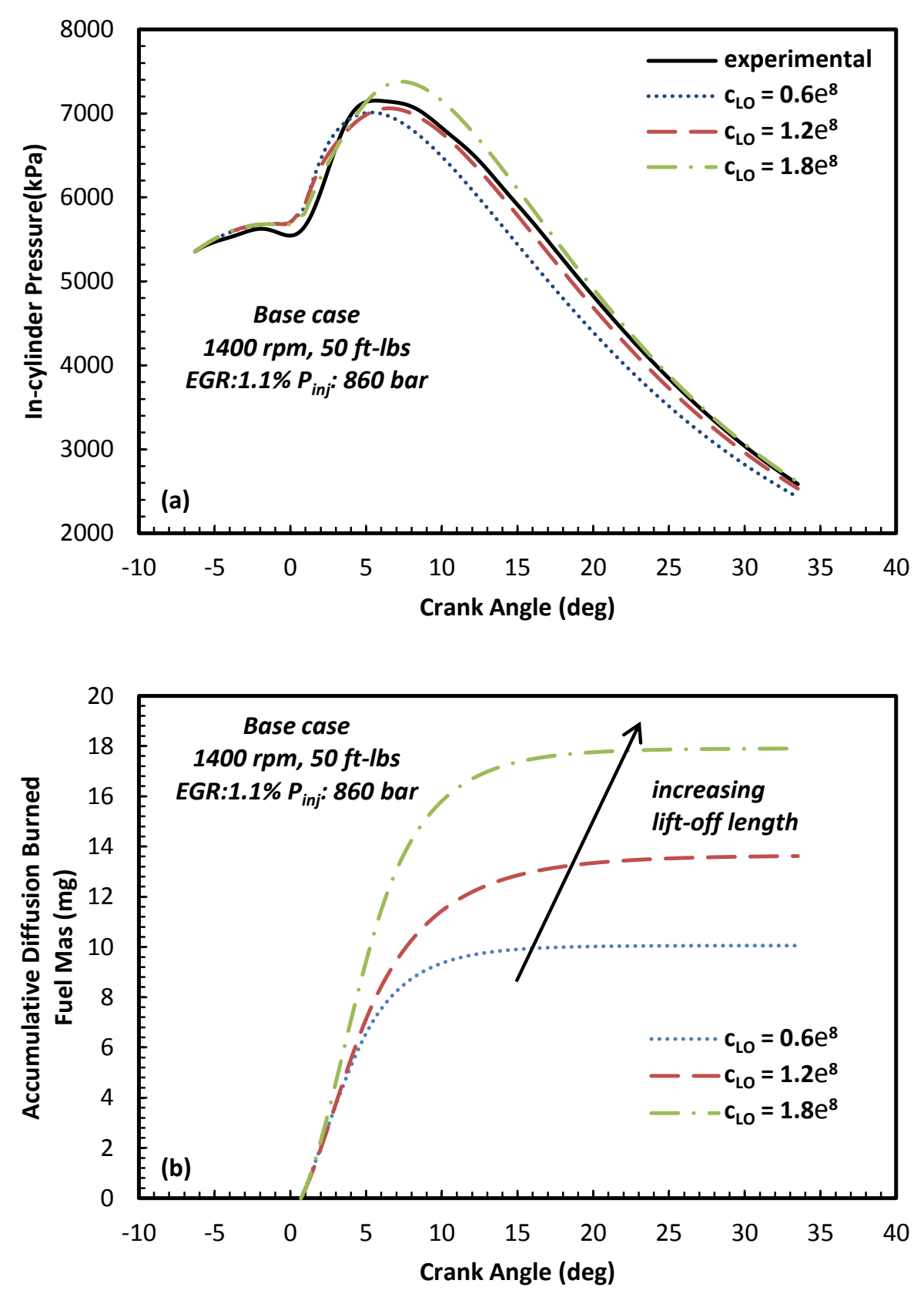

Figure 9. The effect of lift-off length on the calculated in-cylinder pressure and accumulative diffusion burned fuel mass for the base case. 
Gas entrainment multiplier, $\mathrm{c}_{\mathrm{after}, 4}$, is another parameter to be calibrated. The gas entrainment into combustion product zone 4 is highly related with the heat release intensity of incomplete combustion products in zone 4 and thus affects the predicted incylinder pressure. Figure 10 shows the effect of gas entrainment rate into zone 4 on the calculated in-cylinder pressure and fuel-rich combustion product temperature for the base case. More gas entrainment results in higher in-cylinder pressure. As indicated in Figure 10(b), the fuel-rich combustion product temperature increases since more gas entrainment enhances the oxidation rate and thereby releases more energy of the incomplete combustion products during the initial combustion phase. The empirical coefficient $c_{\text {after,4 }}=0.25$ is found to provide best agreement.

It is noted that constant $\mathrm{c}_{\mathrm{LO}}$ effects the location of the peak pressure, while the constant $c_{a f t e r, 4}$ has a higher effect on the intensity of initial rapid pressure raise rate. Bearing this in mind, the constant $\mathrm{c}_{\mathrm{LO}}$ was first tuned to achieve the best agreement on the location of the peak pressure, then $\mathrm{c}_{\mathrm{after}, 4}$ was adjusted to achieve the best fit. Taking into account the existing experimental uncertainties, the level of accuracy between calculated and experimental pressure is acceptable. Further adjustment of engine constants is not considered in this work. 

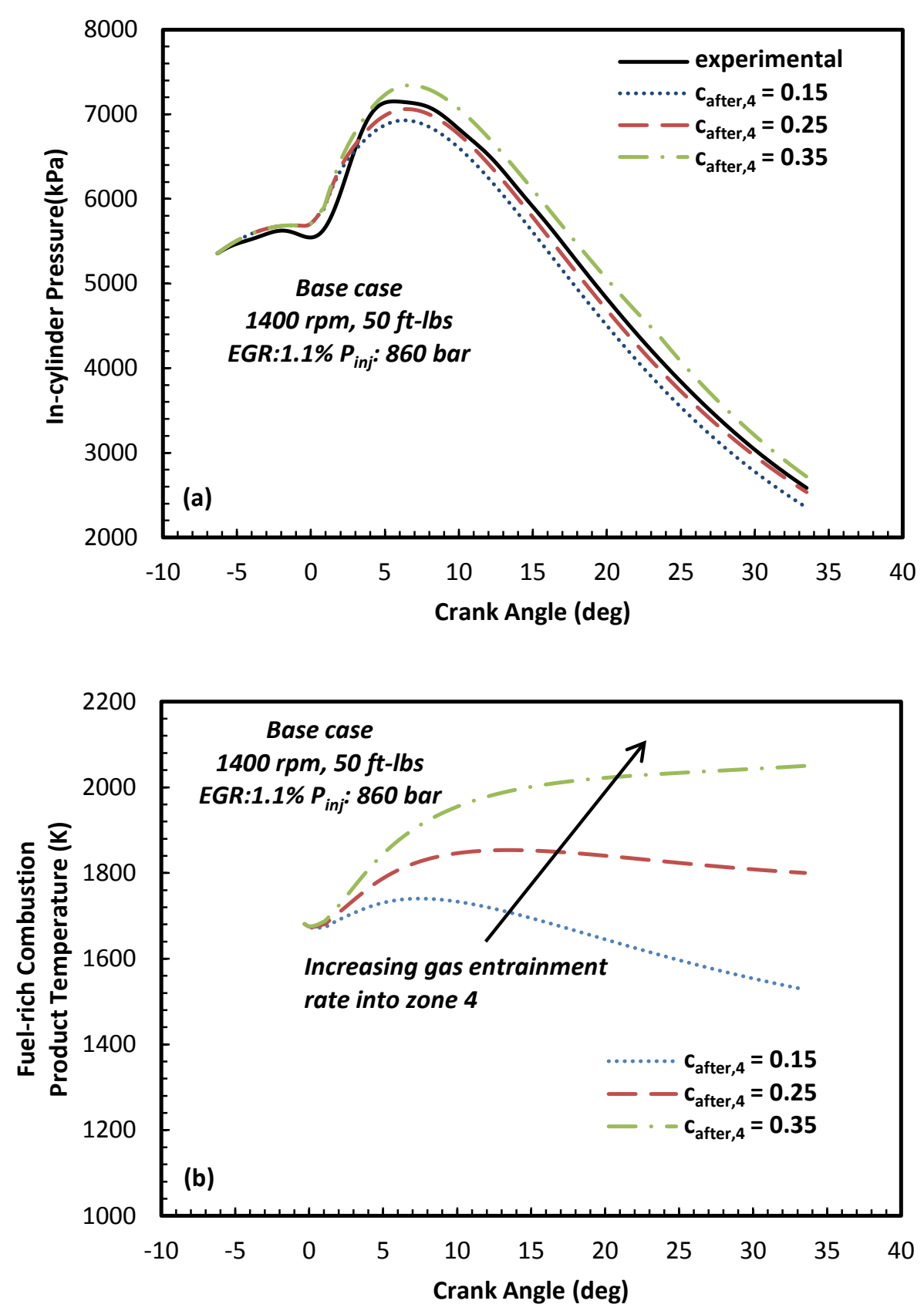

Figure 10.The effect of gas entrainment rate into zone 4 on the calculated in-cylinder pressure and fuel-rich combustion product temperature for the base case. 


\subsubsection{NO versus gas entrainment rate}

The entrainment of unburned gas into the existing diffusion combustion product zone makes the local equivalence ratio leaner and reduces the product temperature, and thereby influences the nitric oxide formation. Figure 11 shows the effect of gas entrainment rate into zone 5 on the instantaneous nitric oxide concentration and product temperature of zone 5 for the base case. The increase of nitric oxide concentration for higher gas entrainment rate is attributed to the enhanced available oxygen in the combustion product zone. Although the product temperature is reduced slightly, the sufficient combustion temperature and residence time prevent the temperature from becoming a limiting factor. The dominant effect of gas entrainment rate on the nitric oxide concentration is clearly illustrated.

Since the gas entrainment into the diffusion combustion product zone 5 greatly effects the nitric oxide formation, proper adjustment of parameter $\mathrm{c}_{\mathrm{after}, 5}$ can be implemented to achieve the best agreement of experimental result on nitric oxide emissions. This parameter is adjusted as $c_{\mathrm{after}, 5}=0.05$ for the base case. It is also noted that this phenomenon does not involve fuel heat release and thus has modest effect on the overall calculated in-cylinder pressure. In addition, the fact that gas entrainment rates in zone 4 and zone 5 are different is expected. The developed high-temperature, lowdensity products in zone 5 at the jet edge are recognized to reduce the turbulence level of shear flows and local strain, and thereby suppress the turbulent mixing with ambient unburned gas. 

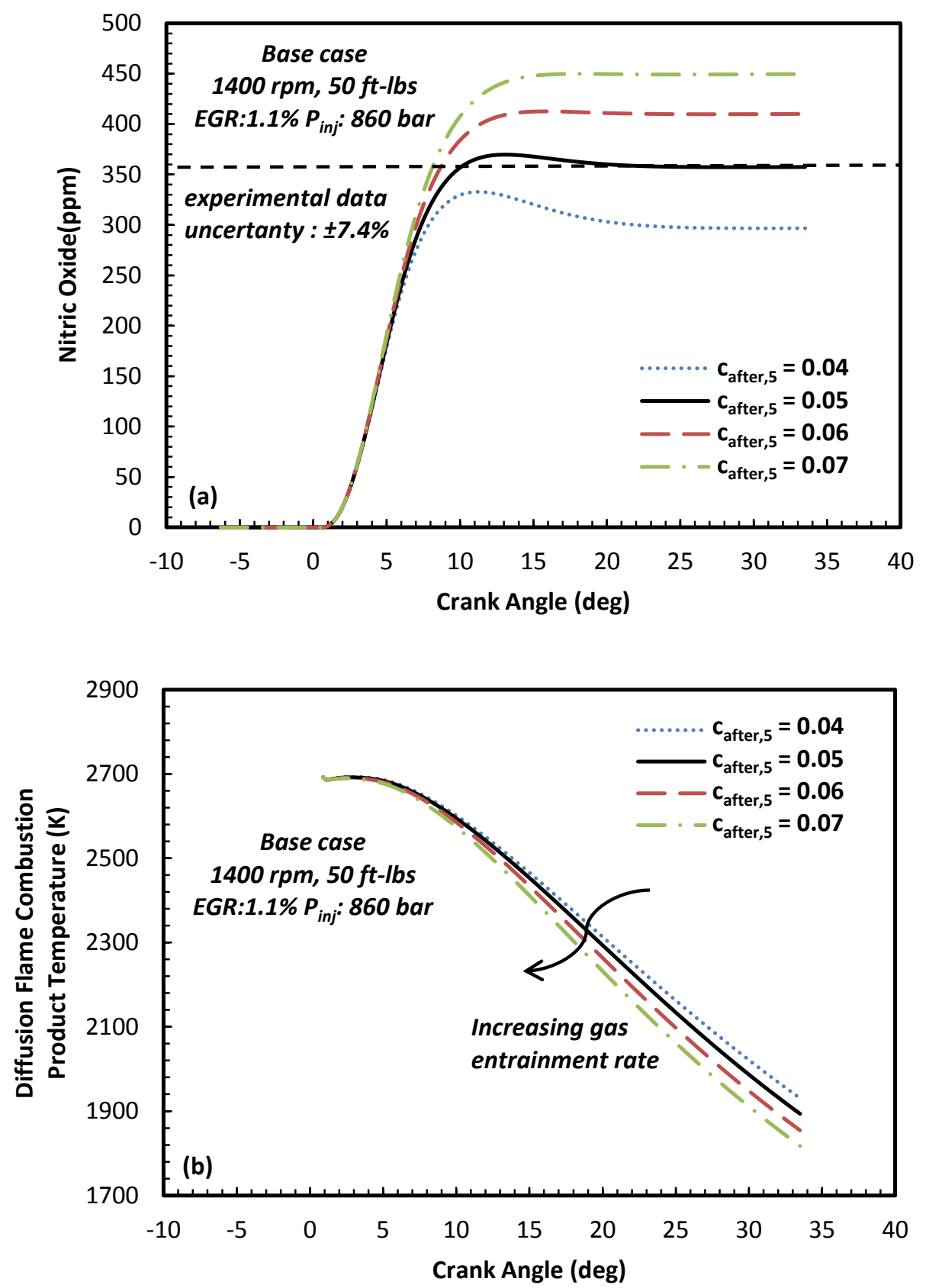

Figure 11. The effect of gas entrainment rate into zone 5 on nitric oxide formation and diffusion flame combustion product temperature for the base case. 


\subsubsection{Soot versus model constants}

The three-step soot model (eq. 46-48) has four different parameters that need to be calibrated: the pre-exponential factors $A_{p}, A_{f}, A_{o}$ and the pressure exponent term $n$ of the soot oxidation equation (48). The determination of the best single set of four constants needs a series of experimental data points. Preliminary calculations indicate that $A_{p}$ with a range of 10 to 20 , and $n$ with a range of 0.5 to 1 are reasonable trial choices. $\mathrm{A}_{\mathrm{o}}$ is adjusted to match engine-out soot mass for the base case with different values of $A_{p}$ and n. $\mathrm{A}_{\mathrm{f}}$ is set as $1 \mathrm{e}^{10}$ initially based on the work of Fusco et al. [30]. Figure 12 shows the sensitivity of each parameter to engine-out soot emissions for different EGR and injection pressure conditions. Figures 12 (a) and (b) illustrate the effect of the pressure exponent term $n$ on the soot emissions as functions of injection pressure and EGR, respectively. $A_{p}$ is set as 15 for both figures. The pressure exponent term $n$ determines the effect of cylinder pressure on soot oxidation. Since reduced injection pressure or increased EGR level result in lower cylinder pressure (will be shown later), higher value of $n$ results in higher soot emissions with increased EGR and steeper gradient of soot emissions with increased injection pressure. An $n$ value of 0.75 shows the best agreement with different EGR and injection pressure conditions.

Figures 12 (c) and (d) show the effect of the pre-exponential factors $A_{p}$ on the soot emissions with $n$ set as 0.75 . The effect of $A_{p}$ for the injection pressure sweep (Figure 12(c)) is relatively small. This is because the final engine-out soot mass is the difference between two large quantities of the soot formation and oxidation. The oxidation percentages are above $95 \%$ for injection pressure sweep (Figure 40). Higher value of $A_{p}$ 
definitely produces more soot precursors and therefore higher soot formation, the soot oxidation is also enhanced since $A_{o}$ has already been adjusted to match engine-out soot mass for the base case. The effect of $A_{p}$ for the EGR sweep (Figure 12(d)), however, is significant since higher EGR greatly reduces the soot oxidation and causes overestimated soot emissions with higher $A_{p}$ value. The oxidation percentage is reduced down to $38 \%$ for $49.6 \%$ EGR (Figure 33). The value of $A_{p}$ is selected as 15 in this work.

The last parameter is the soot formation pre-exponential factor $A_{f}$. Figures 12 (e) and (f) show the effect of $A_{f}$ on soot emissions with $A_{p}=15$ and $n=0.75$. In fact, the effect of $A_{f}$ is extremely small compared to the previous two parameters. A change of this value does not influence the overall mass of soot formed, but only the rate, under the same amount of soot precursors. The changed soot formation rate would slightly affect the soot oxidation. For this reason, the soot formation pre-exponential factor with a value of $1 \mathrm{e}^{10}$ which is consistent with Fusco et al. [30] is retained in this work.

The final set of pre-exponential factors and the pressure exponent term are summarized in Table 4. Because of the inherent measurement uncertainties and potential inaccuracy of correlation between FSN and absolute soot mass, further improvement of these parameters is not warranted. The predicted results, however, closely follow the trends of the experimental data regardless of the values selected in the soot model. The qualitative effects of engine parameters such as the injection pressure and EGR level on soot emissions are successfully predicted. 

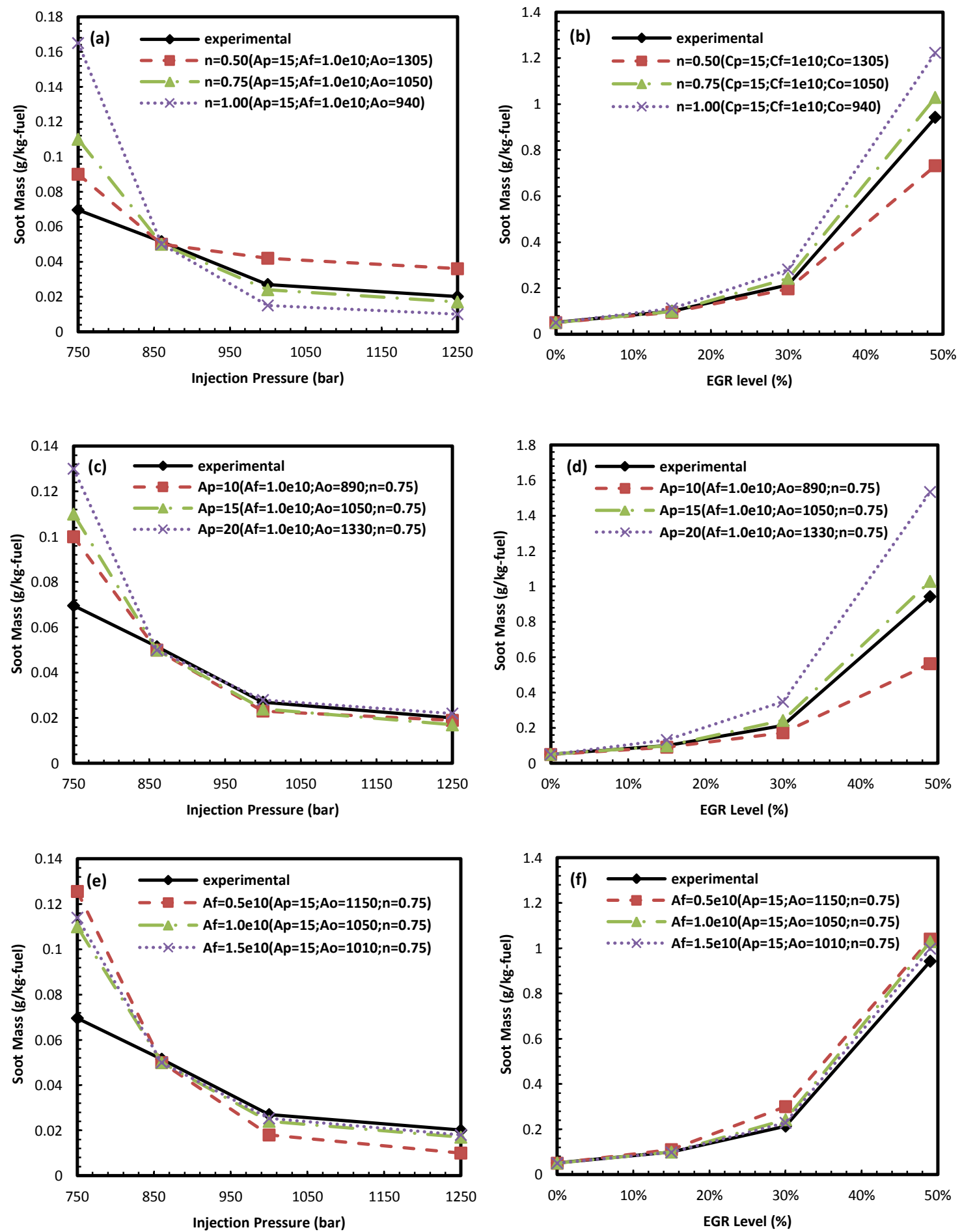

Figure 12. The sensitivity of soot model parameters to engine-out soot emissions. 


\subsection{Numerical accuracy of results}

The numerical solutions would lead to some deviations. To implement a high level of accuracy in this simulation, the computational time step size is examined. Figure 13 shows the in-cylinder maximum pressure as a function of time step for the base case.

Fluctuations are noted when the time step is greater than $0.25^{\circ} \mathrm{CA}$. Larger time steps cause more unstable results and if the time step is larger than $0.6^{\circ} \mathrm{CA}$, the calculated cylinder pressure has strong fluctuation due to inaccurate solution of the differential equations and missing important features (i.e. the lift-off length is close to the liquid length under this operating condition).The selected time step needs to be less than $0.2^{\circ} \mathrm{CA}$ which is shown small enough such that solution is independent of time step.

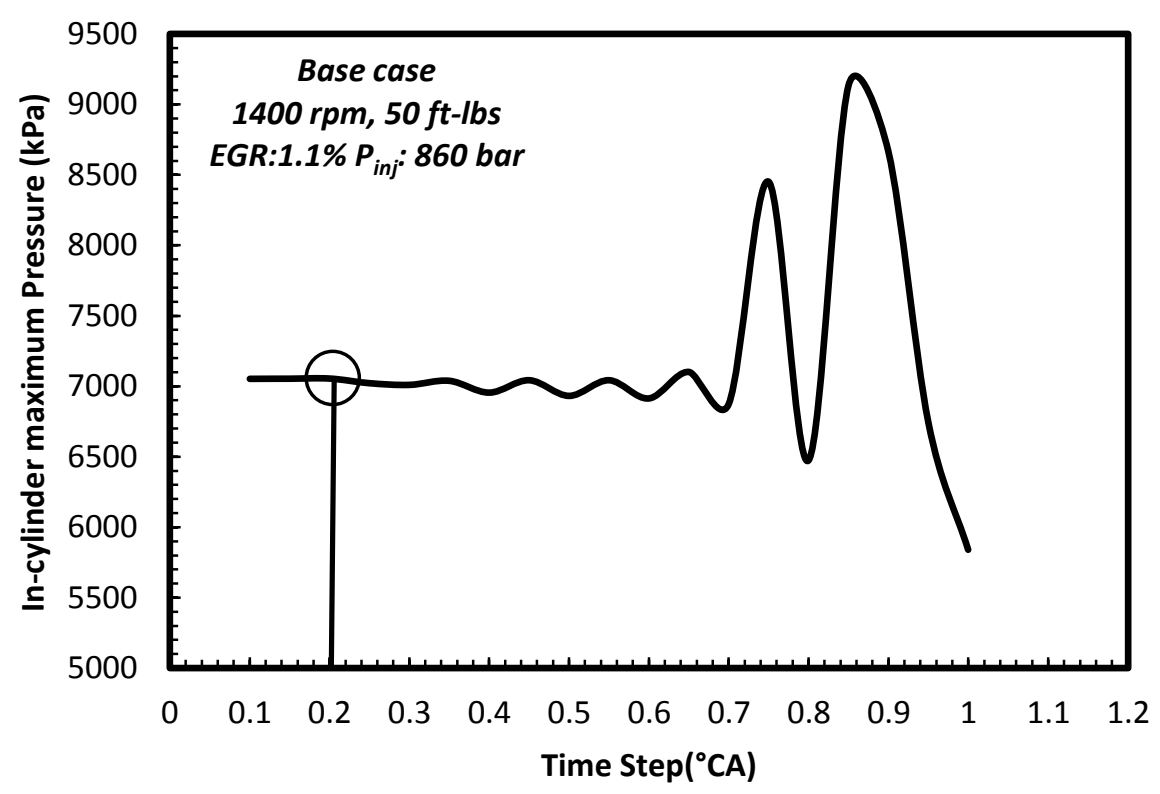

Figure 13. In-cylinder maximum pressure as a function of time step for the base case. 
An internal consistency check is used by applying the overall energy balance (equation 51). Figure 14 presents the absolute error as a function of crank angle for the base case. Two major peaks of errors are observed at the injection and initial premixed combustion phases with $0.26 \%$ and $0.45 \%$ respectively. Instant fuel injection and volumetric combustion cause instantaneous rapid variations of the cylinder thermodynamic properties which may affect the calculation accuracy of the differential equations. As time proceeds, the absolute error gradually goes down below $0.1 \%$.

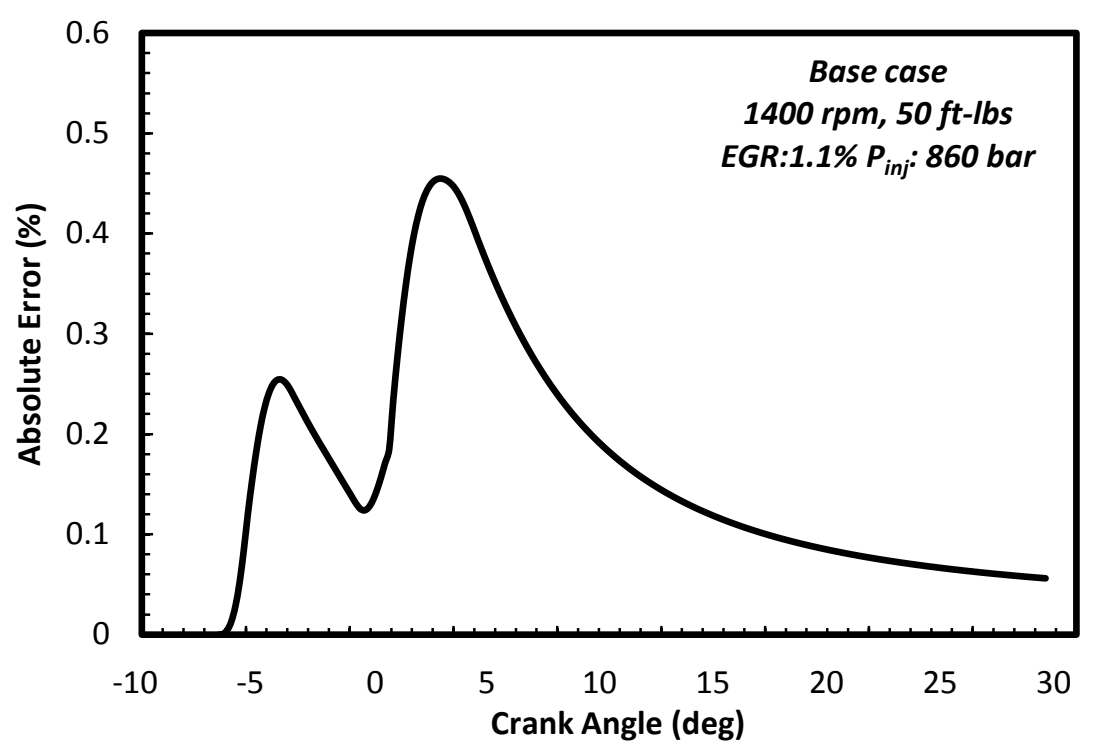

Figure 14. Absolute error as a function of crank angle for the base case.

\subsection{Model validation}

After calibration of the empirical coefficients and rigorous evaluation of numerical accuracy, the calculated cylinder pressures and AHRRs are checked against experimental data. Figure 15 shows the comparisons between the calculated in-cylinder 
pressures and AHRRs with experimental data for three different speed/load cases. The agreements are fairly good.

During the ignition delay period, however, the negative heat release predicted in this model is smaller than that from experiments. The calculated results overestimate the peak values of in-cylinder pressures for higher speed and load cases. The causes of these discrepancies result from (1) the assumption of free fuel jet without interaction with cylinder wall. The fuel jet impingement, especially under high load operating conditions, causes "quench layers" with some amount of unburned hydrocarbon which may reduce the combustion intensity. (2) the inaccuracy of the spray model. The application of the non-vaporizing fuel spray penetration correlation ignores the effect of vaporization which could reduce the fuel penetration. (3) the gas blow-by during the combustion phasing may be more serious under higher engine load conditions and results in reduced in-cylinder pressure. Not including this phenomenon may cause some discrepancies.

Figures 16 and Figure 17 show the pressure and AHRR comparisons as the injection pressure or EGR level is varied for the base case. The results show good agreements between the model and experimental data. Higher injection pressure reduces the ignition delay period and results in higher cylinder pressures. The dilution effect of EGR decreases the cylinder pressure and retards the combustion phase. The predicted incylinder pressure reproduces these tendencies, although the results show a slight underestimation of the peak value of heat release. In general, the model is considered to be valid for the accurate prediction of the experimental engine results within acceptable tolerances. 


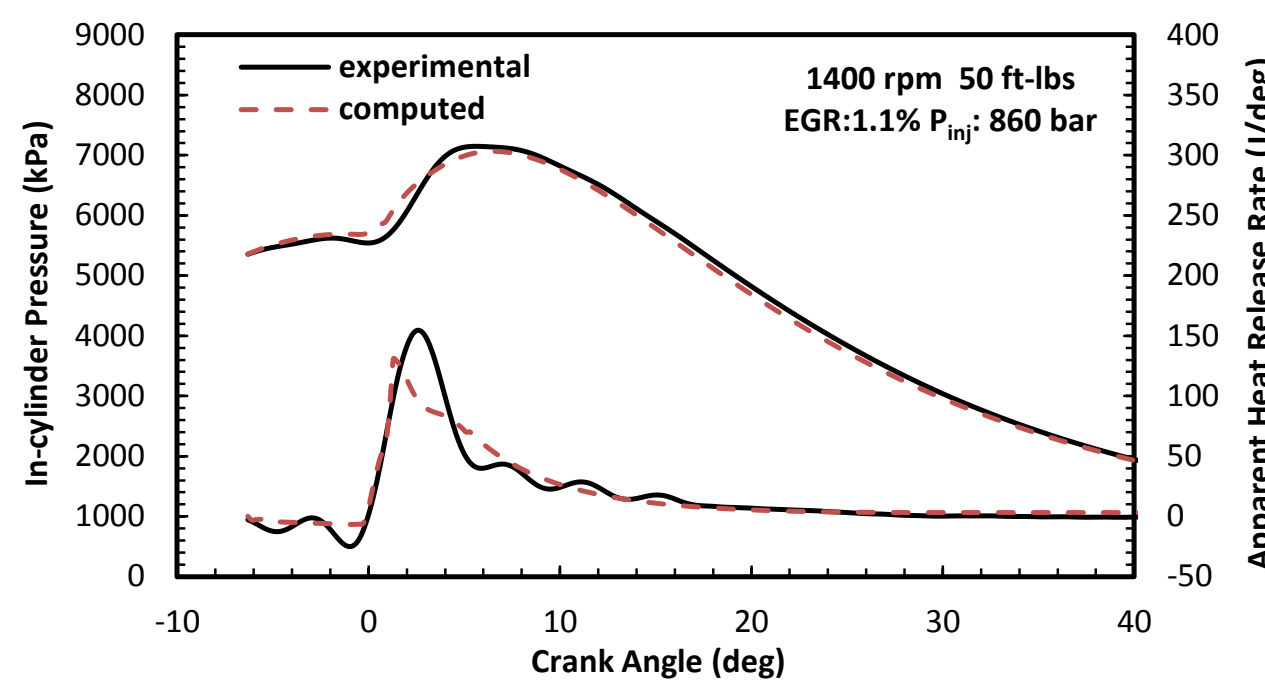

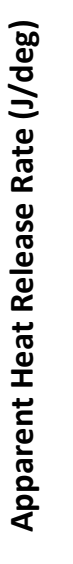
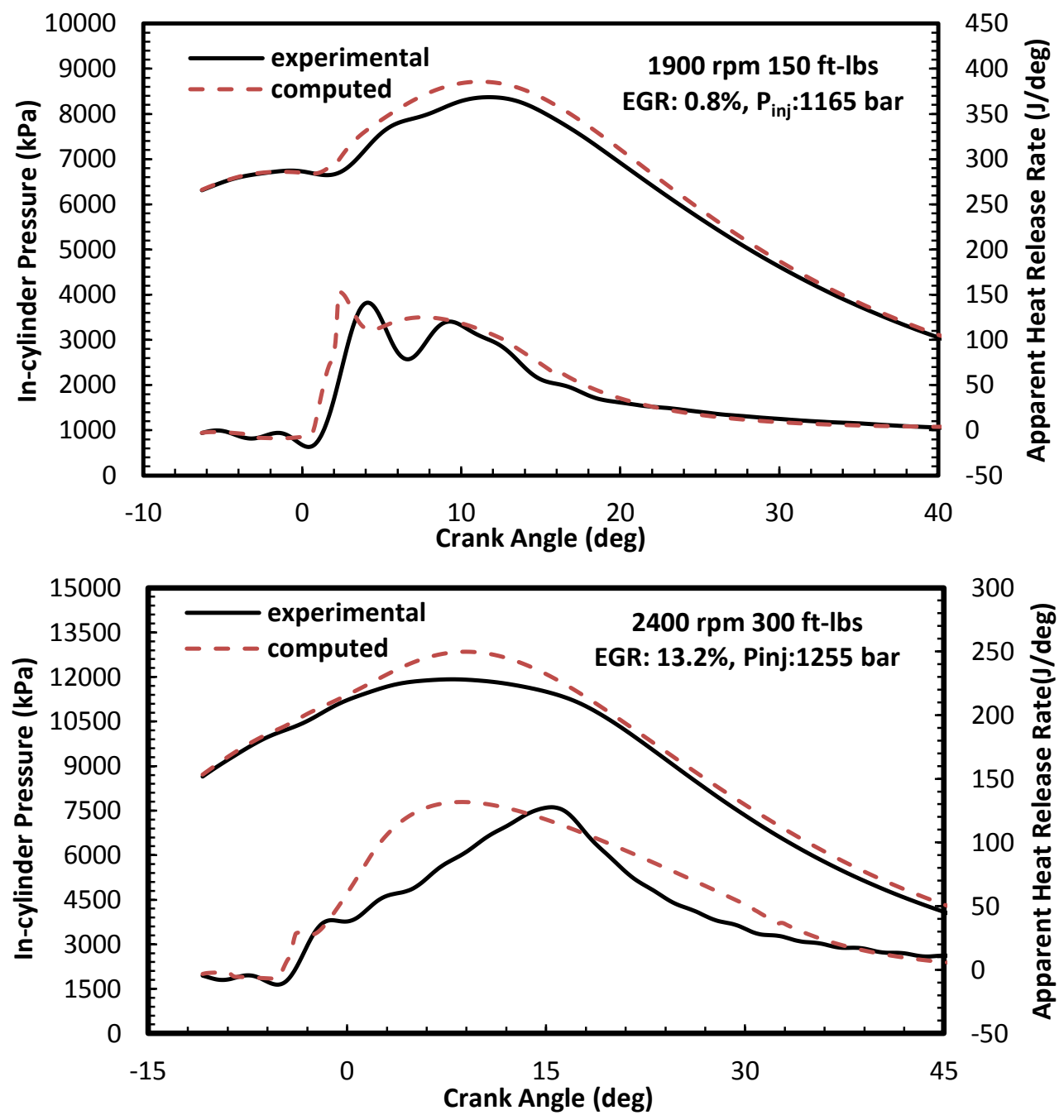

Figure 15. Pressure and AHRR comparisons for three different speed/load cases 

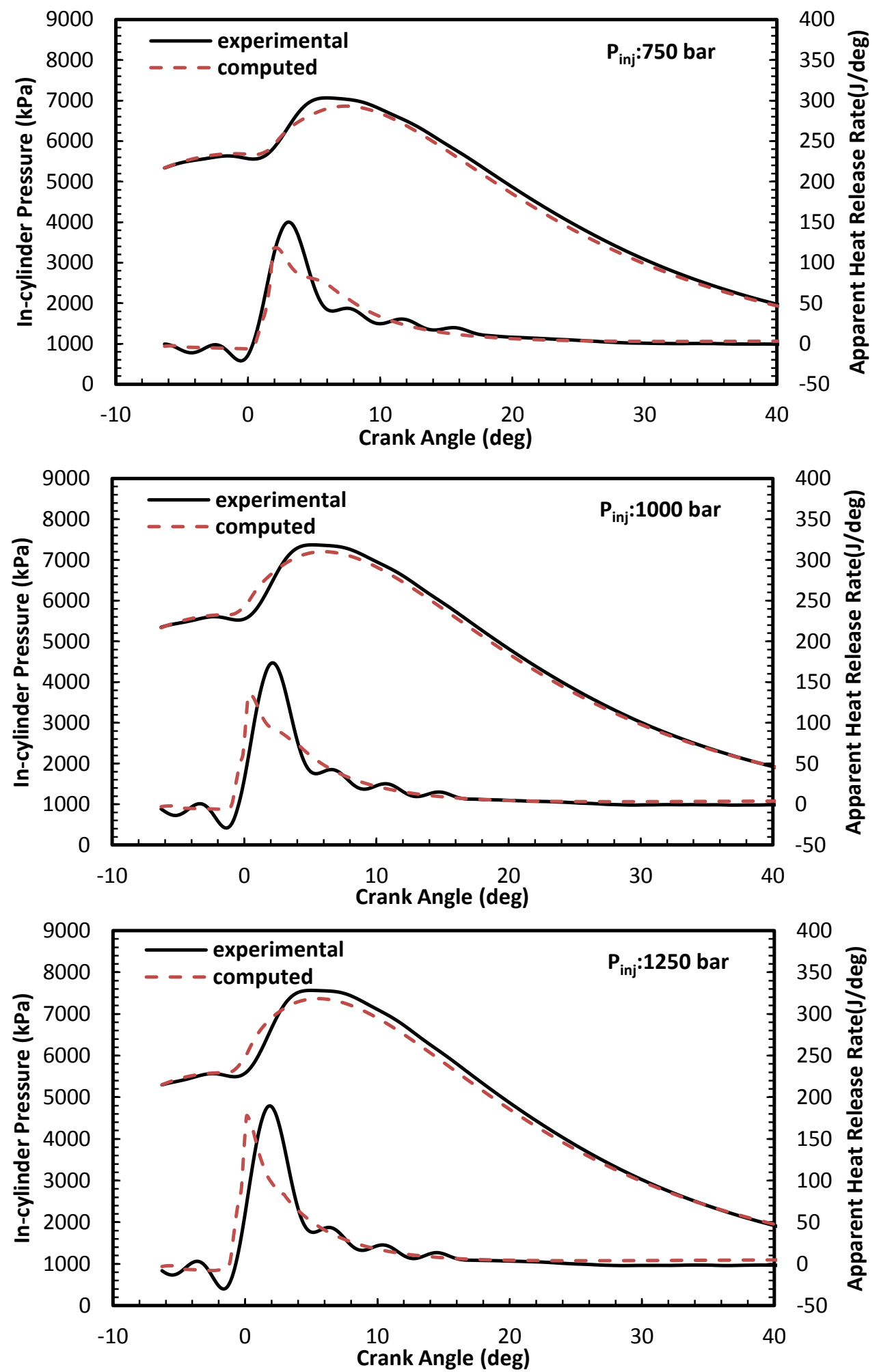

Figure 16. Pressure and AHRR comparisons as injection pressure is varied for the base case (1400 rpm, $50 \mathrm{ft}-\mathrm{lbs}, 1.1 \%$ EGR, 860 bar injection pressure). 


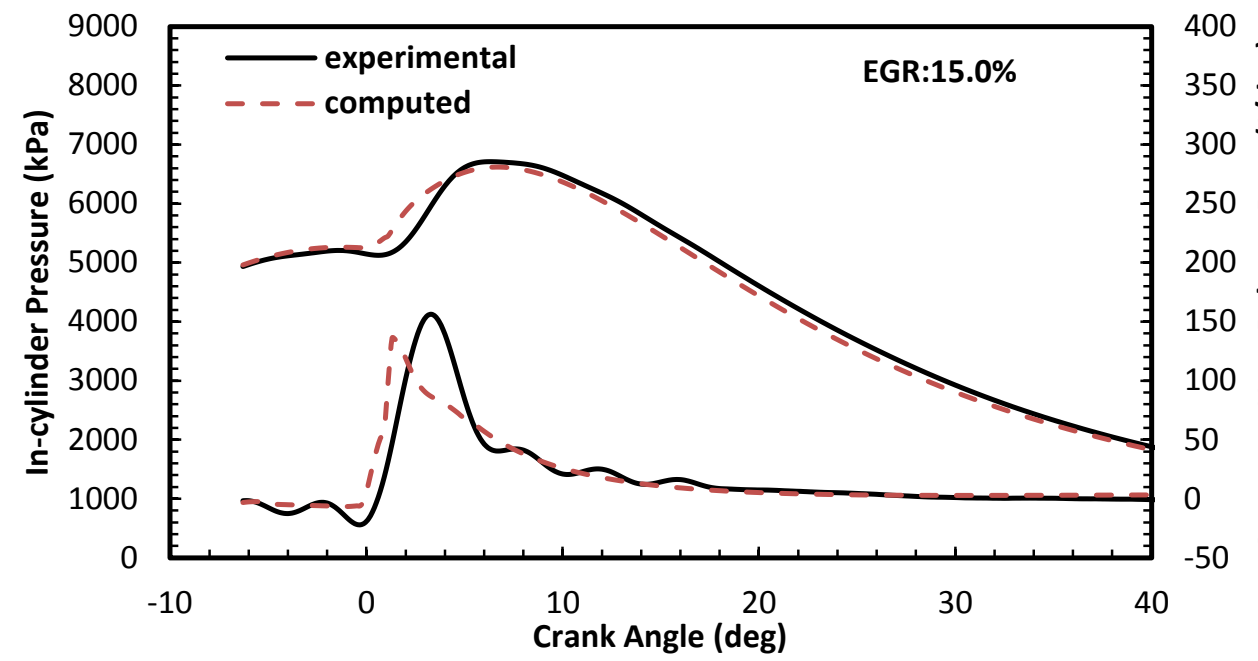

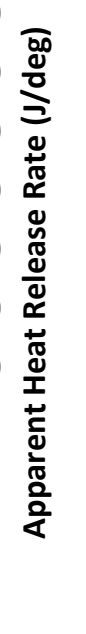
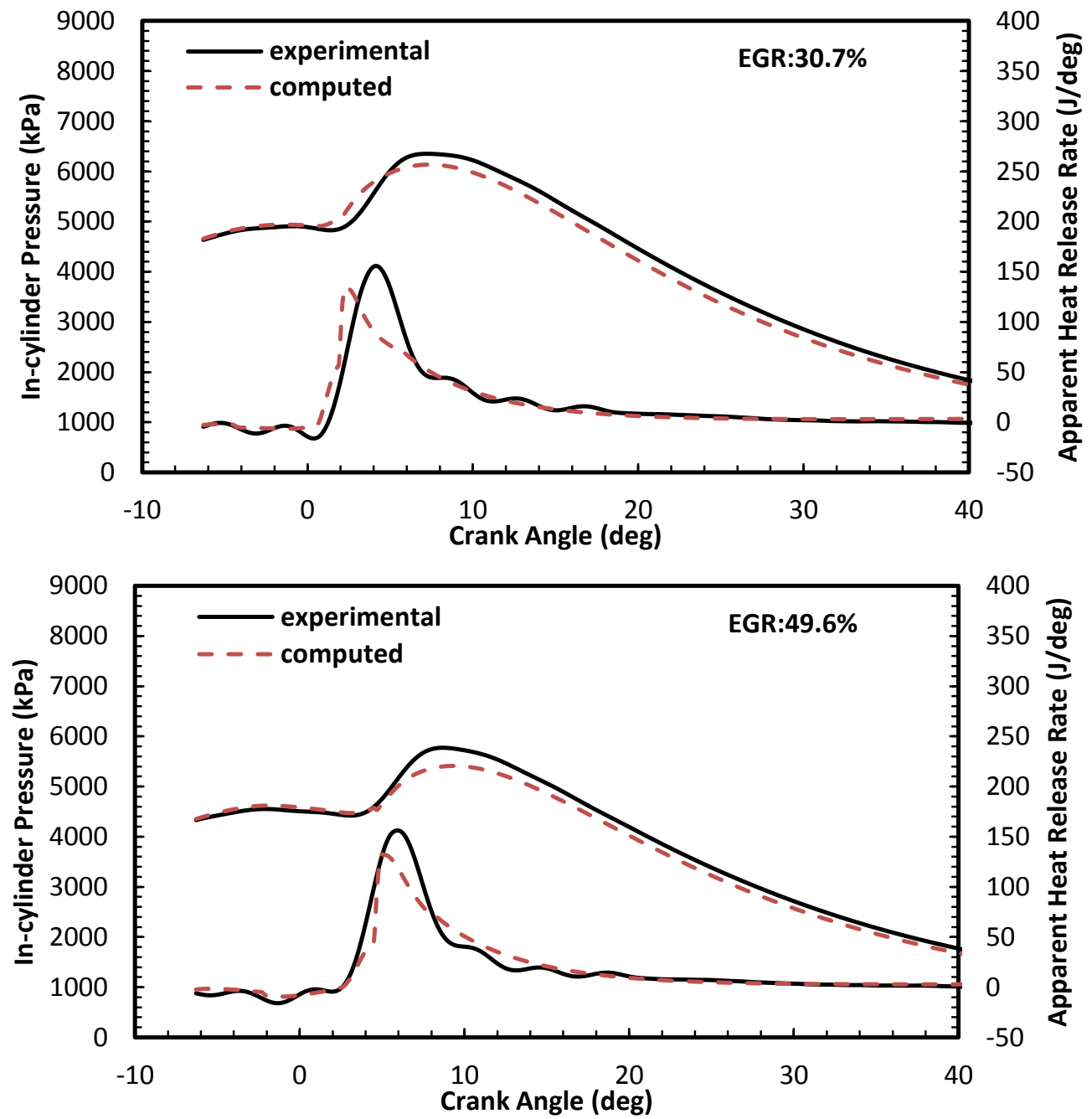

Figure 17. Pressure and AHRR comparisons as EGR is varied for the base case (1400 rpm, $50 \mathrm{ft}-\mathrm{lbs}, 1.1 \% \mathrm{EGR}, 860$ bar injection pressure). 
With confidence of accurate prediction of in-cylinder pressures for different operating conditions, the calculated nitric oxide and soot emissions are compared with the experimental data. Figure 18 shows the nitric oxide and soot comparisons for three different speed/load cases. Uncertainty of experimental data is reported as error bars on the plots. As described earlier, the model constants have been adjusted to match the engine-out emissions for the base case and are the same for all conditions. Again, the base case is $1400 \mathrm{rpm}$ and a torque of $50 \mathrm{ft}-\mathrm{lbs}$ (1.1\% EGR, 860 bar injection pressure).

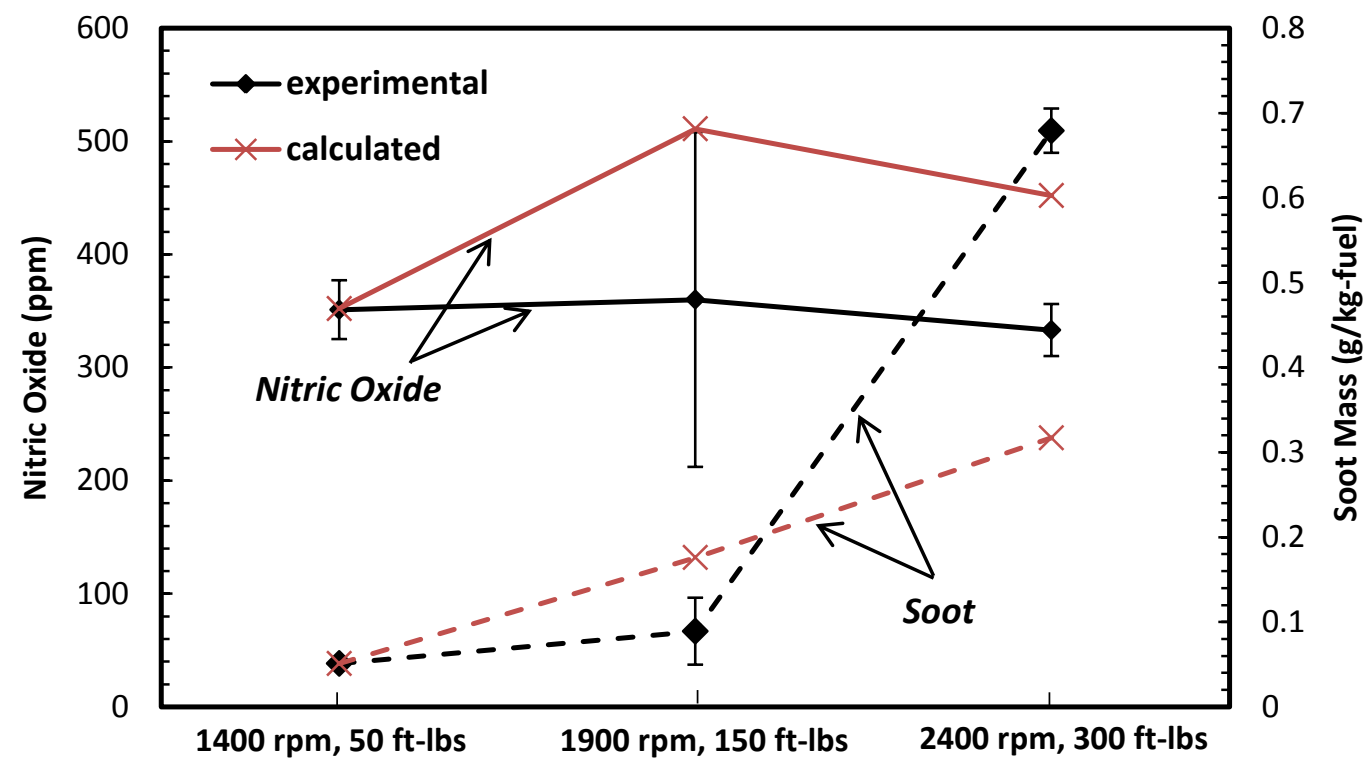

Figure 18. The nitric oxide and soot comparisons for three different speed/load cases.

The quality of the nitric oxide prediction is closely coupled to the predicted quality of the in-cylinder pressure, and calculated temperature. As indicated in Figure 18, the calculated nitric oxide emissions are overestimated under higher speed and load cases partially due to the over-predicted in-cylinder pressures. For the highest speed and load 
case (2400 rpm, $300 \mathrm{ft}-\mathrm{lbs})$, the predicted soot mass does not have a good agreement with the experimental data. This lack of good agreement may be at least partly due to the unclear physical significance in the applied global soot kinetic mechanisms and a lack of high level detail of soot formation with detailed fuel gas chemistry reaction. The tendency, higher engine load produces more engine-out soot emissions, however, is still reproduced.

Figure 19 shows the soot emissions as functions of the nitric oxide emissions as either injection pressure (Figure 19(a)) or EGR level (Figure 19(b)) is varied for the base case condition. The simulation results successfully reproduce the emission trends for different injection pressures and EGR levels. The typical soot-NO tradeoffs for injection pressure and EGR sweeps are clearly exhibited. In spite of the high sensitivity of nitric oxide formation in the diesel engine combustion process, the calculated values are still in reasonable agreement with the measured values. The disagreements at 750 bar and 1250 bar injection pressures are partially due to the underestimated in-cylinder pressures. The underestimation of nitric oxide concentration under high EGR level may be due to the lack of the prompt mechanism.

Furthermore, it is important to realize that the assumption of uniform temperature and chemical composition for each zone may cause some errors of the engine-out emission predictions. The concept of uniform temperature and chemical composition is considered to be under fairly high fidelity for the unburned zones. The temperature gradients in the combustion product zones, however, may lead to different emission formation behaviors. Several high temperature regimes, which may exist in the un- 
homogenous zone 4, would contribute to a small amount of NO formation especially under higher injection pressure conditions. Further improvement could be considered by introducing more subzones in the combustion product zones when accurately prediction of nitric oxide becomes an issue.
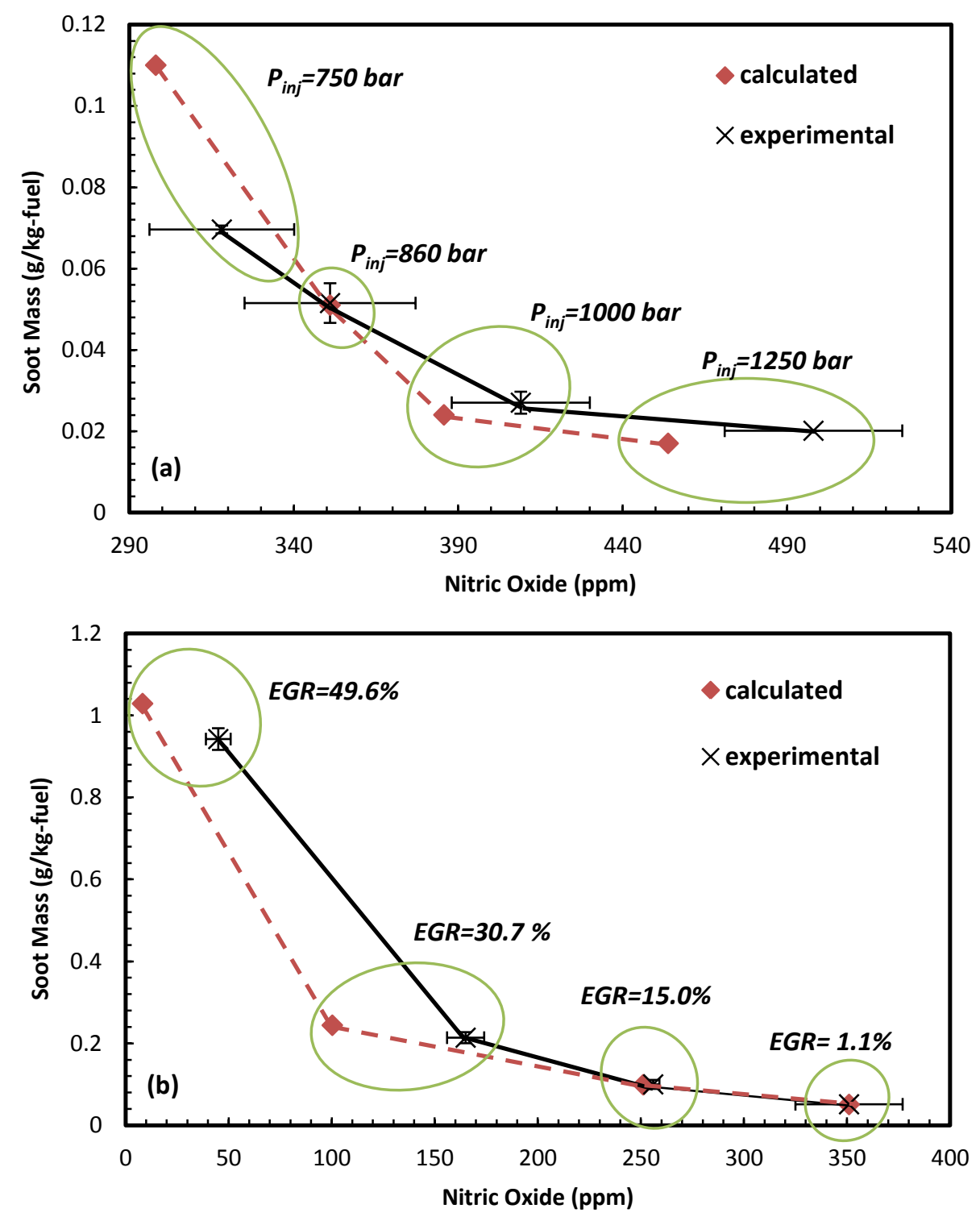

Figure 19. Soot emissions as functions of the nitric oxide emissions as either injection pressure (a) or EGR level (b) is varied for the base case. 


\subsection{Detailed thermodynamic analysis}

A detailed thermodynamic analysis of the DI diesel engine combustion and emission formation processes is presented in this section. For the purpose of investigating the typically heterogeneous-type combustion system, this model provides a detailed assessment of the fuel spray penetration, evaporation, ignition delay and eventual heat release. The complete description of these mechanisms could uncover several fundamental insights of the DI combustion system. Results from this simulation are described in the following subsections.

\subsubsection{Load and speed}

The selected three different speed and load cases including low speed/load, moderate speed/load and high speed/load have been shown in Table 2. Figures 20-22 show the calculated zonal temperatures, the cylinder averaged temperatures, and the corresponding stoichiometries of the mixture (equivalence ratio) for these three cases. The start of combustion (SOC) and start of diffusion combustion (SOD) are noted.

Zone 1 is the liquid zone where the fuel/gas mixture is extremely rich. The equivalence ratio of zone 1 , therefore, is excluded. The average temperature in this zone represents the fuel droplet saturated temperature under supercritical conditions. The temperature of zone 2 goes from about $650 \mathrm{~K}$ to $750 \mathrm{~K}$. The average equivalence ratio of zone 2, which is dependent on the injection pressure, ambient gas density and oxygen concentration, varies from case to case and generally ranges between 2 and 6 . The mixture temperature, $\mathrm{T}_{3}$, continues to increase slightly with fuel penetration and gas entrainment into zone 3, and at the SOC, the reduced equivalence ratio and increased 
temperature are sufficient for the fuel-rich mixture to auto-ignite. The rapid consumption of the premixed oxygen resulting from the volumetric premixed combustion and subsequent entrained fuel-rich mixture from zone 2 lead to a rise of equivalence ratio and a slight temperature reduction in zone 3 . After a few crank angles, a diffusion flame forms at the jet edge. The ambient fresh gas is consumed in the diffusion flame, replenishes the high temperature product zone 5. Since there is no fresh gas entrained into zone 3 , the temperature and equivalence ratio of the fuel-rich mixture in zone 3 tend to be stable. The combustion gradually transitions to be mixing-controlled, diffusion flame combustion mode.

The fuel-rich premixed combustion produces a great amount of combustible materials such as carbon monoxide and unburned hydrocarbon in zone 4 due to the high equivalence ratio, which results in a relatively lower combustion temperature. The oxidation process in zone 4 due to the subsequent gas entrainment gradually releases the energy of the incomplete combustion products, and causes a slight increase of zone 4 temperature. The average zone 4 temperature is resulting from the mutual effects among heat release of incomplete combustion products, expansion cooling as well as heat transfer. Soot formation is considered to mainly occur in this fuel-rich, low combustion temperature environment.

Zone 5 shows the highest temperature resulting from the mixing-controlled diffusion flame. The onset of the diffusion combustion occurs corresponding to the midpoint of the premixed combustion [9]. The gas entrainment into the combustion products, in contrast, dilutes the diffusion flame products, and thereby reduces 
temperature of zone 5 together with the associated expansion cooling and heat transfer. The high product temperature, combined with the available source of oxygen, provides an ideal environment for both nitric oxide production and soot oxidation.
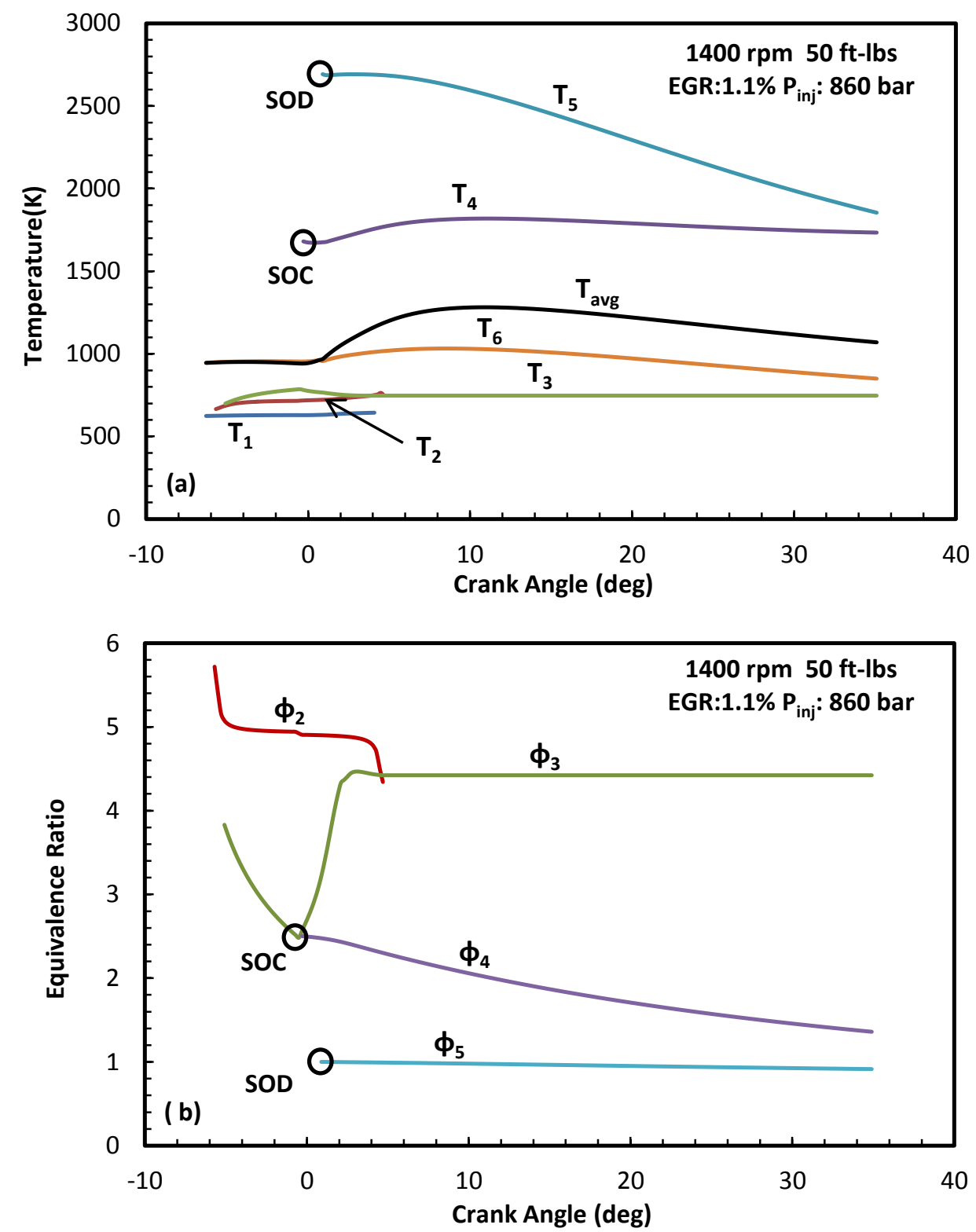

Figure 20. The calculated zonal temperatures, cylinder averaged temperature, and corresponding mixture stoichiometries for the low speed/load case. 

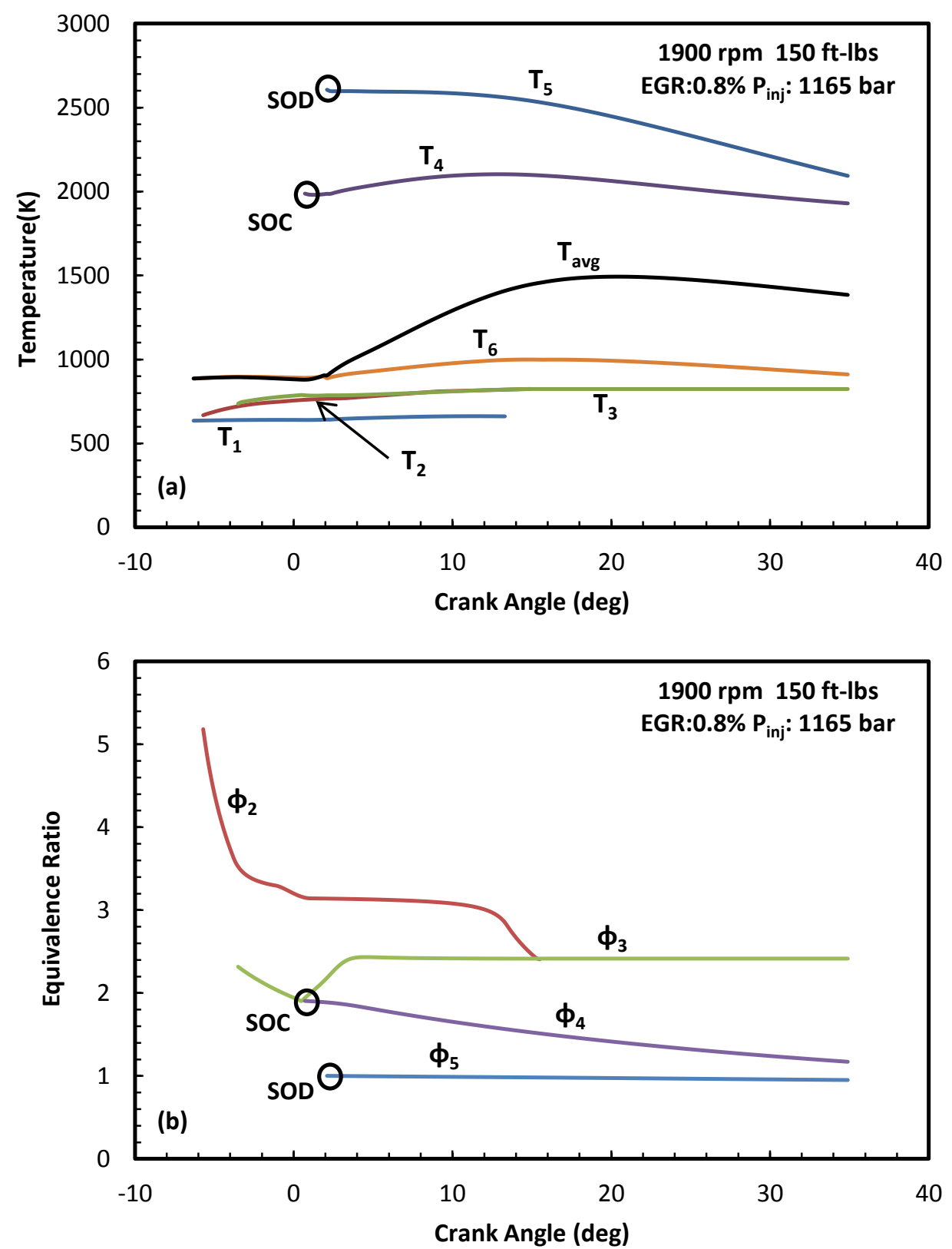

Figure 21. The calculated zonal temperatures, cylinder averaged temperature, and corresponding mixture stoichiometries for the moderate speed/load case. 

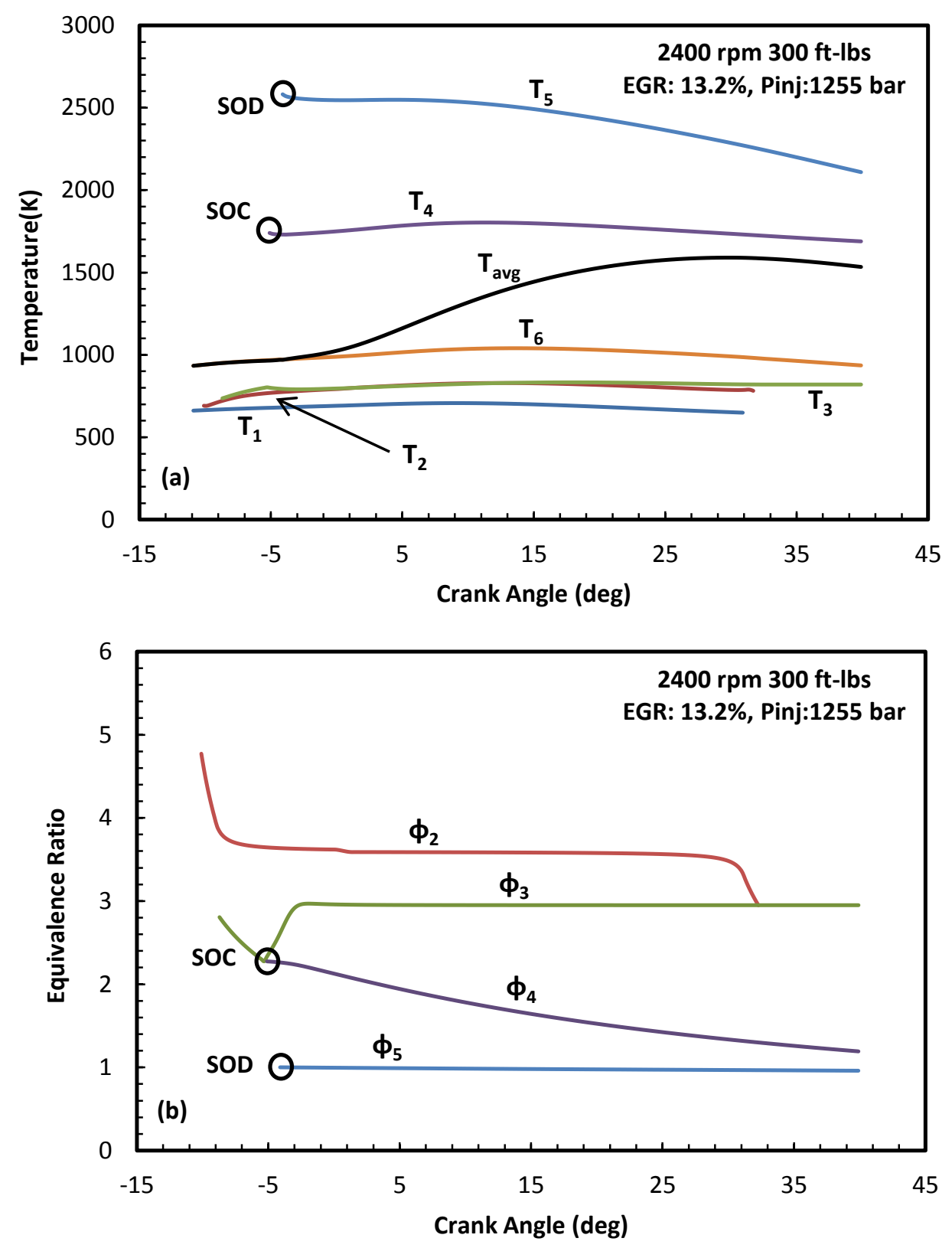

Figure 22. The calculated zonal temperatures, cylinder averaged temperature, and corresponding mixture stoichiometries for the high speed/load case. 
The next set of results is based on examining the fuel distributions for different speed/load cases. Figure 23 presents the fuel burn rates and corresponding accumulative values for premixed and diffusion combustion as a function of crank angle for three different speed/load cases. The fuel that has premixed with ambient gas during the ignition delay period burns volumetrically. The volumetric premixed fuel combustion duration is only several crank angles. The second, broader diffusion flame combustion is controlled by the fuel/gas mixing rate, and lasts 20 to $60 \mathrm{crank}$ angles dependent on the engine operating conditions.

Different engine speed/load operating conditions would lead to different fuel distributions. As shown in Figure 23, for the low speed/load case (1400 rpm/50 ft-lbs), nearly $46 \%$ of total injected fuel burns out as the volumetric premixed combustion. And this fraction is reduced down to approximately $18 \%$ for the moderate speed/load case $(1900 \mathrm{rpm} / 150 \mathrm{ft}-\mathrm{lbs})$. For the high speed/load case $(2400 \mathrm{rpm} / 300 \mathrm{ft}-\mathrm{lbs})$, the fraction of total injected fuel for volumetric premixed combustion is only $2.5 \%$. The decreasing amount of the premixed fraction for higher engine load is clearly illustrated. 

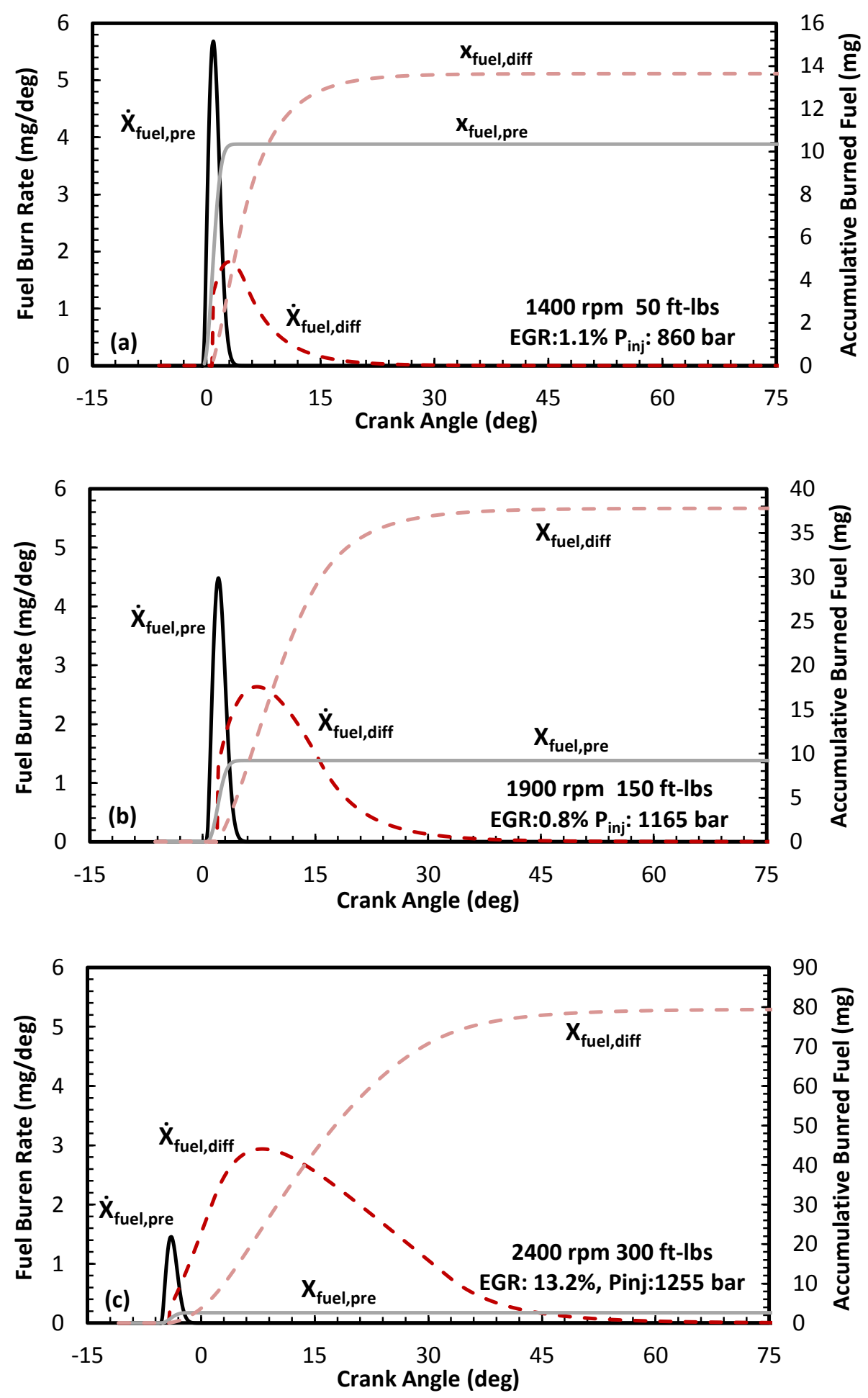

Figure 23. The fuel distributions for three different speed/load cases (note the scale change for (a), (b), (c)). 
Figure 24 shows the calculated instantaneous nitric oxide formations for three different speed/load cases. The injection duration is noted for each case. Since the high activation energy (equation 40) is required in order to decompose the stable triple-bond of $\mathrm{N}_{2}$ molecule which initiates the overall mechanism for nitric oxide formation, the nitric oxide emissions are produced only in the hot products regions --- diffusion flame combustion product zone. The calculated diffusion flame combustion temperature is critical for accurate determination of nitric oxide concentrations.

Because of the relatively "slow" nitric oxide formation mechanism, it is often considered to be detached from the fuel chemical kinetics. Chemical equilibrium of nitric oxide is not reached. The initial high combustion temperature and available source of oxygen in zone 5 account for the rapid increase of nitric oxide formation. As time proceeds, the gradually dropped temperature of zone 5 as a result of expansion cooling, heat transfer and gas entrainment becomes a limiting factor. The nitric oxide concentration "freezes" as a constant value due to dramatically reduced N-, O- and $\mathrm{H}$ atoms which are necessary for the reverse reactions to proceed. As a consequence, the nitric oxide emissions are eventually exhausted out of the cylinder. 

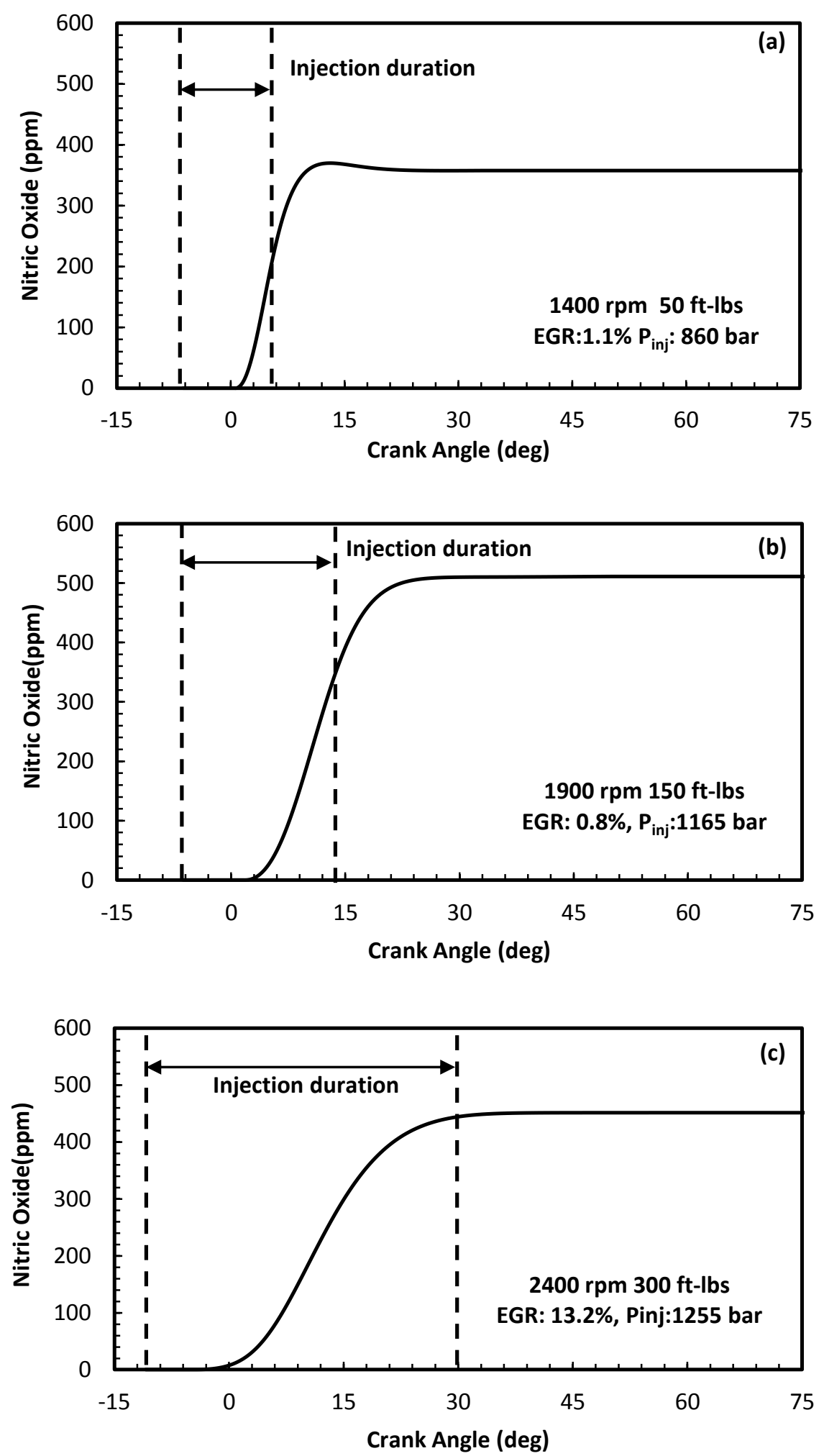

Figure 24. The instantaneous NO concentrations for three different speed/load cases 
Figure 25 illustrates the instantaneous behaviors of soot mass and soot precursor mass as a function of crank angle for three different speed/load cases. The calculated soot formation and oxidation at the end of each combustion cycle are presented. The soot precursor formation results from the fuel pyrolysis originating from the fuel-rich partially premixed flame between zone 3 and zone 4 . The soot precursors are almost completely converted to soot particles under the low speed/load case. With the increase of engine speed and load (Figure 25(b) (c)), the soot precursors are not completely converted into soot particles and some are exhausted out of the cylinder.

The soot formation mainly occurs in zone 4 . The rapid rise of soot mass within the reacting diesel fuel jet is corresponding to the depletion of soot precursor mass. The soot mass reaches its peak value in a short period of time during the early stage of combustion. Soot oxidation takes place as the soot particles reach or pass through the high temperature diffusion flame combustion product zone 5. The soot mass is depleted rapidly, and nearly constant levels are reached. The soot oxidation percentages are $98.0 \%$ (low speed/load case), 95.8\% (medium speed/load case) and 89.6\% (high speed/load case), respectively. The gradually reduced soot oxidation percentage with the increase of engine load is observed. The final engine-out soot mass is a result of the balance of soot formation and oxidation. 

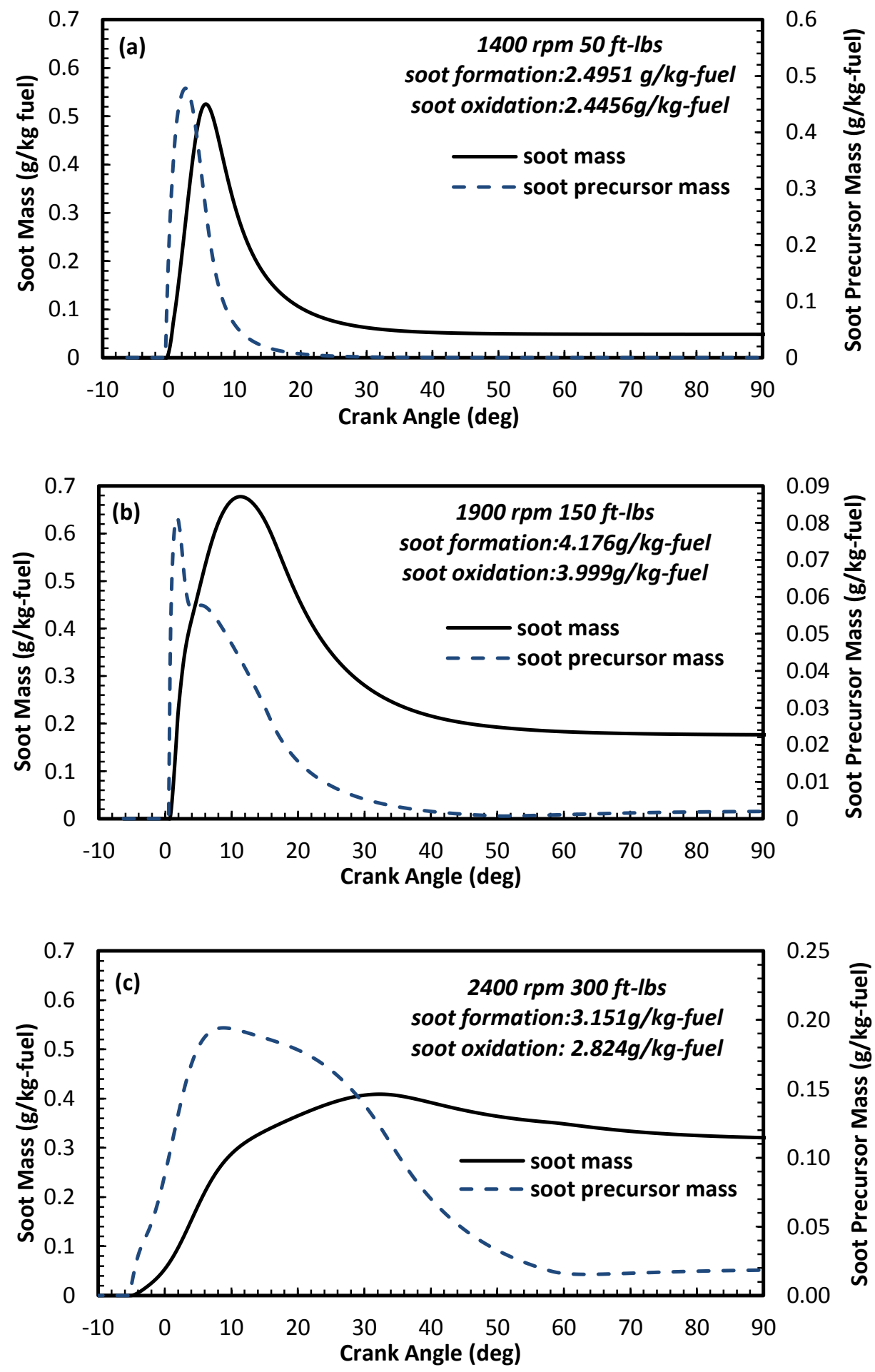

Figure 25. The instantaneous behaviors of soot mass and soot precursor mass for three different speed/load cases (note the scale change for (a), (b), (c) ). 


\subsubsection{EGR level variation}

The dilution effect of EGR has been deemed an effective method to change the diesel engine combustion behavior as well as the nitric oxide and soot formation processes. Figure 26 shows the calculated in-cylinder pressure and AHRR as EGR level is varied for the base case (1400 rpm, $50 \mathrm{ft}-\mathrm{lbs}, 1.1 \%$ EGR, 860 bar injection pressure). The re-circulated exhaust gas reduces the oxygen concentration within the cylinder, increases the specific heat capacity of the cylinder contents, prolongs the ignition delay and significantly depresses the in-cylinder pressure. The combustion is gradually shifted to the expansion stroke for the fixed injection timing.

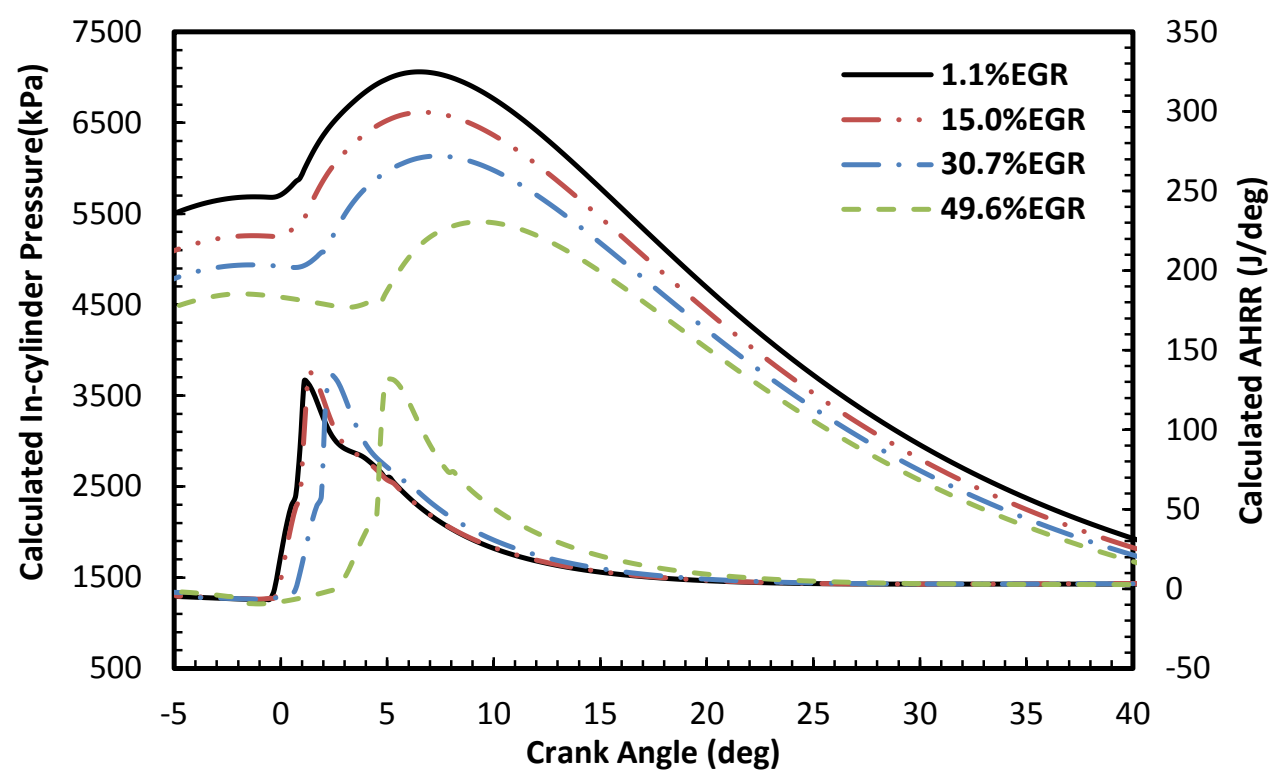

Figure 26. The calculated in-cylinder pressure and AHRR as EGR level is varied for the base case. 
One of the most important impacts by the employment of EGR is on the combustion product temperatures. Figure 27 illustrates the effect of EGR on the combustion product temperatures for zone 4 and zone 5 and average cylinder temperature. The combustion product temperatures in zones 4 and 5 are significantly reduced with the increase of EGR level due to the dilution effect (Figure 27 (a) (b)). The zone 5 temperature is decreased nearly below $2200 \mathrm{~K}$ for $49.6 \%$ EGR level. The reduced combustion product temperatures would lead to different behaviors of emission formation processes (described later).

As shown in Figure 27(a), increased EGR level leads to a relatively more rapid temperature drop in zone 4 . This is largely because of reduced oxygen concentration which leads to less oxygen entrained into the fuel-rich combustion products in zone 4 with the higher EGR levels. The prohibited oxidation process of incomplete combustion products leads to more incomplete combustion products emitted into the environment. Figure 27(c) is the calculated average cylinder temperature for the different EGR levels. The average temperature shows the highest peak value for $15.0 \%$ EGR at least partly due to the increased inlet temperature. As more EGR is added to the cylinder, excess dilution plays a more crucial role, which lowers the averaged cylinder temperature. 

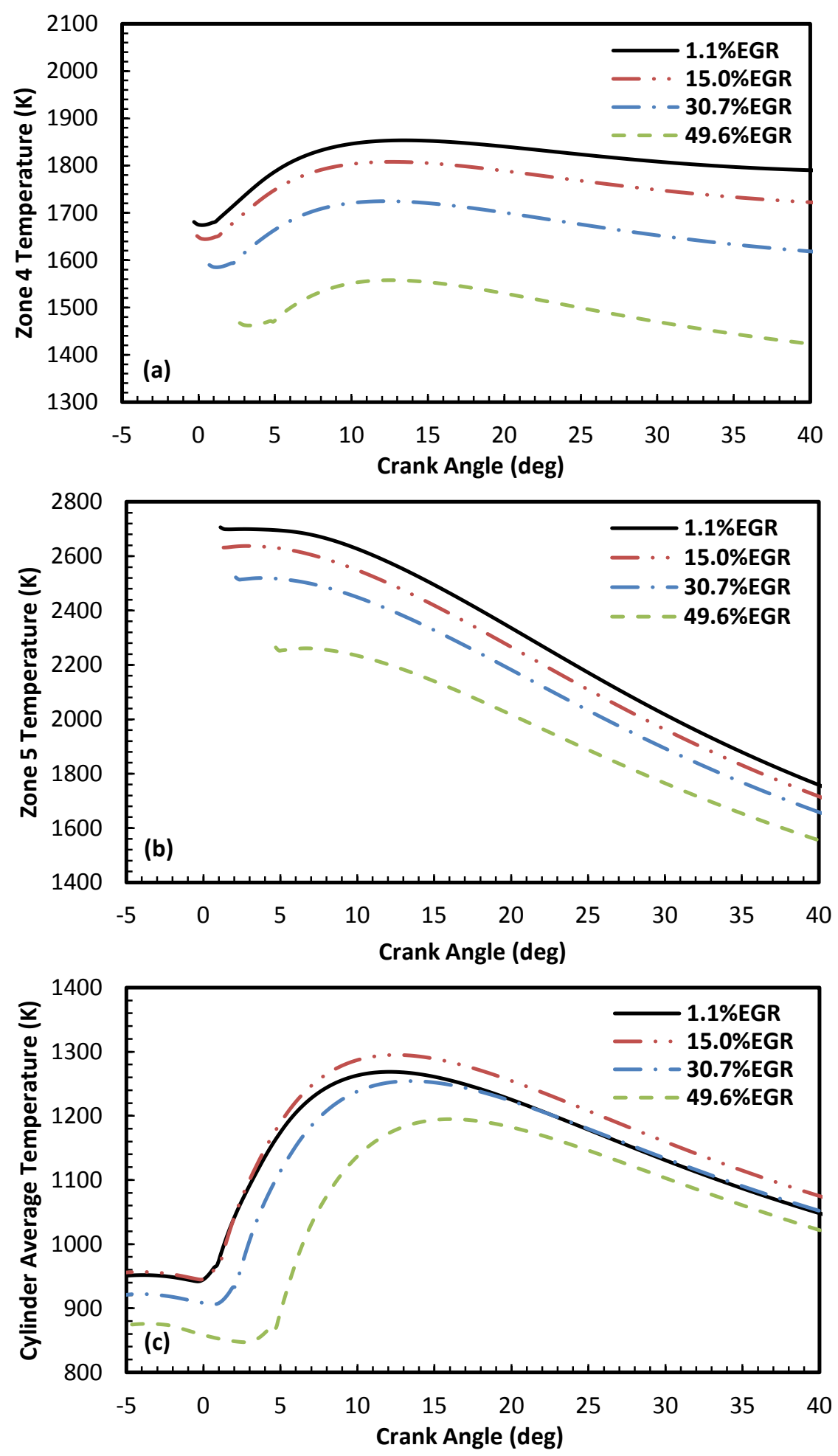

Figure 27. The calculated temperatures for (a) zone 4, (b) zone 5, and (c) cylinder average temperatures as EGR level is varied for the base case. 
Figure 28 shows the overall heat transfer rate as a function of crank angle for different EGR levels. The highest heat transfer rate varies between $8^{\circ}$ to $10^{\circ}$ after top dead center (TDC). The instantaneous heat transfer rate is corresponding to the incylinder pressure and average temperature profiles. From the thermodynamic perspective, one of the benefits by employment of EGR, as shown in Figure 28, is the substantially reduced heat losses to combustion chamber surfaces due to the decreased in-cylinder pressure and temperature. This feature allows more energy to be "available" for conversion to mechanical work during the expansion stroke.

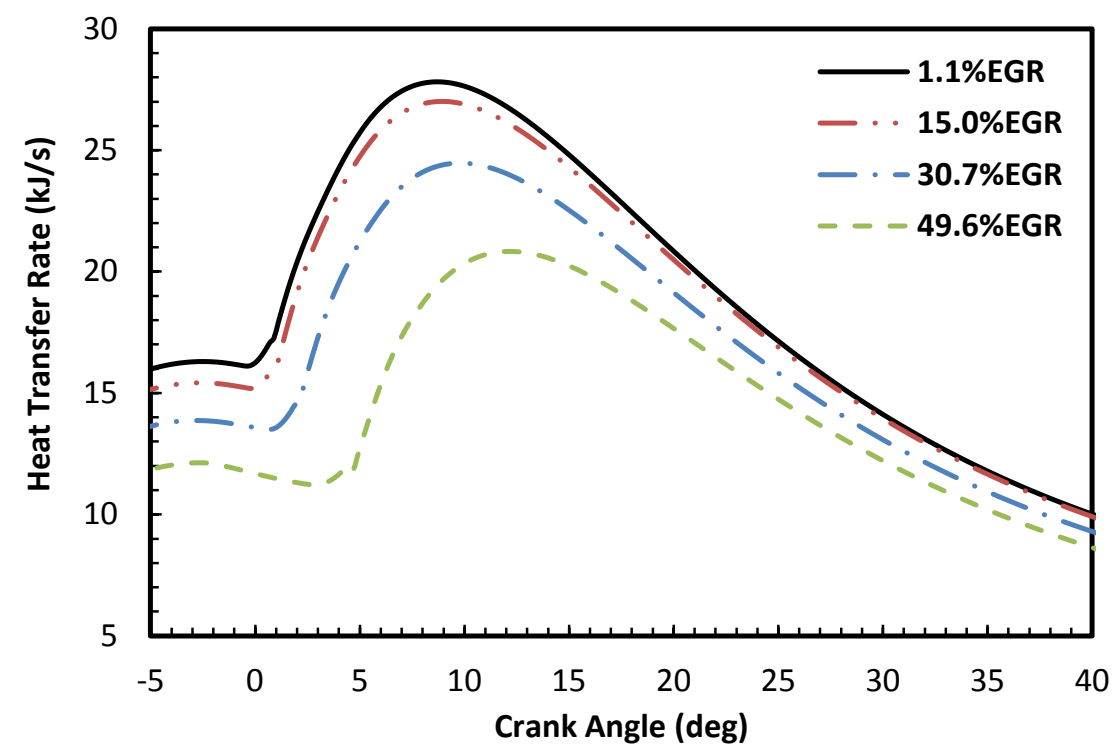

Figure 28. The heat transfer rate as a function of crank angle as EGR level is varied for the base case. 
Figure 29 presents the instantaneous fuel mass in zone 3 (Figure 29(a)) and premixed fuel burn rate (Figure 29(b)) as EGR level is varied for the base case. SOC is denoted by the circles shown in Figure 29(a). The fuel mass in zone 3 is calculated from the difference between the entrained fuel and consumed fuel. After the SOC, the fuel mass entrained into zone 3 is consumed via the premixed combustion mode and the subsequent diffusion combustion mode until the end of combustion. By introducing more EGR into the cylinder, the ignition delay is prolonged so that more fuel is injected into the cylinder and mixed with the hot gas. The combustion phasing is shifted later. Although more fuel is mixed with the hot gas before the SOC, the premixed burn rate still slows down (Figure 29(b)) for 49.6\% EGR level. In addition, the combustion duration is extended with the increase of EGR level. 

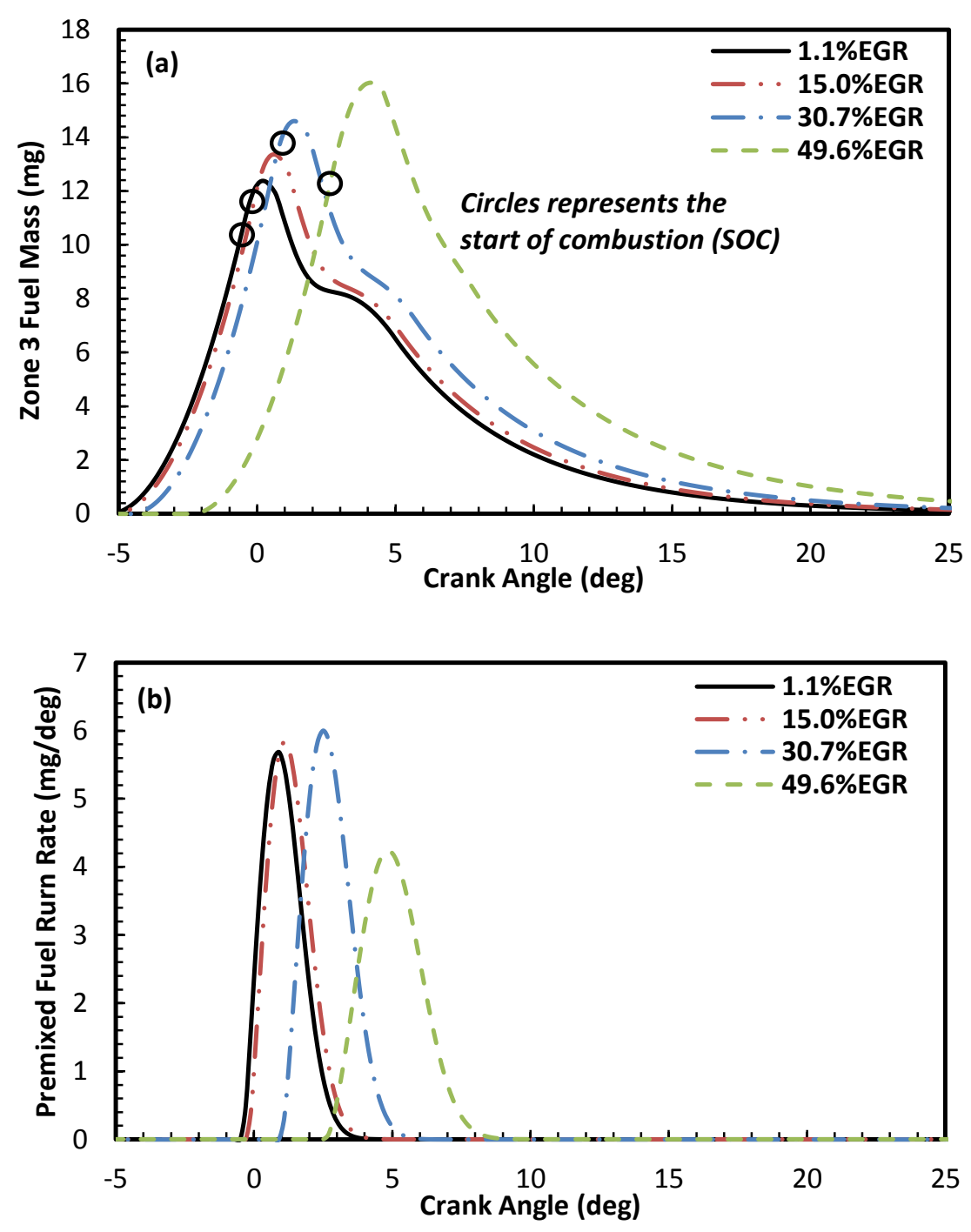

Figure 29. The (a) instantaneous fuel mass in zone 3 and (b) the premixed fuel burn rate as a function of crank angle as EGR level is varied for the base case.

An important feature of Figure 29 is shown in Figure 30. Figure 30 provides the lift-off length, ambient oxygen mole fraction and $\Phi(\mathrm{LOL})$ (equivalence ratio at lift-off length location) for different EGR levels. The flame lift-off length is inversely proportional to the ambient oxygen mole fraction. The lift-off length is prolonged from $2.09 \mathrm{~cm}$ up to $4.29 \mathrm{~cm}$ with the increase of EGR from $1.1 \%$ to $49.6 \%$. 


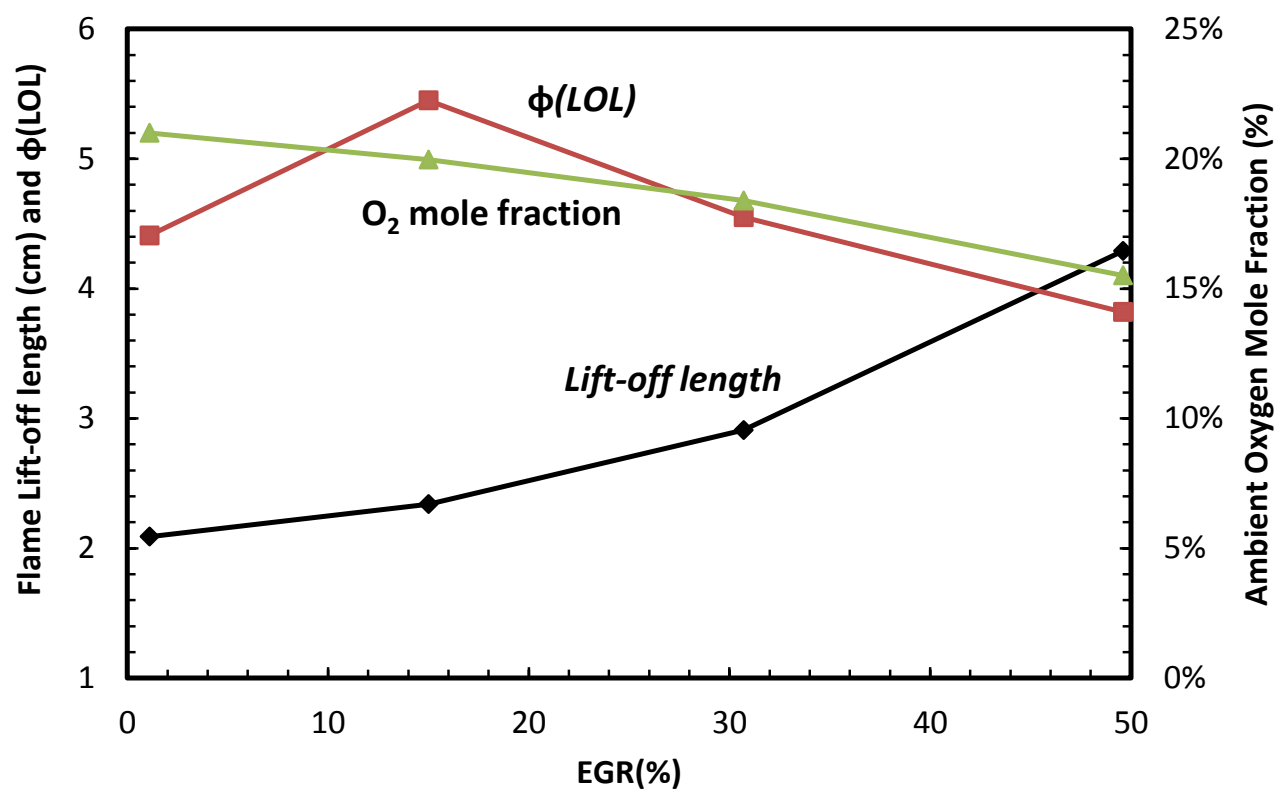

Figure 30 . The flame lift-off length, ambient oxygen mole fraction and $\phi(\mathrm{LOL})$ as EGR level is varied for the base case.

The fuel mass involved in the volumetric premixed combustion is derived from the mutual offset between the ignition delay and flame lift-off length for the same injection profile. As indicated by the circles in Figure 29(a) which show the fuel mass in zone 3 at the start of combustion, the initial increase of EGR level prolongs ignition delay which allows more fuel to get involved in the premixed combustion and leads to intensive volumetric combustion. Under the heavy EGR level (49.6\%), however, the substantial extension of the flame lift-off length prohibits the further increase of fuel mass involved in the premixed combustion. This phenomenon, combined with the extension of premixed combustion duration, explains the reason why the heavy EGR level can reduce the pressure rise rate as indicated in many experiments $[62,63]$. 
Figure 31 and Figure 32 show the instantaneous behaviors of nitric oxide (ppm), soot mass (g/kg-fuel), and soot precursor mass (g/kg-fuel) for different EGR levels. The reduction of the diffusion flame combustion temperature in zone 5 due to the employment of EGR causes a significant reduction of nitric oxide emissions. For $49.6 \%$ EGR level, the zone 5 temperature is decreased nearly below $2200 \mathrm{~K}$ and the thermal nitric oxide formation is reduced close to zero.

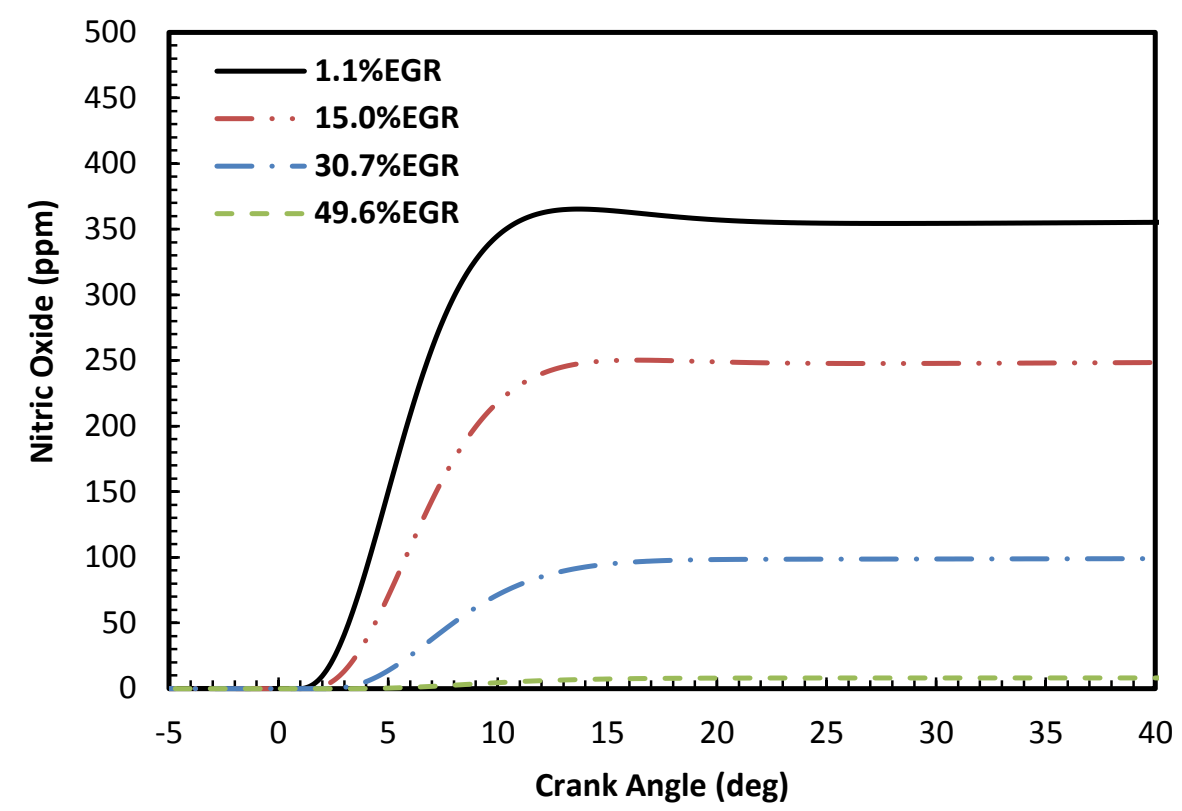

Figure 31. The instantaneous nitric oxide formation as EGR level is varied for the base case.

The reduction of in-cylinder oxygen concentration and lower combustion temperature also lead to deteriorated soot oxidation and increased soot emissions. As indicated in Figure 32, the soot particles exhibit a slow formation rate because of the lower combustion temperature of zone 4 with the increase of EGR level. For the case 
with $49.6 \%$ EGR, the soot formation rate is too low and some precursors are not completely depleted by the end of the expansion stroke. This slow soot formation rate agrees with the experimental observation shown by Idicheria and Pickett [14].

Note that the possible further reduced engine-out soot emissions may be achieved at aggressive EGR levels ( $>50 \%)$. The diesel engine combustion would gradually transition from the conventional combustion mode to low temperature combustion (LTC). The extensively prolonged ignition delay ensures a more homogenous fuel/gas mixture to suppress the formation of soot precursors. The further reduction of combustion product temperature is expected to significantly prohibit the conversion rate from soot precursors to soot particles. A simultaneous reduction of soot and nitric oxide emissions can be achieved. Low temperature diesel combustion exhibits several new characteristics such as the emergence of cool flame reaction and no steady state flame lift-off length [64]. The current simulation would need to be modified to capture these features for the investigation of low temperature diesel combustion processes. 

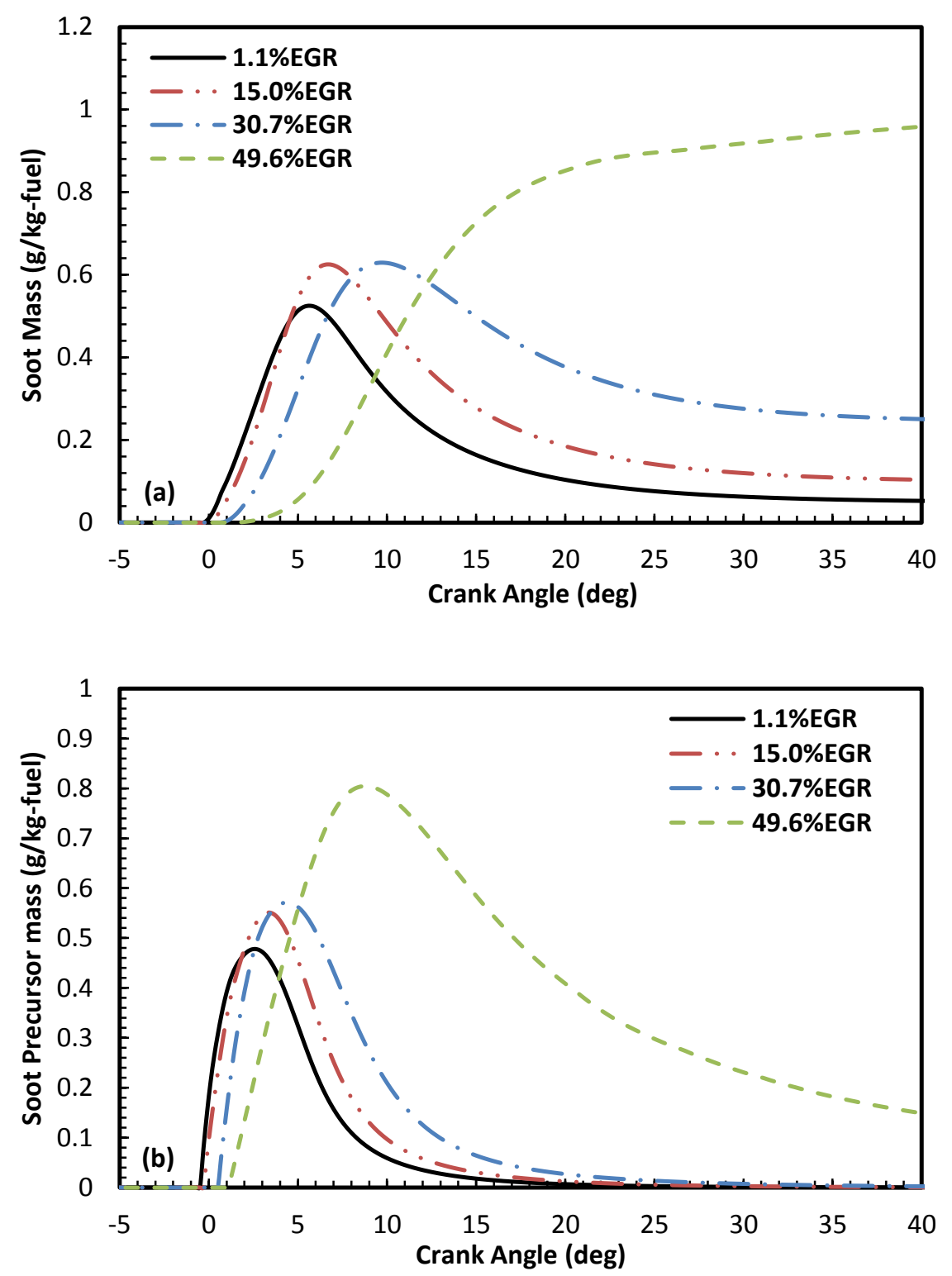

Figure 32. The instantaneous behaviors of soot mass and soot precursor mass as EGR level is varied for the base case. 
Figure 33 shows the calculated soot formation and oxidation as well as the oxidation percentage at the end of each combustion cycle in the cylinder for different EGR levels. Soot formation slightly increases first and then decreases with the increasing EGR level. The soot oxidation is dramatically reduced as EGR increases, and therefore, results in higher engine-out soot emissions. The oxidation percentage decreases from $98.0 \%$ (1.1\% EGR) to $38.1 \%$ (49.6\% EGR).

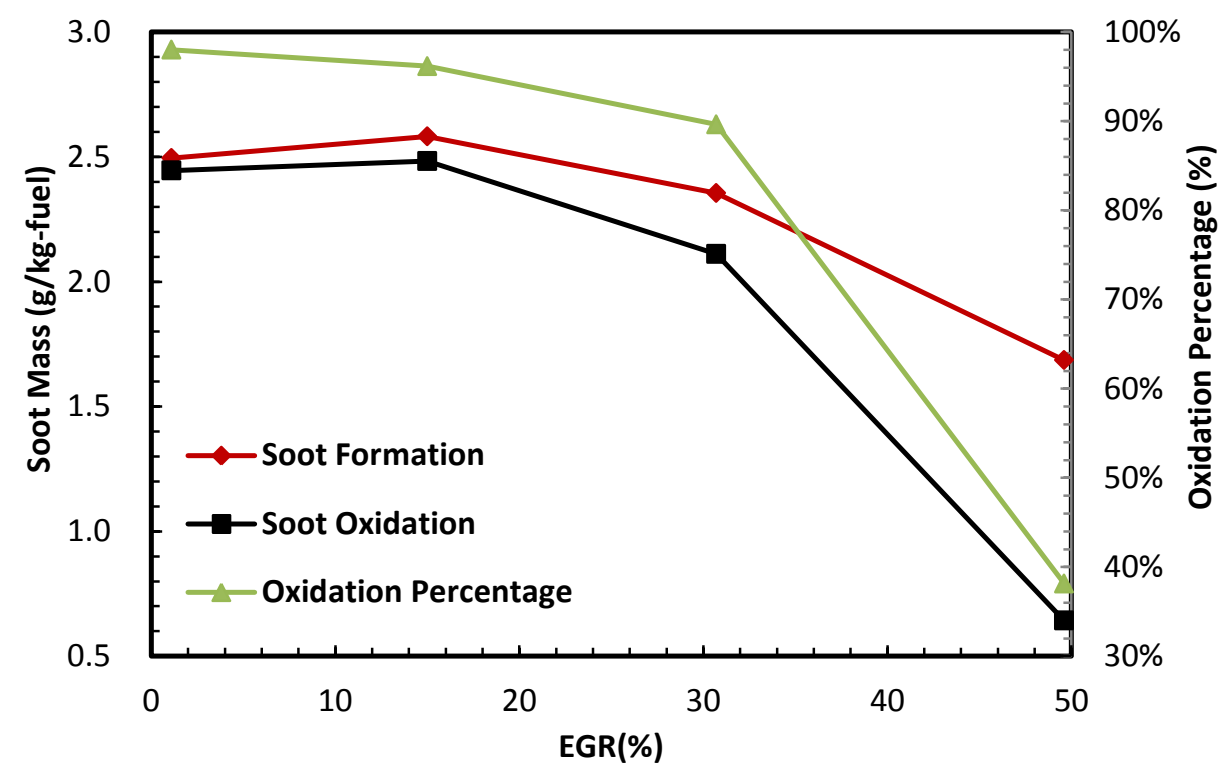

Figure 33. The calculated soot formation and oxidation, oxidation percentage at the end of each combustion cycle as EGR level is varied for the base case.

The flame lift-off length and corresponding equivalence ratio (Figure 30) help explain the soot formation behaviors for different EGR levels. As indicated before, the soot formation correlates well with the local equivalence ratio. Initial increase of soot formation is due to the higher equivalence ratio at the lift-off length location. The 
increasing EGR level enhances the flame lift-off length and makes more gas mix with the fuel vapor upstream of the flame lift-off. This happens even though the overall oxygen concentration in the cylinder is reduced. The reduced local equivalence ratio makes fuel-rich partially premixed reaction occur with more fresh gas involved. In summary, the reduced local equivalence ratio and lower combustion temperature are the major features accounting for the decrease of soot formation.

\subsubsection{Injection pressure variation}

Injection pressure is another important parameter that affects the combustion, nitric oxide and soot emissions of the DI diesel engine. Higher injection pressure would produce higher injection velocity, enhance fuel spray penetration length, increase the injection induced turbulent level, and promote the fuel/gas mixing process. Figure 34 shows the calculated in-cylinder pressure and AHRR as the injection pressure is varied for the base case. The promoted fuel/gas mixing reduces the equivalence ratio within the fuel jet and shortens the ignition delay. These features result in rapid fuel heat release near TDC and thereby enhance the in-cylinder pressure. The peak value of heat release rate is increased correspondingly. 


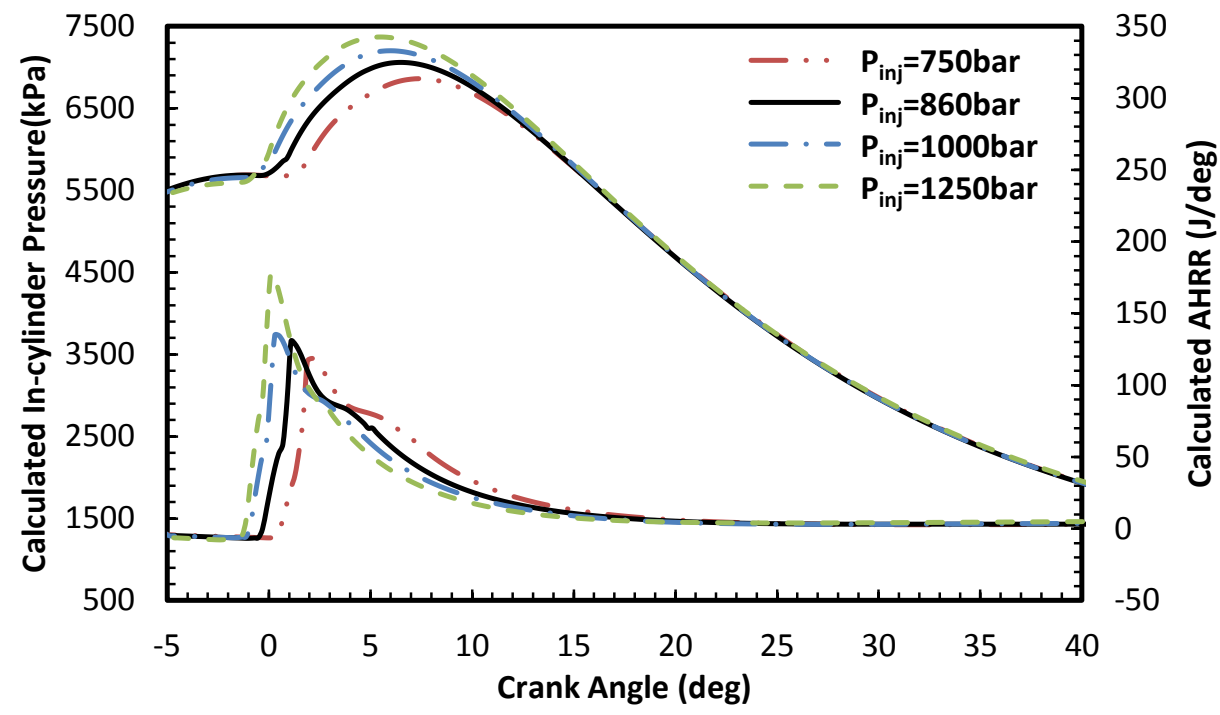

Figure 34. The calculated in-cylinder pressure and AHRR as injection pressure is varied for the base case.

Figure 35 illustrates the fuel-rich combustion product temperatures (zone 4), diffusion flame combustion product temperatures (zone 5) and cylinder average temperatures for different injection pressures. The enhanced fuel spray penetration and promoted gas entrainment for higher injection pressure reduce the equivalence ratio of the fuel jet during the ignition delay, and thereby, result in increased fuel-rich combustion product temperature in zone 4. On the contrary, the diffusion combustion product temperature in zone 5 is reduced with the increase of injection pressure. The increased kinetic energy of high pressure fuel injection substantially enhances the incylinder turbulence level so that more unburned gas is entrained into the already existing combustion products and the local equivalence ratio becomes leaner. This leads to lower temperature of zone 5 as time proceeds. The cylinder average temperature is monotonously increased with the increase of injection pressure 

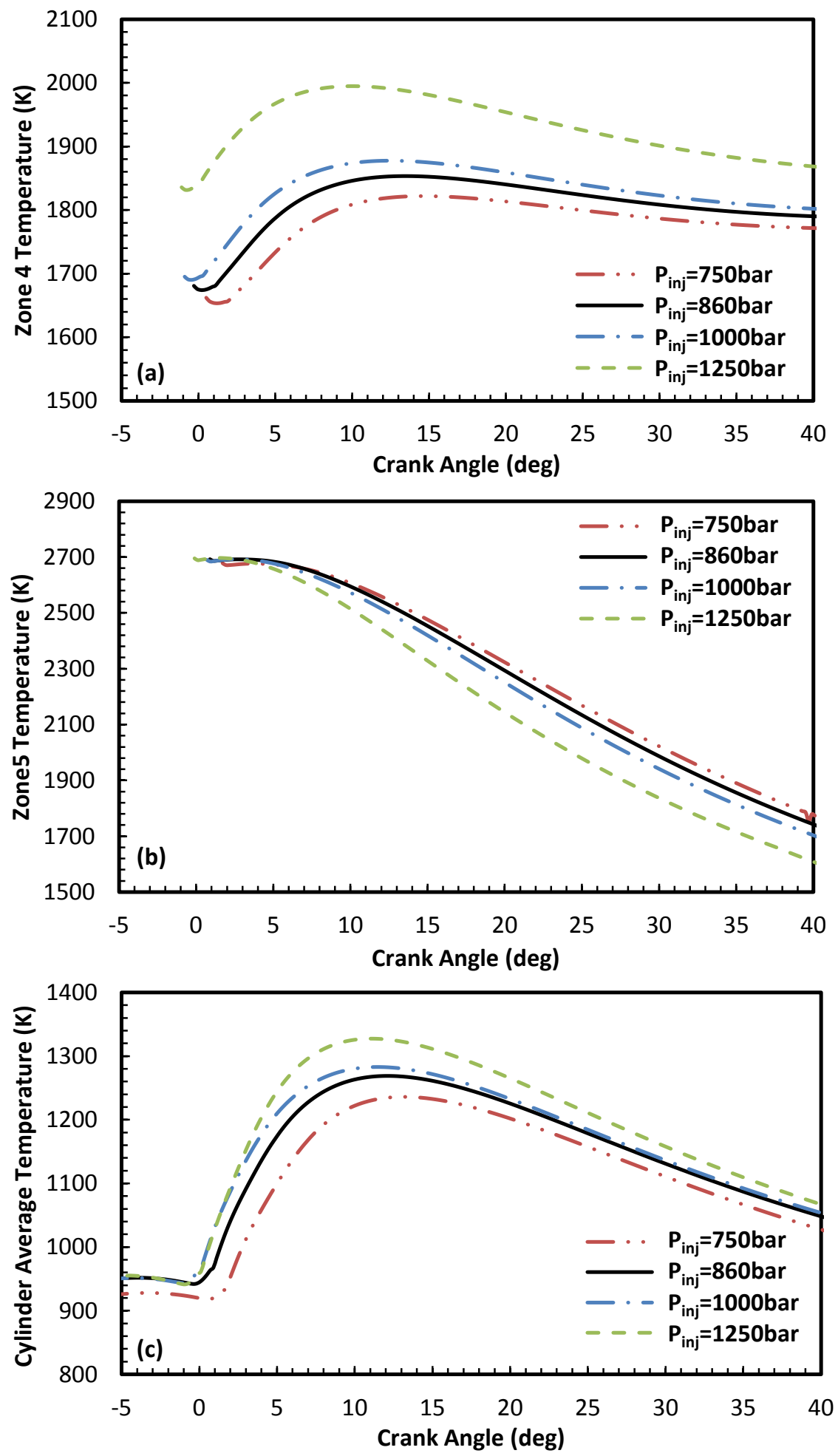

Figure 35. The calculated temperatures for (a) zone 4, (b) zone 5, and (c) cylinder average temperature as injection pressure is varied for the base case. 

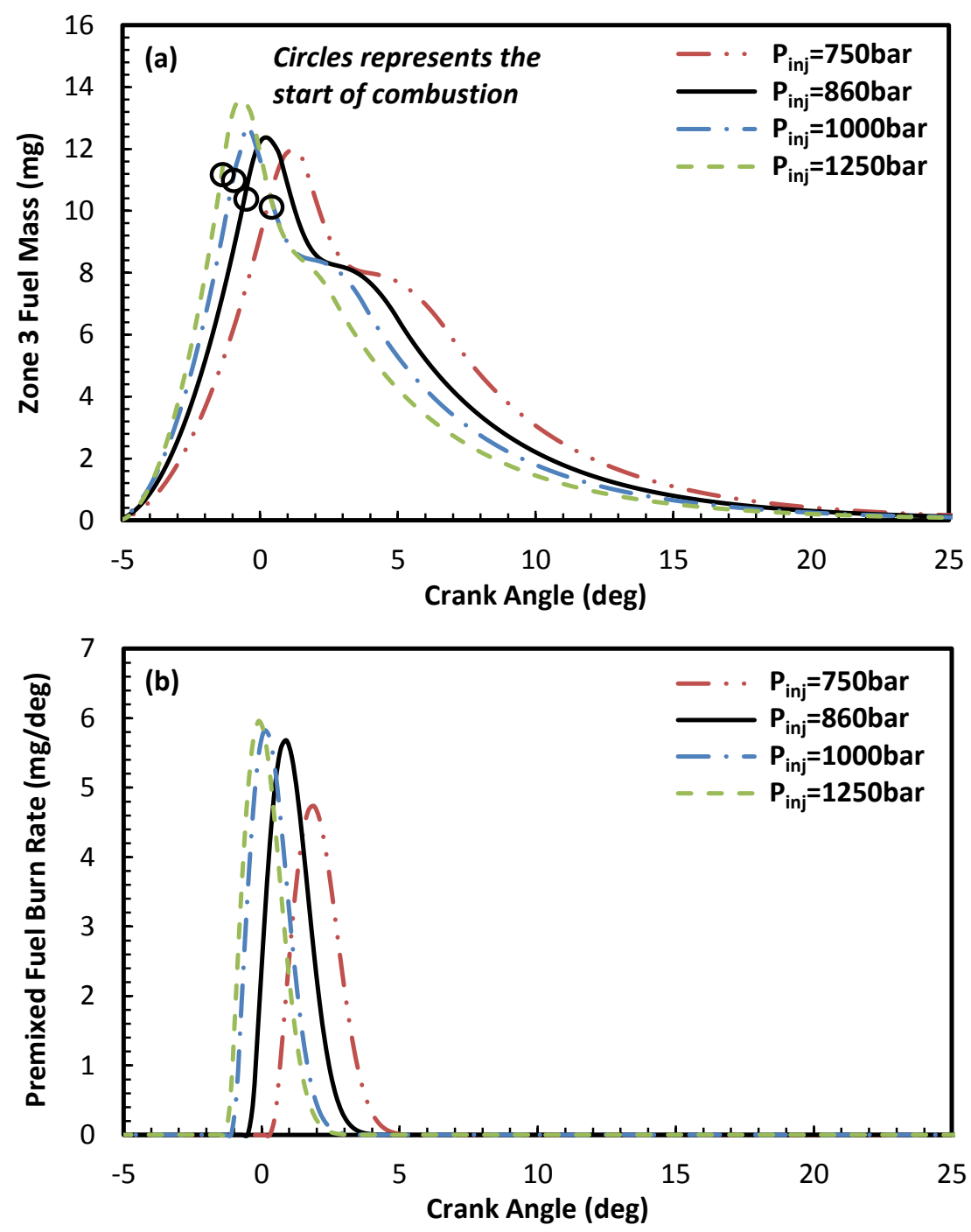

Figure 36. The instantaneous fuel mass in zone 3 (a) and the premixed fuel burn rate (b) as a function of crank angle as injection pressure is varied for the base case.

Figure 36 presents the instantaneous fuel mass in zone 3 (Figure 36(a)) and premixed fuel burn rate (Figure 36(b)) as injection pressure is varied for the base case. Although the ignition delay period is reduced with the increase of injection pressure, and also the flame lift-off length is extended (will be shown later), the dominant effects of 
enhanced fuel injection velocity and penetration length still result in higher peak value of fuel mass in zone 3 and make more fuel involved in the volumetric premixed combustion. The peak value of the premixed fuel burn rate is enhanced correspondingly.

Figure 37 shows the flame lift-off length and corresponding equivalence ratio as injection pressure is varied for the base case. There is a linear increase in flame lift-off length with enhanced injection pressure and velocity. The extended flame lift-off length results in reduced equivalence ratio so that more fresh gas is entrained into the fuel jet at the upstream of flame lift-off. Since fuel pyrolysis and soot precursor formation are highly related with the flame lift-off length and the corresponding equivalence ratio, this phenomenon is deemed as an important indicator to explain the reduced soot mass with increased injection pressure which will be discussed in more detail later.

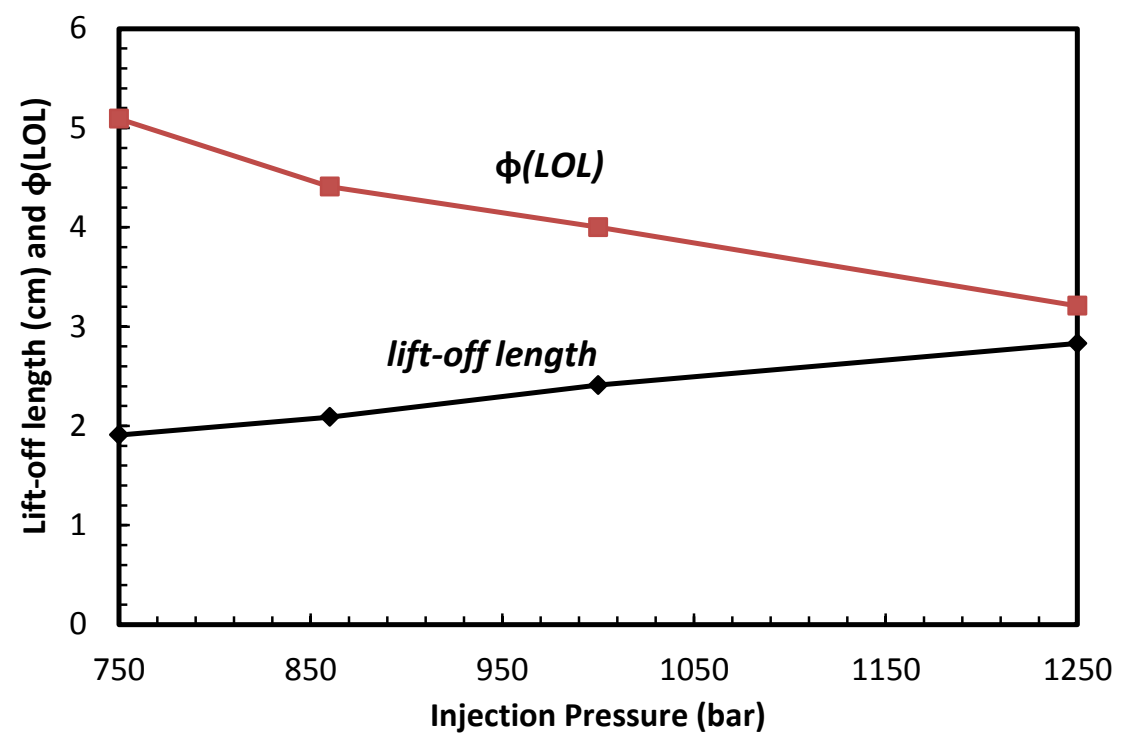

Figure 37. The flame lift-off length and $\phi(\mathrm{LOL})$ as injection pressure is varied for the base case. 
Figure 38 shows the instantaneous nitric oxide formations as a function of crank angle for different injection pressures. As explained above, the fresh gas entrainment into the combustion products has a significant effect on the nitric oxide formation.

Higher injection pressure enhances the gas entrainment rate into combustion products and thereby results in more available oxygen in zone 5. The phenomenon, together with the shortened ignition delay, accounts for the increase of nitric oxide emissions, in spite of slightly reduced combustion temperature of zone 5 .

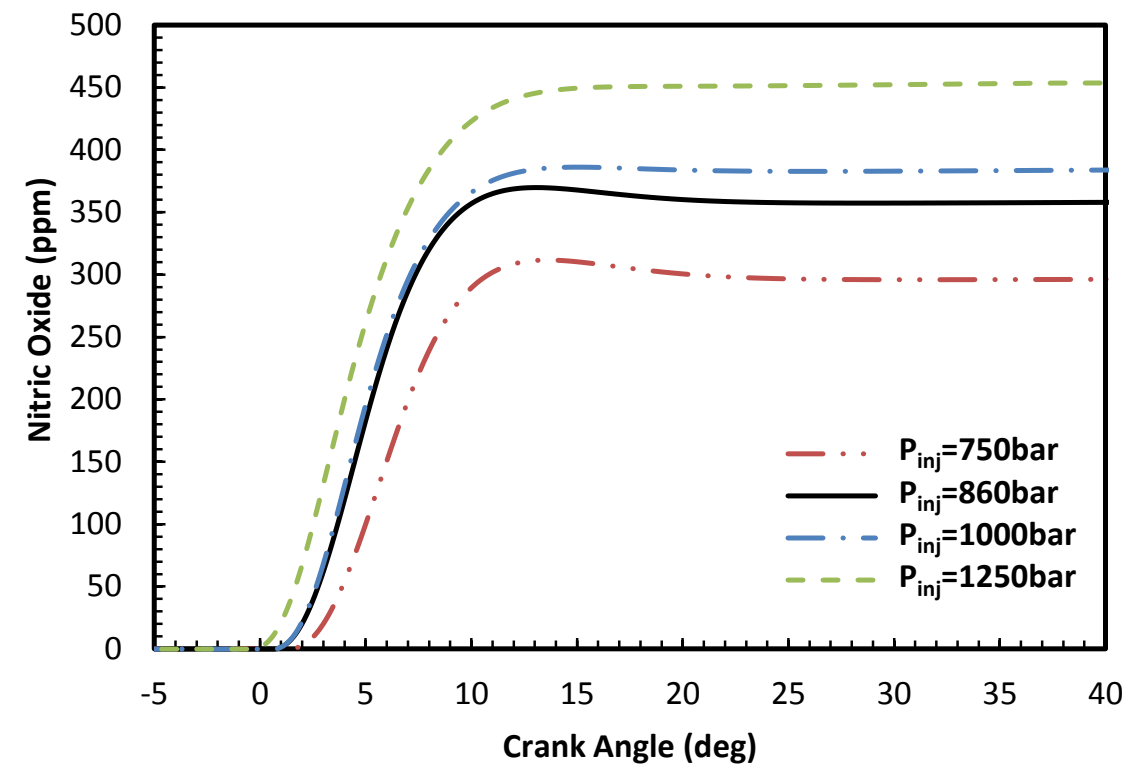

Figure 38. The instantaneous nitric oxide formation as injection pressure is varied for the base case. 
Figure 39 compares the instantaneous behaviors of soot mass (g/kg-fuel), and soot precursor mass ( $\mathrm{g} / \mathrm{kg}$-fuel) for different injection pressures. Consistent with the experimental evidence [13], lower injection pressure causes higher peak and engine-out soot emissions. The corresponding increased soot precursor mass (Figure 39(b)) is clearly observed. The soot precursor mass is almost completely converted to soot mass for all injection pressure cases. Another interesting observation is that the peak soot mass for 1250 bar injection pressure is comparable to that for 1000 bar injection pressure. This is because, for 1250 bar injection pressure, the extensively increased fuel-rich combustion product temperature (Figure 35(a)) substantially enhances soot formation rate, and therefore leads to a high peak value of soot mass. 

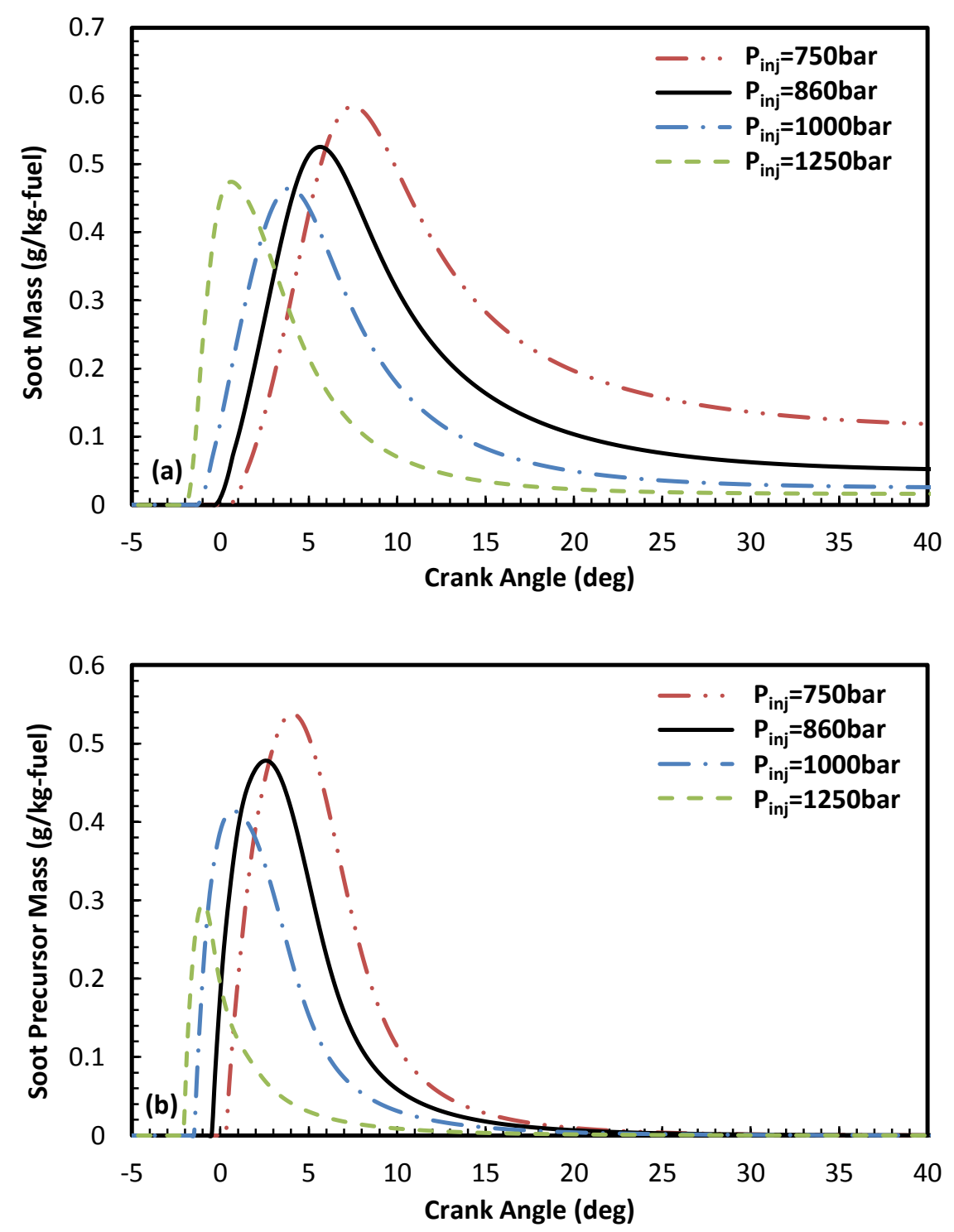

Figure 39. The instantaneous behaviors of soot mass and soot precursor mass as injection pressure is varied for the base case.

Figure 40 explores the calculated soot formation and oxidation, oxidation percentage at the end of each combustion cycle as a function of the injection pressure. Soot formed in the cylinder monotonically increases with the decreased injection pressure, which may partially explain the higher peak soot and soot precursor mass 
under lower injection pressure. Although the total mass of soot oxidation is increased correspondingly, the soot oxidation percentage is reduced from $99.3 \%$ ( $\left.\mathrm{P}_{\mathrm{inj}}=1250 \mathrm{bar}\right)$ to $95.5 \%\left(\mathrm{P}_{\mathrm{inj}}=750 \mathrm{bar}\right)$. This is mainly due to the reduced oxygen in zone 5 (as implied in Figure 35(b)) as well as the reduced cylinder pressure. The extended flame lift-off length and corresponding reduced equivalence ratio suppress the formation of soot precursors and the subsequent soot formation for higher injection pressure. Together with the intensified soot oxidation, higher injection pressure finally results in lower peak and engine-out soot emissions.

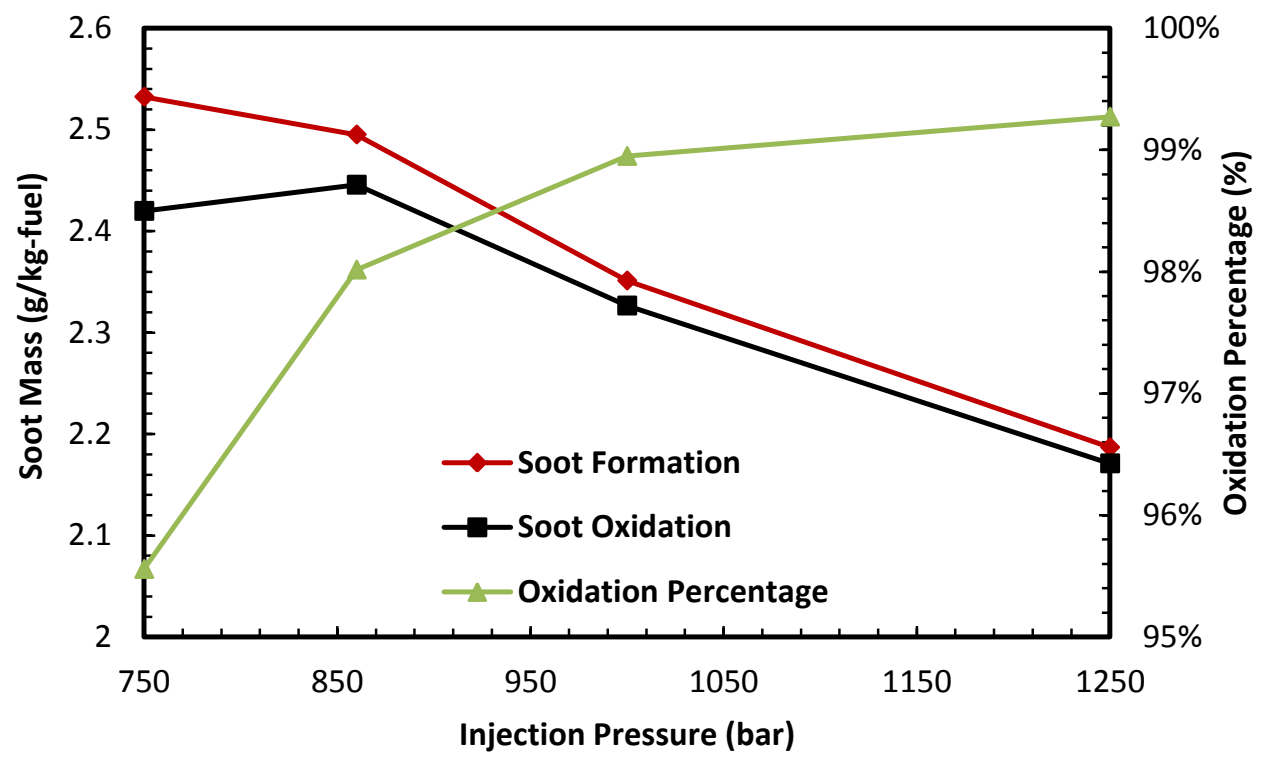

Figure 40. The calculated soot formation and oxidation, oxidation percentage at the end of each combustion cycle as injection pressure is varied for the base case. 


\subsubsection{Injection timing variation}

In this subsection, the effect of injection timing (SOI) is investigated. The injection timing is commonly used to control the combustion phasing. The combustion phasing, in turn, impacts the in-cylinder diesel fuel combustion and emission formation processes. For this topic, no experimental data is available. The injection timing is adjusted from $12^{\circ} \mathrm{bTDC}$ to $6^{\circ} \mathrm{bTDC}$ with 860 bar injection pressure, and 1.1\% EGR level. All other parameters are the same as for the base case.

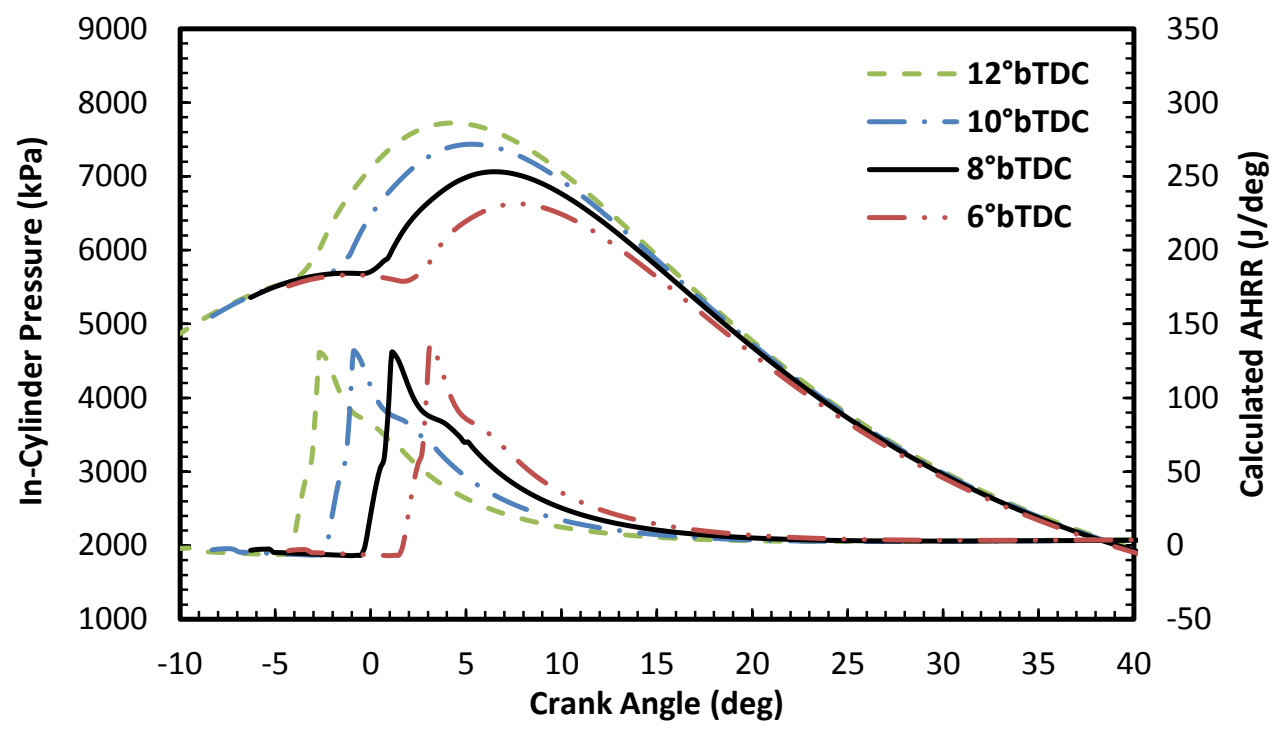

Figure 41. The calculated in-cylinder pressure and AHRR as injection timing is varied for the base case.

Figure 41 shows the calculated in-cylinder pressure and AHRR as injection timing is varied for the base case. Advanced injection timing makes the start of combustion occur during the compression stroke which leads to higher in-cylinder pressure. On the other hand, retarded injection timing makes the combustion phasing shift towards the 
expansion stroke. The pressure rise due to combustion is offset by the cylinder volume expansion, and therefore, the net results in lower in-cylinder pressure.

Figure 42 shows the fuel-rich combustion product temperatures (zone 4), diffusion flame combustion product temperatures (zone 5) and cylinder average temperatures for different injection timing cases. The combustion product temperature is highly correlated with the gas entrainment into the combustion products, as indicated in equation (32). Advanced injection timing makes the start of combustion occur earlier. The more residence time the combustion event occurs around TDC, the higher the gas entrainment into the combustion products is. This is because of the higher characteristic mixing frequency $\mathrm{f}_{\mathrm{M}}$ (equation 25) due to the reduced characteristic mixing length around TDC. More gas entrainment by advancing injection timing results in higher fuel-rich combustion product temperature in zone 4 , while lower diffusion flame combustion product temperature in zone 5 . The cylinder average temperature is enhanced by advanced injection timing. The advanced combustion phasing is considered to be the major reason for the enhanced cylinder average temperature, associated with the increased in-cylinder pressure. 

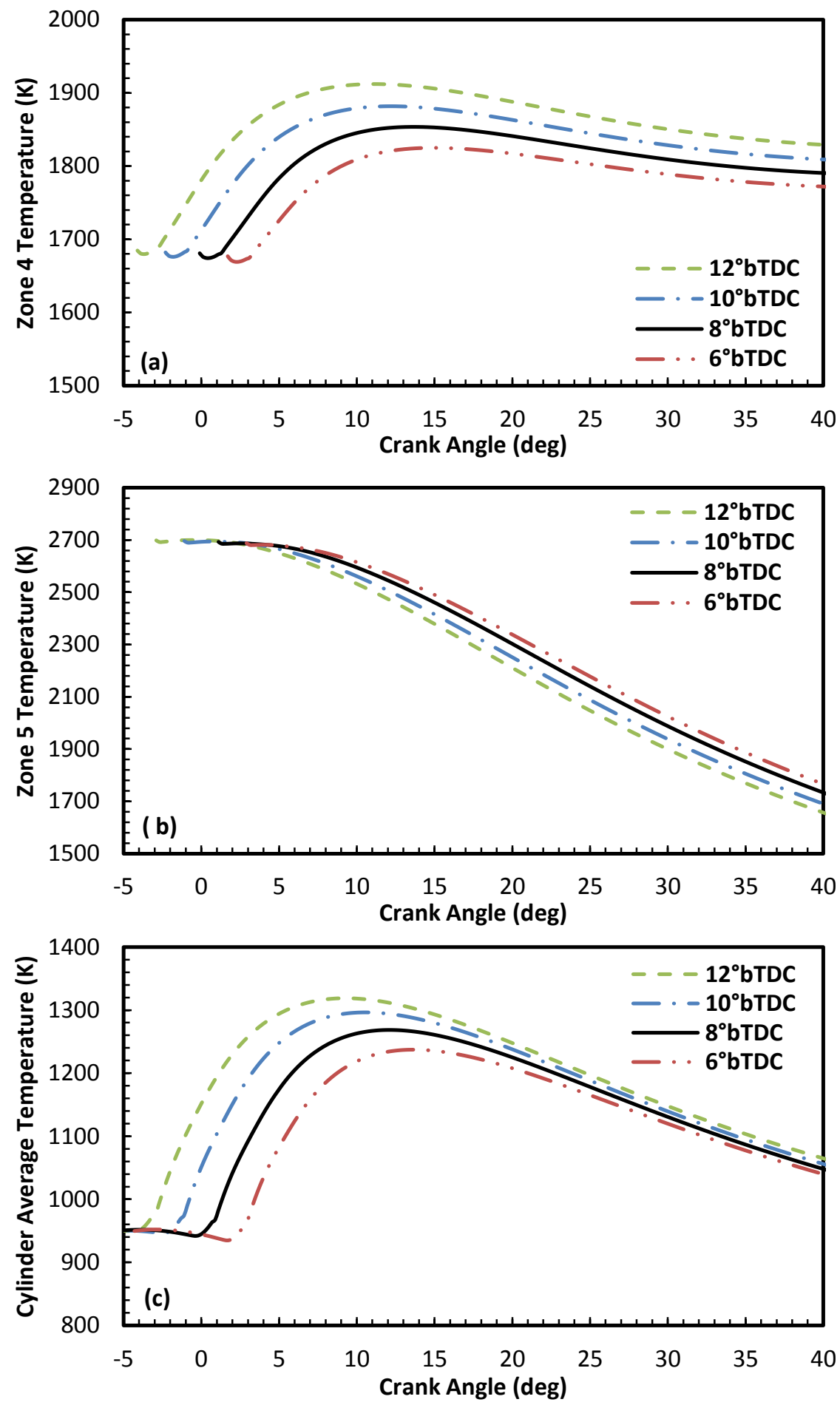

Figure 42. The calculated temperatures for (a) zone 4, (b) zone 5, and (c) cylinder average temperatures as injection timing is varied for the base case. 
One of the important thermodynamic features by advancing the injection timing is the enhanced heat losses to the combustion chamber surfaces. As shown in Figure 43, the increased residence time of high temperature combustion products as well as enhanced in-cylinder pressure and average temperature lead to more thermal energy losses. Meanwhile, higher in-cylinder pressure during the compression stroke results in more "negative" work. An appropriate selection of injection timing, therefore, is critical in order to achieve maximum power output for a constant engine speed and fuel flow rate.

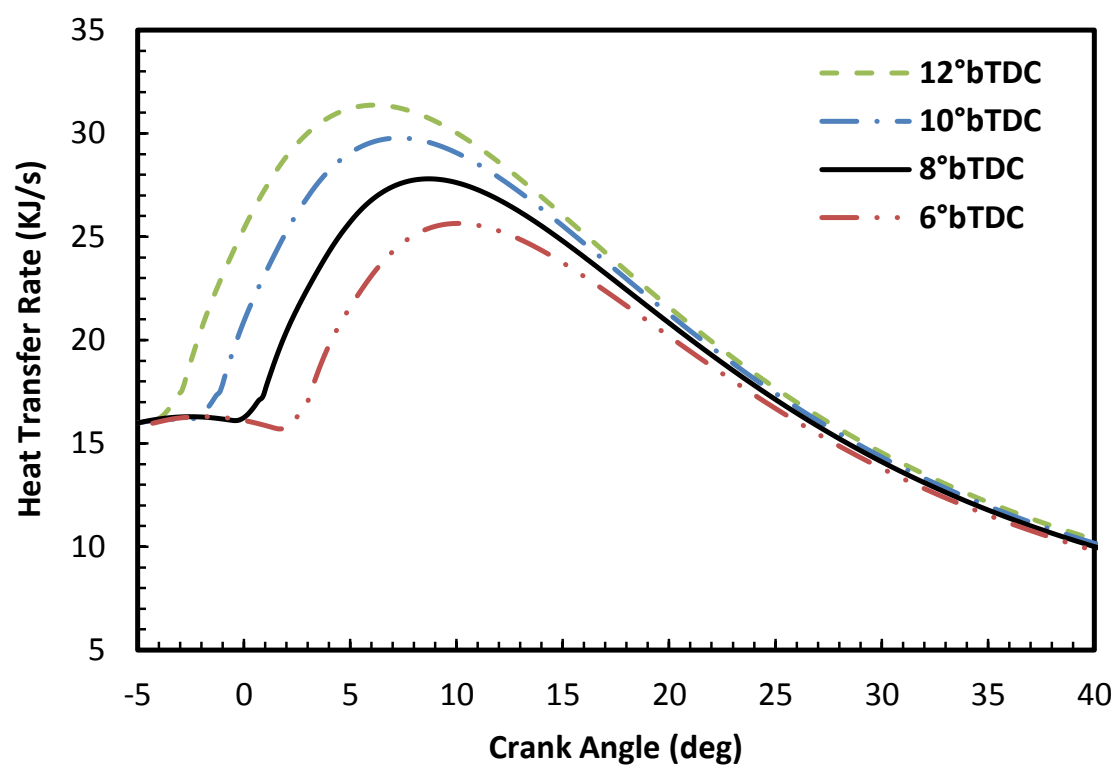

Figure 43 . The heat transfer rate as a function of crank angle as injection timing is varied for the base case. 
Figure 44 shows the flame lift-off length and corresponding equivalence ratio as injection timing is varied for the base case. Compared to the effect of EGR and injection pressure, the impact of injection timing on the flame lift-off length is relatively small. With the advanced injection timing before TDC, the fuel is injected into a reduced incylinder temperature and pressure environment. Lower cylinder temperature and pressure lead to higher flame lift-off length as well as reduced equivalence ratio.

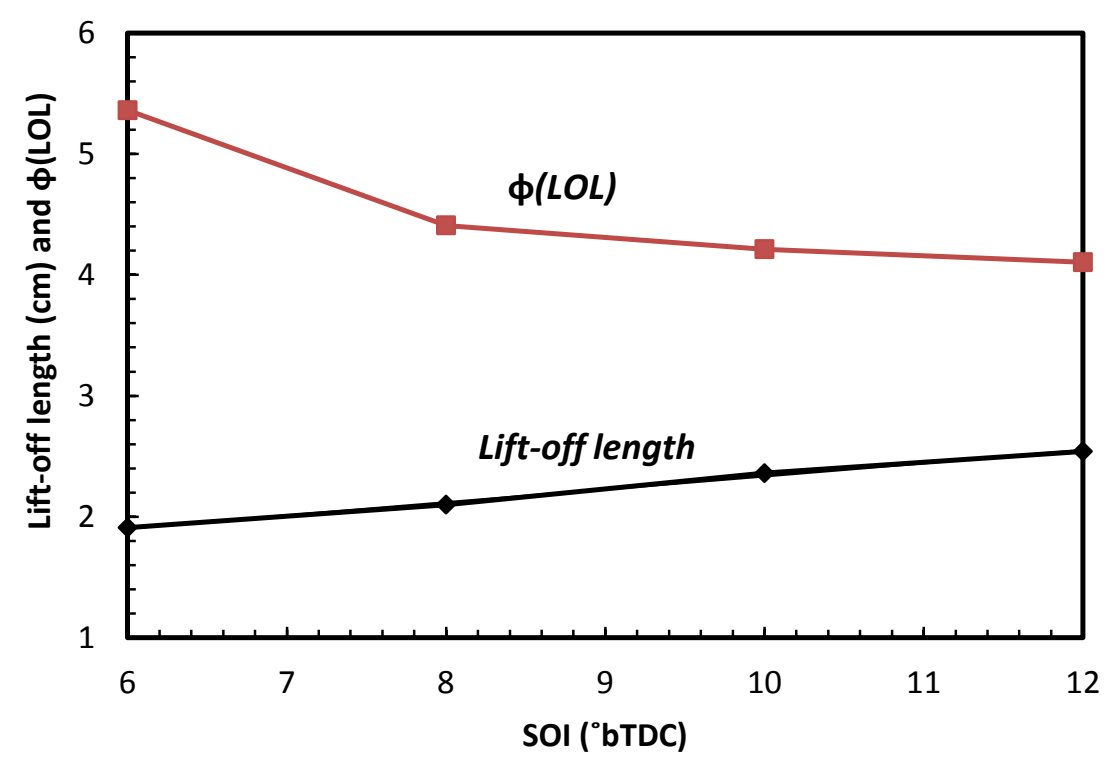

Figure 44. The flame lift-off length and $\phi(\mathrm{LOL})$ as injection timing is varied for the base case.

Figure 45 and Figure 46 show the instantaneous nitric oxide (ppm), soot mass (g/kg-fuel), and soot precursor mass (g/kg-fuel) for different injection timings. Consistent with many experimental observations, nitric oxide emissions increase with advanced injection timing, while lower soot mass is expected which commonly results in 
another classic soot-NO tradeoff. The effect of injection timing on emission production can be related with the resulting combustion timing. Advanced combustion timing allows NO formation and soot oxidation to occur earlier and therefore more residence time is available. The more oxygen concentration in zone 5 is another feature that leads to the increased NO concentration and soot oxidation process. The reduced peak values of soot mass and soot precursor mass with advanced injection timing are observed.

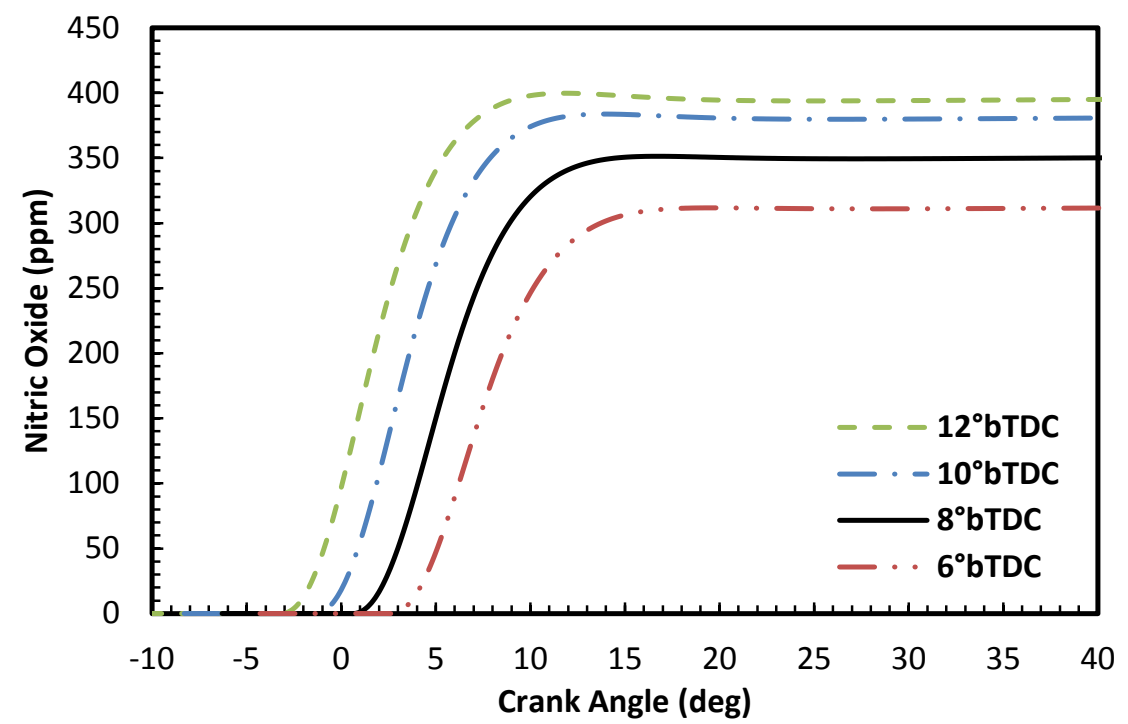

Figure 45. The instantaneous nitric oxide formation as injection timing is varied for the base case. 

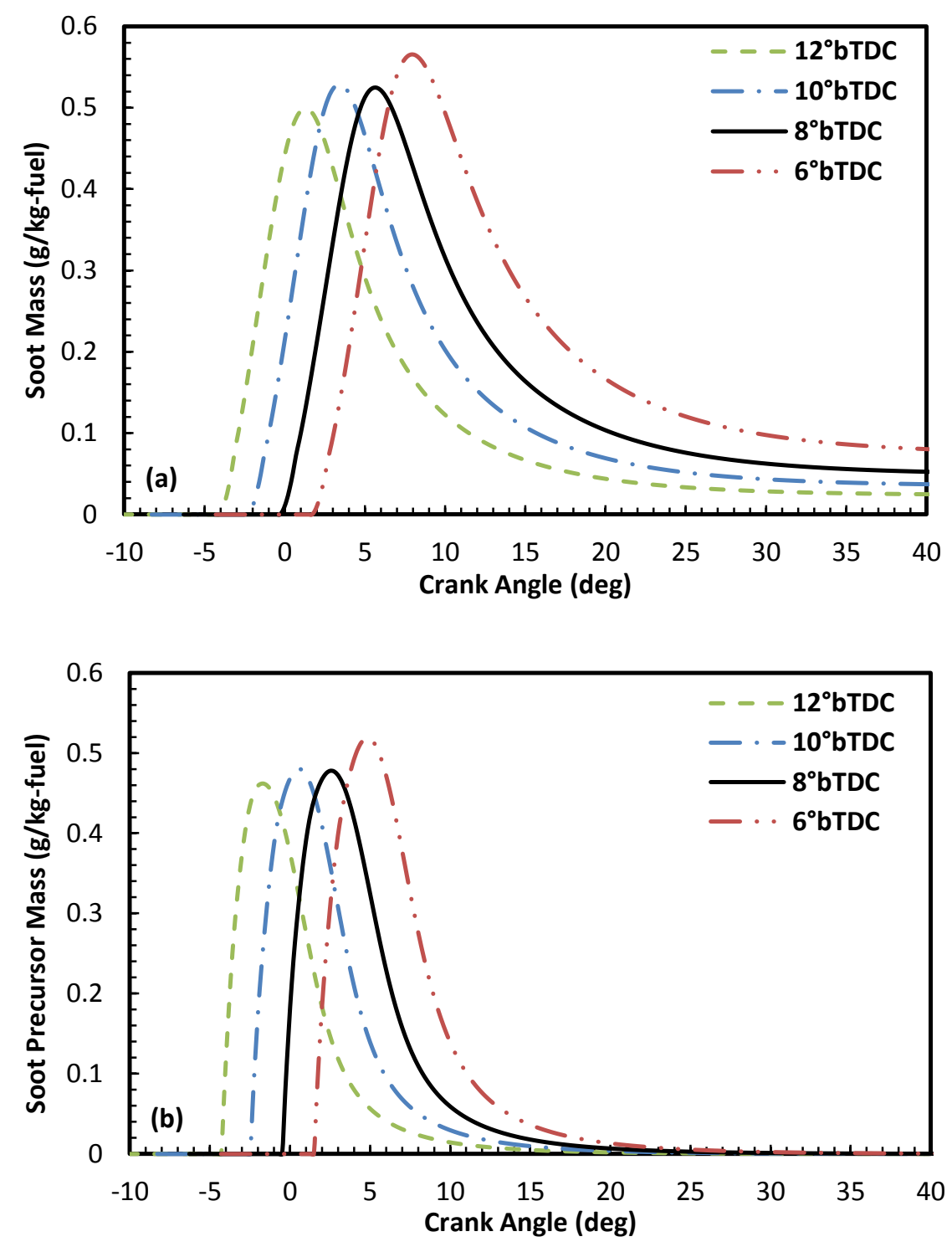

Figure 46. The instantaneous behaviors of soot mass and soot precursor mass as injection timing is varied for the base case. 
Figure 47 shows the calculated soot formation and oxidation as well as oxidation percentage at the end of each combustion cycle for different injection timing cases. The total mass of soot formation, again, is highly related with the flame lift-off length and corresponding equivalence ratio. The enhanced fuel/gas mixing by advancing injection timing reduces soot precursor and the subsequent soot particle formation. As injection is advanced, the oxidation percentage is increased due to more residence time for soot oxidation, higher in-cylinder pressure as well as more available oxygen in zone 5 .

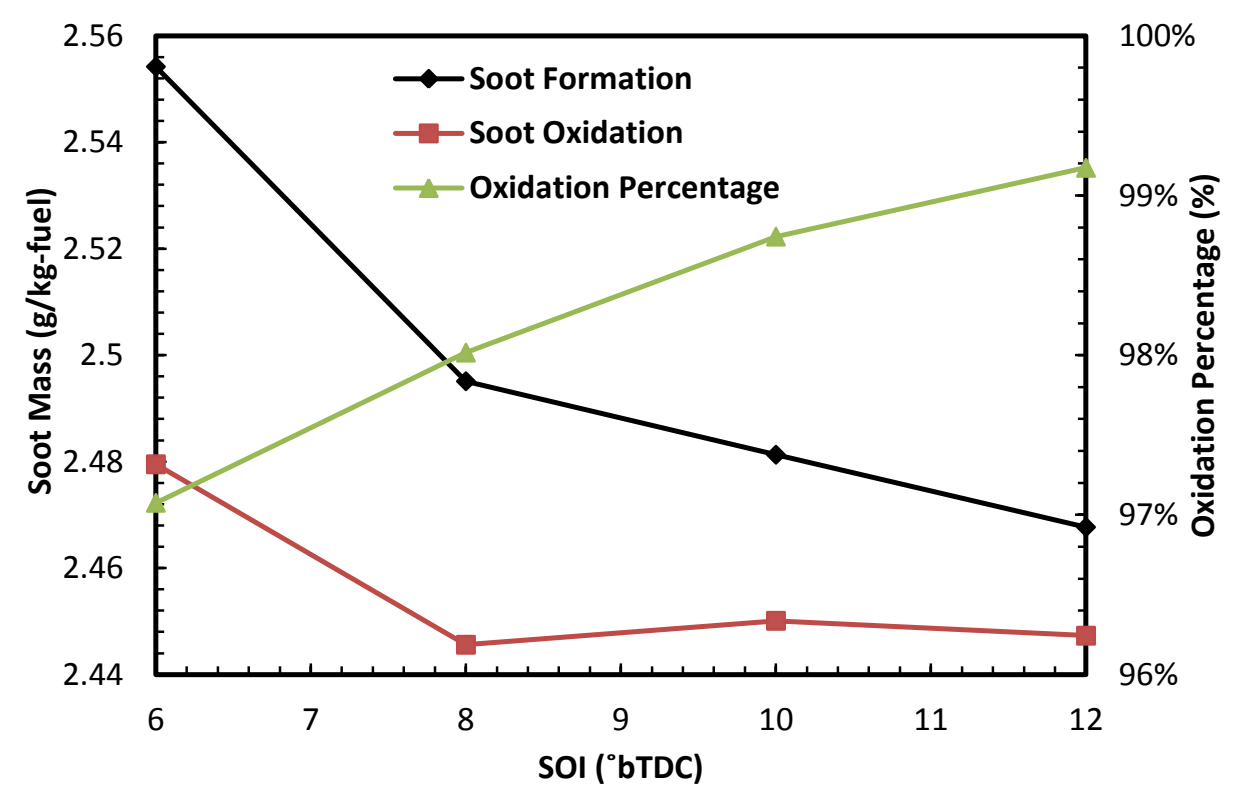

Figure 47. The calculated soot formation and oxidation, oxidation percentage at the end of each combustion cycle as injection timing is varied for the base case. 


\section{CONCLUSIONS AND RECOMMENDATIONS}

A comprehensive thermodynamic simulation was developed by applying the current understanding of conceptual models for the direct-injection diesel engine combustion process. A typical medium-duty diesel engine was selected for this study. The combustion chamber was divided into six zones to account for the surrounding bulk gas, liquid- and vapor- phase fuel, pre-ignition mixing, fuel-rich combustion products, as well as the diffusion flame combustion products. A reduced three-step phenomenological soot model and a nitric oxide formation model were successfully imbedded into the diesel engine combustion model. Both calibration and validation were completed by comparisons between measured and calculated cylinder pressures, and engine-out emissions under different operating conditions. This multi-zone thermodynamic phenomenological model was demonstrated to be able to accurately predict the diesel fuel jet evolution process within the combustion chamber. The results from the emission models demonstrated at least trend-wise predictions concerning the effects of major engine parameters on the engine-out soot and nitric oxide emissions. The conclusions and perspectives of this work are summarized as follows.

\subsection{Conclusions}

1. The new multi-zone combustion simulation based on the current understanding of diesel engine combustion process presents good agreement between the experimental and calculated results. Three typical soot-NO tradeoffs for various EGR levels, injection pressures and timings were successfully reproduced. 
2. The detailed local thermodynamic properties and energy mass distributions obtained from the simulation provide new insights into heterogeneous type combustion systems. The information is crucial for analysis of the emission trends and understanding of specific combustion processes with various engine speed/loads, EGR levels, and injection configurations, and thereby offers a convenient access for researchers to conduct parametric studies accurately.

3. The fuel-rich premixed combustion (zone 4) results in a relatively low combustion temperature due to the high equivalence ratio. The subsequent oxidation process gradually releases the energy of the incomplete combustion products, and may cause a slight increase of zone 4 temperature. The diffusion flame combustion (zone 5) shows the highest temperature resulting from the mixing-controlled diffusion combustion. The gas entrainment into the combustion products, in contrast, dilutes the diffusion flame products, and thereby reduces temperature of zone 5 together with the associated expansion cooling and heat transfer.

4. The dilute effect of EGR significantly reduces the fuel-rich and diffusion flame combustion temperatures. In contrast, increased injection pressure and advanced injection timing promote the gas entrainment within the fuel spay, resulting in higher fuel-rich combustion product temperature, while lower diffusion combustion product temperature during the combustion phase.

5. The formation of nitric oxide is highly related with the gas entrainment rate into combustion products. Higher nitric oxide concentration produced via increased injection pressure and advanced injection timing results not only from the increased 
residence time, but also from the enhanced oxygen concentration in the diffusion flame combustion product zone. The employment of EGR is an effective method to decrease the nitric oxide formation due to the greatly reduced diffusion combustion temperature.

6. The soot formation during the diesel fuel jet evolution process is greatly affected by the flame lift-off length and local equivalence ratio. Higher injection pressure and advanced injection timing before TDC result in decreased soot formation because of the extension of the lift-off length and the reduced local equivalence ratio. The corresponding increased oxidation percentage due to the increased residence time, higher in-cylinder pressure and enhanced available oxygen leads to smaller engineout soot emissions.

7. For high EGR levels, the ambient oxygen concentration decreases, but the extended flame lift-off length reduces the local equivalence ratio. This phenomenon, together with the reduced combustion temperature, contributes to the reduced soot formation. The less effective soot oxidation, however, results in higher engine-out soot emissions with the increase of EGR level. For 49.6\% EGR, the conversion rate of soot particles is too low and some precursors are not completely depleted. 


\subsection{Recommendations}

Based on the development of the current thermodynamic engine model and simulation results, some recommendations can be made for further work.

1. Some approximations in the simulation development include: (a) the free fuel jet without swirl and wall interactions, (b) the non-vaporizing fuel spray penetration correlation was applied to calculate the fuel spray model. (c) the steady state flame lift-off length. These assumptions cause some discrepancies, and further improvements can be conducted from these aspects.

2. The engine model is only limited to describe the diesel engine combustion under conventional operating conditions. Nowadays, some modern diesel engines operate under some form of low temperature combustion (LTC) strategies. The proposed model is subject to improvement for accurately predicting the premixed operating conditions with positive ignition dwell (and thus no steady state lift-off length). 


\section{NOMENCLATURE}

A

$\mathrm{A}_{\mathrm{f}}$

$A_{0}$

$A_{\mathrm{p}}$

B

$\mathrm{C}_{\mathrm{v}}$

$\mathrm{c}_{\mathrm{a}}$

$\mathrm{c}_{\mathrm{d}}$

$\mathrm{c}_{\text {diss }}$

$\mathrm{c}_{\mathrm{G}}$

$\mathrm{c}_{\mathrm{k}}$

$\mathrm{C}_{\mathrm{LO}}$

$\mathrm{c}_{\text {spray }}$

$\mathrm{C}_{\mathrm{after}, 4}$

$\mathrm{C}_{\mathrm{after}, 5}$

$\mathrm{c}_{\mathrm{V}}$

$\mathrm{d}_{\mathrm{f}}$

$\mathrm{d}_{0}$

$f_{M}$

$\mathrm{f}_{\mathrm{s}}$
Total surface area

Soot formation constant

Soot oxidation constant

Precursor formation constant

Specific energy ratio

Constant volume specific heat capacity

Area contraction coefficient

Discharge coefficient

Pre-factor of energy dissipation

Empirical coefficient for turbulence caused by the air motion

Empirical coefficient for turbulence caused by fuel injection

Empirical coefficient for lift-off length

Pre-factor of the injected fuel kinetic energy

Empirical coefficient for gas entrainment into zone 4

Empirical coefficient for gas entrainment into zone 5

Velocity contraction coefficient

Effective nozzle diameter

Nozzle orifice diameter

Characteristic mixing frequency

Ambient gas mass necessary for the combustion of $1 \mathrm{~kg}$ of fuel 
m

$n$

$\mathrm{n}_{\mathrm{N}}$

P

$\mathrm{P}_{\mathrm{O} 2}$,

$\mathrm{P}_{\mathrm{O} \text {,ref }}$

Phi

Q

$\mathrm{R}$

$\mathrm{R}_{\mathrm{i}}$

$\mathrm{r}_{\mathrm{EGR}}$
Enthalpy

Heat transfer coefficient

Ignition delay

Turbulent kinetic energy

Forward rate constant of the nitric oxides kinetics

Kinetic energy of the injected fuel

Variable for premixed burn rate

Variable for premixed burn rate

Reverse rate constant of the nitric oxides kinetics

Characteristic mixing length

Molecular weights

Mass

Exponent term in the computation of soot oxidation

Number of nozzle holes

Pressure

Partial pressure of oxygen

Oxygen partial pressure of air under the standard state.

$\Phi$, equivalence ratio

Heat transfer

Gas constant

Equilibrium rate for the $\mathrm{i}$-th reaction of nitric oxide kinetics

Mole EGR ratio 


\begin{tabular}{ll}
$\mathrm{S}_{\mathrm{noz}}$ & Nozzle area \\
$\tilde{\mathrm{s}}$ & Dimensionless penetration distance \\
$\mathrm{s}^{+}$ & Normalization factor of penetration distance \\
$\mathrm{T}$ & Temperature \\
$\mathrm{t}$ & Time \\
$\mathrm{t}_{\text {norm }}$ & Normalized time ranging from 0 to 1 \\
$\tilde{\mathrm{t}}$ & Dimensionless penetration time \\
$\mathrm{t}^{+}$ & Normalization factor of penetration time \\
$\mathrm{U}$ & Internal energy \\
$\mathrm{U}_{\mathrm{f}}$ & Fuel injection velocity \\
$\mathrm{V}$ & Volume \\
$\overline{\mathrm{V}}_{\mathrm{p}}$ & Mean piston speed \\
$\mathrm{X}_{\mathrm{O} 2 \text {,EGR }}$ & Oxygen mole fraction of EGR \\
$\mathrm{x}$ & Mole of product species for one mole fuel \\
$\mathrm{Z}$ & Compressibility \\
$\mathrm{Z}_{\mathrm{st}}$ & Stoichiometric fuel mass fraction \\
\hline
\end{tabular}

\section{Greek letters}

$\Phi$

$\rho$

$\tilde{\rho}$

$\theta$

$\alpha$
Equivalence ratio

Density

Ratio of fuel density to surrounding gas density

Measured spray angle

Modeled spray angle 


$\begin{array}{ll}\gamma_{\text {mix }} & \text { Characteristic mixing velocity } \\ \tau_{\mathrm{m}} & \text { Characteristic mixing time } \\ \gamma & \text { Ratio of specific heat }\end{array}$

Abbreviations

$\begin{array}{ll}\text { AHRR } & \text { Apparent heat release rate } \\ \text { bTDC } & \text { Before top dead center } \\ \text { CA } & \text { Crank angle } \\ \text { CFD } & \text { Computational fluid dynamics } \\ \text { DI } & \text { Direct injection } \\ \text { EGR } & \text { Exhaust gas recirculation } \\ \text { FSN } & \text { Filter smoke number } \\ \text { LL } & \text { Liquid length } \\ \text { LOL } & \text { Lift off length } \\ \text { LTC } & \text { Low temperature combustion } \\ \text { NO } & \text { Molecular formula of nitric oxide } \\ \text { PAH } & \text { Polycyclic aromatic hydrocarbons } \\ \text { PL } & \text { Penetration length } \\ \text { ppm } & \text { Parts per Million } \\ \text { rpm } & \text { Revolution per Minute } \\ \text { SOC } & \text { Start of combustion } \\ \text { SOD } & \text { Start of diffusion combustion } \\ \text { TDC } & \text { Top dead center }\end{array}$




\section{Subscripts}

\begin{tabular}{|c|c|}
\hline avg & Average \\
\hline chem & Chemical \\
\hline cyl & Cylinder \\
\hline diff & Diffusion \\
\hline diss & Dissipation \\
\hline e & Equilibrium concentration \\
\hline evap & Evaporation \\
\hline $\mathrm{f}$ & Fuel \\
\hline $\mathrm{g}$ & Gas \\
\hline hr & Heat release \\
\hline ign & Ignition \\
\hline inj & Injection \\
\hline LO & Lift-off \\
\hline noz & Nozzle \\
\hline $\mathrm{p}$ & Precursor \\
\hline $\mathrm{pf}$ & Precursor formation \\
\hline pre & Premixed \\
\hline prod & Product \\
\hline ref & Reference \\
\hline S & Saturation \\
\hline & Soot formation \\
\hline
\end{tabular}


SO

SOC

V
Soot oxidation

Start of combustion

Vapor 


\section{REFERENCES}

[1]. Faeth, G. M., "Current Status of Droplet and Liquid Combustion," Prog. Energy Combust. Sci., vol.3, pp.191-224, 1977.

[2]. Heywood, J. B., Internal Combustion Engine Fundamentals, McGraw-Hill, New York, 1988.

[3]. Kuo, K. K., Principles of Combustion, Wiley \& Sons, New York, pp.589-594, 1986.

[4]. Bosch Automotive Handbook, 3rd Ed., Robert Bosch GmbH, Stuttgart, Germany, worldwide distribution through the SAE, Warrendale, PA, 1993.

[5]. Espey, C. and Dec, J. E., "The Effect of TDC Temperature and Density on the Liquid-Phase Fuel Penetration in a D.I. Diesel Engine," SAE Technical Paper 952456, doi:10.4271/952456, 1995.

[6]. Espey, C., Dec, J. E., Litzinger, T. A. and Santavicca, D.A., "Planar Laser Rayleigh Scattering for Quantitative Vapor-Fuel Imaging in a Diesel Jet," Combustion and Flame, vol.109, pp.65-78, 1997.

[7]. Dec, J. E. and Espey, C., "Ignition and Early Soot Formation in a D.I. Diesel Engine Using Multiple 2-D Imaging Diagnostics," SAE Technical Paper 950456, doi:10.4271/950456, 1995.

[8]. Dec, J. E. and Coy, E. B., "OH Radical Imaging in a DI Diesel Engine and the Structure of the Early Diffusion Flame," SAE Technical Paper 960831, doi:10.4271/960831, 1996. 
[9]. Dec, J., “A Conceptual Model of DI Diesel Combustion Based on Laser-Sheet Imaging*," SAE Technical Paper 970873, doi:10.4271/970873, 1997.

[10]. Pickett, L.M., Kook, S., Persson, H., Andersson, O. , “Diesel Fuel Jet Lift-off Stabilization in the Presence of Laser-induced Plasma Ignition," Proceedings of the Combustion Institute, 32 II , pp.2793-2800, 2009.

[11]. Pickett, L.M. and Siebers, D.L., "Soot Formation in Diesel Fuel Jets near the Liftoff Length,” International Journal of Engine Research, vol.7 no.2103-130, 2006.

[12]. Pickett, L.M. and Siebers, D.L., “An Investigation of Diesel Soot Formation Processes Using Micro-orifices," Proceedings of the Combustion Institute, vol.29, pp.655-662, 2002.

[13]. Pickett, L.M. and Siebers, D.L., "Soot in Diesel Fuel Jets: Effects of Ambient Temperature, Ambient Density, and Injection Pressure," Combustion and Flame, vol.138, pp.114-135, 2004.

[14]. Idicheria, C. and Pickett, L., "Soot Formation in Diesel Combustion under HighEGR Conditions," SAE Technical Paper 2005-01-3834, doi:10.4271/2005-013834, 2005.

[15]. Dobner, D. J., "Dynamic Engine Models for Control Development, Part 1. Nonlinear and Linear Formulation,” IM. J. of Vehicle Design. Technological Advances in Vehicle Design Series, SP4, Application of Control Theory in the Automotive Industry, pp.54-74, 1982. 
[16]. Cantrell, B. A., Ge, H., Reitz, R.D. and Rutland, C. J., "Validation of Advanced Combustion Models Applied to Two-Stage Combustion in a Heavy Duty Diesel Engine," SAE Technical Paper 2009-01-0714, doi:10.4271/2009-01-0714, 2009.

[17]. Stiesch, G., Modeling Engine Spray and Combustion Processes, Springer, New York, 2003.

[18]. Arsie, I., Genova, F. Di, Mogavero, A., Pianese, C., Rizzo G., Caraceni, A., Cioffi P. and Flauti, G., "Multi-Zone Predictive Modeling of Common Rail MultiInjection Diesel Engines," SAE Technical Paper 2006-01-1384, doi:10.4271/2006-01-1384, 2006.

[19]. Kuleshov, A. S., "Multi-Zone DI Diesel Spray Combustion Model for Thermodynamic Simulation of Engine with PCCI and High EGR Level," SAE Int. J. Engines 2(1):1811-1834, doi:10.4271/2009-01-1956, 2009.

[20]. Maiboom, A., Tauzia, X., Shah, S. R., and Hetet, J., "New Phenomenological SixZone Combustion Model for Direct-Injection Diesel Engines," Energy \& Fuels, 23(2), pp.690-703, 2009.

[21]. Asay, R. J., “A Five-Zone Model for Direct Injection Diesel Combustion. Master Thesis, Department of Mechanical Engineering," Brigham Young University, UT, 2003.

[22]. Ebrahimi, K., Bazargan, M., and Jazayeri, S. A., “A New Phenomenological Model for Combustion and Performance Studies of Direct Injection Diesel Engine,”SAE Technical Paper 2007-01-1904, doi:10.4271/2007-01-1904, 2007. 
[23]. Zeldovich, J., "The oxidation of nitrogen in combustion and explosions," European Physical Journal A - Hadrons and Nuclei, vol.21, pp.577-628, 1946.

[24]. Fenimore, C.P., "The Formation of Nitric Oxide in Premixed Hydrocarbon Flames," Symposium International on Combustion, vol. 13, pp.373-380, 1971.

[25]. Melte, P.C. and Pratt, D.T., "Measurement of Atomic Oxygen and Nitrogen Oxides in Jet Stirred Combustion," Fifteenth Symposium (International) on Combustion, vol.15, pp.1061-1070, 1975.

[26]. Hiroyasu, H., "Diesel Engine Combustion and Its Modeling," International Symposium on Diagnostics and Modeling of Combustion in Reciprocating Engines, pp.53-75, 1985.

[27]. Tesner, P.A., Snegiriova, T.D. and Knorre, V.G., "Kinetics of dispersed carbon formation," Combustion and Flame, vol.17, pp.253-260, 1971.

[28]. Schubiger, RA, Boulouchos, K, Eberle, MK, "Rubbildung und Oxidation bei der dieselmotorischen Verbrennung. Motortechische Zeitschrift MTZ," vol.63, pp. 342-353, 2002.

[29]. Surovikin, V. F., "Analytical Description of the Processes of Nucleus-formation and Growth of Particles of Carbon Black in the Thermal Decomposition of Aromatic Hydrocarbons in the Gas Phase," Solid Fuel Chemistry, vol.10, pp.92$101,1976$.

[30]. Fusco, A., Knox-Kelecy, A.L., and Foster, D.E., “Application of a phenomenological soot model to diesel engine combustion," In International Symposium COMODIA 94, 1994. 
[31]. Amsden, A. A., "KIVA-3V: A Block-structured KIVA Program for Engines with Vertical or Canted Valves," Los Alamos National Laboratory Report LA-13313MS, USA, 1997.

[32]. Sencic, T., Medica, V. and Bukovac, O., "Soot Model Validation and Development" Advanced Engineering 4, ISSN: 1846-5900, 2010.

[33]. Liu, Y., Tao, F., Foster, D., and Reitz, R., "Application of A Multiple-Step Phenomenological Soot Model to HSDI Diesel Multiple Injection Modeling," SAE Paper 2005-01-0924, doi:10.4271/2005-01-0924, 2005.

[34]. Tao, F., Liu, Y., RempelEwert, B., Foster, D. et al., "Modeling the Effects of EGR and Injection Pressure on Soot Formation in a High-Speed Direct-Injection (HSDI) Diesel Engine Using a Multi-Step Phenomenological Soot Model," SAE Technical Paper 2005-01-0121, doi:10.4271/2005-01-0121, 2005.

[35]. Kazakov, A. and Foster, D., "Modeling of Soot Formation During DI Diesel Combustion Using a Multi-Step Phenomenological Model," SAE Technical Paper 982463, doi:10.4271/982463, 1998.

[36]. Wang H., Frenklach M., "Detailed Kinetic Modeling Study of Aromatics Formation in Laminar Premixed Acetylene and Ethylene Flames", Combustion and Flame, vol.110, pp.173-221, 1997.

[37]. Kitamura, T., Ito, T., Senda, J., and Fujimoto, H.,"Mechanism of Smokeless Diesel Combustion with Oxygenated Fuels Based on the Dependence of Equivalence Ratio and Temperature on Soot Particle Formation", Int. J. Engine Research, 3-4, pp.223-248, 2002. 
[38]. Maly, RR, Stapf, P. Konig, G., "Progress in Soot Modeling for Engines," 4th int Symp COMODIA 98, pp.25-34, 1998.

[39]. Naber, J. D., and Siebers, D. L., "Effects of Gas Density and Vaporization on Penetration and Dispersion of Diesel Spays," SAE Technical Paper 960034, doi:10.4271/960034, 1996.

[40]. Siebers, D.L., "Scaling Liquid-phase Fuel Penetration in Diesel Sprays Based on Mixing-limited Vaporization,” SAE Technical Paper 1999-01-0528, doi:10.4271/1999-01-0528 1999.

[41]. Siebers, D. L., Higgins, B., and Pickett, L. M., "Flame Lift-off on Direct-injection Diesel Fuel Jets: Oxygen Concentration Effects," SAE Technical Paper 2002-010890, doi:10.4271/2002-01-0890, 2002.

[42]. Higgins, B. S., Mueller, C. J., Siebers, D. L., "Measurements of Fuel Effects on Liquid-phase Penetration in DI Sprays,” SAE Technical Paper 1999-01-0519, doi:10.4271/1999-01-0519, 1999.

[43]. Olikara, C., and Borman, G. L., “A Computer Program for Calculating Properties of Equilibrium Combustion Products with Some Applications to I.C. Engines," SAE Technical Paper 750468, doi:10.4271/750468., 1975.

[44]. Hohenberg, G., "Advanced Approaches for Heat Transfer Calculations,” SAE Technical Paper 790825, doi:10.4271/790825. 1979.

[45]. Caton, J. A., “A Multiple-Zone Cycle Simulation for Spark-Ignition Engines: Thermodynamic Details,” 2001 Fall Technical Conference of the ASME-ICED 23-26, 2001. 
[46]. Watson, N., "Dynamic Turbocharged Diesel Engine Simulator for Electronic Control System Development,” ASME Journal of Dynamic Systems, Measurement and Control, vol.106, pp.27-45, 1984.

[47]. Barba, C., Burkhardt, C., Boulouchos, K., and Bargende, M., “A Phenomenological Combustion Model for Heat Release Prediction in High-speed DI Diesel Engines with Common-rail Injection," SAE Technical Paper 2000-012933, doi:10.4271/2000-01-2933, 2000.

[48]. Weisser G, Boubouchos K, "NOEMI-A Tool for the Precalculation of Nitric Oxide Emissions of DI Diesel Engines," Proc 5th Symp "The Working Process of the Combustion Engine”, pp.23-50, Technical University Graz, Austria, 1995.

[49]. Kitamura, T., Ito, T., Kitamura, Y., Ueda, M., Senda, J., Fujimoto, H., “Soot Kinetic Modeling and Empirical Validation on Smokeless Diesel Combustion with Oxygenated Fuels.” SAE Technical Paper 2003-01-1789, doi:10.4271/200301-1789, 2003.

[50]. Dean, A. M. and Bozzelli, J.W., "Combustion Chemistry of Nitrogen," in GasPhase Combustion Chemistry, ed. W.C. Gardiner, Jr., pp.125-342, SpringerVerlag, New York, 2000.

[51]. Ansys Fluent Theory Guide, Ansys Inc, Released 13.0. November, 2010.

[52]. Caton, J.A., "Detailed Results for Nitric Oxide Emissions as Determined From a Multiple-Zone Cycle Simulation for a Spark-Ignition Engine,” ASME 2002 Internal Combustion Engine Division Fall Technical Conference (ICEF2002), pp.131-148, 2002. 
[53]. Lavoie, G.A., Heywood, J.B., and Keck, J.C., "Experimental and Theoretical Study of Nitric Oxide Formation in Internal Combustion Engines," Combustion and Science Technology, vol.1, pp.313-338, 1970.

[54]. Bayer, J. and Foster, D., "Zero-Dimensional Soot Modeling," SAE Technical Paper 2003-01-1070, doi:10.4271/2003-01-1070, 2003.

[55]. Curran, H. J., P. Gaffuri, W. J. Pitz, and C. K. Westbrook, "A Comprehensive Modeling Study of n-Heptane Oxidation" Combustion and Flame, vol.114, pp.149-177, 1998.

[56]. Tompkins, B.T., Esquivel J., and Jacobs, T. J., "Performance Parameter Analysis of a Biodiesel-Fuelled Medium Duty Diesel Engine," SAE Technical Paper 200901-0481, doi:10.4271/2009-01-0481, 2009.

[57]. Knight, B. M., Bittle, J. A., and Jacobs, T. J., "Characterizing the Influence of EGR and Fuel Pressure on the Emissions in Low Temperature Diesel Combustion," SAE Technical Paper 2011-01-1354, doi:10.4271/2011-01-1354, 2011.

[58]. Alkidas, A., "Relationships Between Smoke Measurements and Particulate Measurements," SAE Technical Paper 840412, doi:10.4271/840412, 1984.

[59]. V.R. Christian, F. Knopf, A. Jaschek, W. Schindler., "Eine neue Mebmethodik der Bosch-Zahl mit erhorter Empfindlichkeit," Motortechnishe Zeitschrift, vol.54, pp.16-22, 1993. 
[60]. J.Arregle, V.Bermudez, J.R. Serrano, E. Fuentes., "Procedure for engine transient cycle emissions testing in real time," Experimental Thermal and Fluid Science, vol.30, pp.485-496, 2006.

[61]. Northrop, W.F., Bohac, S.V., Assanis, D.S., and Chin, J, "Comparison of filter smoke number and elemental carbon mass from partially premixed low temperature combustion in a direct injection diesel engine," Journal of engineering for gas turbines and power, vol.133, ISSN :0742-4795, 2011.

[62]. Horibe, N., and Ishiyama, T., "Relations among NOx, Pressure Rise Rate, HC and CO in LTC Operation of a Diesel Engine," SAE Technical Paper 2009-01-1443, doi:10.4271/2009-01-1443, 2009.

[63]. Jacobs, T. J., Bohac, S. V., Assanis, D. N., and Szymkowicz, P. G., "Lean and Rich Premixed Compression Ignition Combustion in a Light-Duty Diesel Engine,” SAE Technical Paper 2005-01-0166, doi:10.4271/2005-01-0166, 2005.

[64]. Musculus M. P. B., "Multiple Simultaneous Optical Diagnostic Imaging of EarlyInjection Low-Temperature Combustion in a Heavy-Duty Diesel Engine," SAE Technical Paper 2006-01-0079, doi:10.4271/2006-01-0079, 2006. 